\title{
5 Das Entwicklungspersonal der beiden deutschen Staaten
}

Der Begriff des Entwicklungspersonals (alternativ auch EntwicklungsarbeiterIn) bezeichnet die heterogene Gruppe von Personen, die in einem internationalen Zusammenhang in der Entwicklungszusammenarbeit tätig sind und sich - in mehr oder minder einflussreichen Positionen - der „Treuhandschaft“ des Entwicklungsprozesses verschreiben. ${ }^{1}$ Unterscheidungskriterien zu lokalem Personal einerseits wie $\mathrm{zu}$ anderen international mobilen Gruppen andererseits sind, dass die Personaleinsätze zeitlich begrenzt und mit einer entwicklungspolitischen Rationalität verbunden sind. Das bedeutet, dass diese Personen nicht nach marktförmigen Bedingungen entsendet werden, sondern ihr Einsatz z. B. in Arrangements der „Technischen Hilfe“ (BRD) oder der „Kulturell-Wissenschaftlichen Zusammenarbeit“ (DDR) bzw. in Einsatzformen wie dem Freiwilligeneinsatz mit Entwicklungshilfeorganisationen (BRD) oder Freundschaftsbrigaden (DDR) eingebettet ist.

Eine Typisierung des Entwicklungspersonals kann sich auf die verschiedenen Einsatzmodi stützen, die im globalen entwicklungspolitischen Feld normbildende Wirkung entfaltet haben. Die grundlegende Unterscheidung von drei „Klassen“ des Personals (advisor, expert, volunteer) entwickelte sich als ein Standard des entwicklungspolitischen Feldes und lässt sich daher gleichermaßen auf die BRD und DDR übertragen. Hochrangige (Regierungs-)BeraterInnen waren eine besonders einflussreiche Stufe des Expertentums, gefolgt von ExpertInnen, die in der DDR „Kooperanten“ oder „Spezialisten“ genannt wurden, während EntwicklungshelferInnen bzw. Mitglieder von FDJ-Freundschaftsbrigaden sich insbesondere durch ihre idealistische Motivation und die basisnahe Arbeit „auf Augenhöhe“ auszeichnen sollten. Im westlichen Diskurs werden diese Entsandten aufgrund der geringeren materiellen Entlohnung und einer angenommenen idealistischen Orientierung bis heute auch als „Freiwillige“ bezeichnet. Mit jedem Modus gingen ein bestimmter Status, ein distinktes Rollenverständnis und spezifische Aneignungs- und Wirkungsmöglichkeiten einher, deren konkrete Ausformungen aber stark vom Entsendekontext und -zeitpunkt sowie Bedingungen im Herkunfts- und Zielland abhingen.

1 Heather Hindman/Anne-Meike Fechter, Introduction, in: Anne-Meike Fechter/Heather Hindman, Hg., Inside the Everyday Lives of Development Workers: The Challenges and Futures of Aidland, Boulder 2011, 1-19, hier: 5-10. Für die verwandten Begriffe „ExpertIn“ bzw. „entsandte Fachkraft“ siehe Franz Nuscheler, Lern- und Arbeitsbuch Entwicklungspolitik, 5., aktualisierte Auflage, Dietz 2011, 467

Ә OpenAccess. (C) 2021 Eric Burton, publiziert von De Gruyter. (cc) BY Dieses Werk ist lizenziert unter der Creative Commons Attribution 4.0 International Lizenz. https://doi.org/10.1515/9783110705621-008 
Im Gegensatz zu Frankreich oder Großbritannien, die auf eine ganze Schar kolonialer EntwicklungsexpertInnen zurückgreifen konnten, ${ }^{2}$ mussten die beiden deutschen Staaten einen „Stamm“ von Entwicklungspersonal erst aufbauen. ${ }^{3}$ Die erste Generation, die in den 1950er und frühen 1960er Jahren entsandt wurde, ging weitgehend ohne spezifische Vorbereitung in den Einsatz. Auf BRD-Seite lassen sich in dieser Generation einige personelle und strukturelle Kontinuitäten zur Kolonialzeit und kolonialrevisionistischen Strömungen erkennen. Die ab 1957 für die Expertenentsendung zuständige GAWI (die Vorläuferorganisation der 1974 ins Leben gerufenen Gesellschaft für Technische Zusammenarbeit, GTZ) ${ }^{4}$ rekrutierte Personal über den Deutschen Afrika-Verein, die Deutsche Afrika-Gesellschaft und andere konservativen Organisationen, die einer zunehmend anachronistischen Kolonialnostalgie Raum boten. ${ }^{5}$ Insgesamt ist der Forschungsstand $\mathrm{zu}$ Biografien, Praktiken, Erfahrungen und Motiven der Entsandten der 1950er und frühen 1960er Jahre noch unzureichend; in den wenigen aktuellen Arbeiten zum Thema, die vor allem kulturhistorisch angelegt sind, dominieren kritische Perspektiven. Hubertus Büschel und Young-Sun Hong etwa haben darauf hingewiesen, dass Mitglieder dieser Pioniergeneration auf BRD- wie DDR-Seite entgegen den Partnerschaftsproklamationen ihrer Regierungen autoritäres Verhalten an den Tag legten, „rassenhygienischem“ Denken anhingen und segregierte Arbeits- und Lebensweisen nicht nur praktizierten, sondern z.T. auch explizit befürworteten. ${ }^{6}$ Die zweite Generation, deren Angehörige ab Anfang der 1960er entsandt wurden, durchlief nicht zuletzt aufgrund solch von offizieller Seite unerwünschter Erscheinungen spezifische Vorbereitungskurse. Im Westen bildete

2 Joseph Morgan Hodge, British Colonial Expertise, Post-Colonial Careering and the Early History of International Development, in: Journal of Modern European History 8/1 (2010), 24-46.

3 Der Begriff „Stamm“ ist entlehnt von Hüsken, Der Stamm der Experten.

4 Zur GAWI siehe Büschel, Hilfe zur Selbsthilfe, S. 197-199. Das Kürzel verweist noch auf den alten Namen aus der Zeit der Marshall-Hilfe: Garantie-Abwicklungsgesellschaft. Ab 1964 firmierte die GAWI, bei verwirrender Beibehaltung der alten Abkürzung, jedoch als Deutsche Förderungsgesellschaft für Entwicklungsländer. Die Organisation war eine Tochter der 1923 gegründeten Deutschen Revisions- und Treuhand AG, die ihrerseits als staatliche Gesellschaft zur Wirtschaftsprüfung fungiert hatte.

5 Büschel, Hilfe zur Selbsthilfe, S. 66.

6 Ebd.; Hong, Cold War Germany, v.a. Kap. 2 und 3. Angesichts der Nazifizierung mancher Sektoren und der lückenhaften Entnazifizierung im Nachkriegsdeutschland - v. a. in der Ärzteschaft, die fast vollständig der NSDAP angehört hatte - ist anzunehmen, aber empirisch bisher unzureichend belegt, dass in beiden Staaten auch zahlreiche ehemalige NSDAP-Mitglieder in der Entwicklungsarbeit landeten. Siehe etwa in Bezug auf einen Arzt und eine Krankenschwester, die die DDR „ohne jeglische [sic] politische Vorbereitung“ und „mit zum Teil völlig falschen Vorstellungen“ nach Sansibar entsendet hatte, SAPMO BArch Berlin, DY 30/98149, SED-Delegationsbericht, Über den Aufenthalt in der VR Sansibar vom 12.1. bis 26.1.1965, Berlin, 9.2.1965, Bl. 63. 
sich ein Stamm genuiner BerufsentwicklungsexpertInnen heraus, die ihre ganze berufliche Laufbahn im Entwicklungssektor verbrachten, während manche der zurückgekehrten DDR-Auslandskader durch Sprachkenntnisse und fachliche wie „politische“ Bewährung höhere Chancen auf einen Wiedereinsatz hatten. So lässt sich schon ab den 1960er Jahren von einer beginnenden Routinisierung sprechen.

Wie in vielen Ländern des Westens und Ostens wurden auch in den beiden deutschen Staaten zusätzlich zur Experten- und Beraterentsendung auch Jugenddienste gegründet, deren Entsandte sich durch ihre besondere Praxisnähe, ihren Idealismus und enge Beziehungen zu befreundeten Jugendorganisationen, KollegInnen und der lokalen Bevölkerung in den Einsatzländern auszeichnen sollten. ${ }^{7}$ Bei den „Freiwilligen“ der BRD stieg das Durchschnittsalter der Entsandten bis in die 1980er-Jahre stetig, sie waren öfter verheiratet (der DED war anfangs gar als Dienst für Ledige konzipiert gewesen), hatten im Durchschnitt häufiger und mehr Kinder und verfügten bei Einsatzbeginn über zunehmend mehr Berufs- und Auslandserfahrung sowie höhere Bildungsabschlüsse - Letzteres auch wegen gestiegener Ansprüche in den Einsatzländern, die zunehmend über eigene Fachkräfte verfügten und nur noch in hochspezialistierten Bereichen auf die Rekrutierung von expatriates angewiesen waren. ${ }^{8}$

Neben den relativ eindeutigen Tendenzen zur Professionalisierung, Akademisierung und Routinisierung des Entwicklungspersonals ist auffällig, dass der Frauenanteil in der Expertenentsendung stieg, bei den „Freiwilligen“ jedoch sank. ${ }^{9}$ Die Experten- und Beraterebenen blieben bis in die 1970er-Jahre

7 Eric Burton, Solidarität und ihre Grenzen. Die „Brigaden der Freundschaft“ der DDR, in Frank Bösch/Caroline Moine/Stefanie Senger (Hg.), Internationale Solidarität: Globales Engagement in der Bundesrepublik und der DDR, Göttingen 2018, S. 152- 85; Ingo Haase, Handlungsspielräume einer quasi-staatlichen Entwicklungshilfe-Organisation. Der Deutsche Entwicklungsdienst. Münster 1991, S. 76-90; 285-290. Laut Haase war das Drängen der USA wiederum selbst mitverursacht von Initiativen aus privaten Kreisen in der BRD, die ihre Kontakte zur Familie Kennedy dazu benutzten, die zögerliche Bundesregierung unter Druck zu setzen. Siehe Ingo Haase, Zwischen Lenkung und Selbstbestimmung. Geschichte und Gegenwart des Deutschen Entwicklungsdienstes, Berlin 1996, S. 16, 20 - 24.

8 Zwischen 1971 und 1990 stieg das Durchschnittsalter von DED-EntwicklungshelferInnen kontinuierlich von 25 auf 33,8; die durchschnittliche Zahl der mitreisenden Angehörigen (mitreisende Partner ohne Einsatz und Kinder) pro EntwicklungshelferIn stieg von nahe null auf 0,98. Siehe Haase, Zwischen Lenkung und Selbstbestimmung, S. 112. Zur Akademisierung und dem bis Mitte der 1980er gleichbleibenden Geschlechterverhältnis in der GTZ siehe BArch Koblenz, B 213/7675, Krumbein, Bericht über Projektleitertagung in Dar es Salaam, Bonn, 8.3.1973; Pollvogt, Zur Anatomie, S. 201-205.

9 Unter den DED-EntwicklungshelferInnen (für alle Einsatzländer) fiel der Frauenanteil von 38,8\% (1966) auf 21,7\% (1986). Der vor allem in den 1960er Jahren höhere Frauenanteil unter DED-EntwicklungshelferInnen erklärt sich u. a. dadurch, dass hier stärker Berufsgruppen gefragt 
Männerdomänen. ${ }^{10}$ Die explizite Thematisierung von Geschlechterbeziehungen in westlichen entwicklungspolitischen Theoriedebatten ab den 1970er-Jahren führte in der bundesdeutschen Entwicklungszusammenarbeit zu ersten Ansätzen eines gender mainstreaming, auch der Anteil von Frauen auf westdeutscher Experten- und Projektleiterebene stieg stetig, wenngleich langsam an. ${ }^{11}$ Eine Interviewpartnerin betonte, dass sie 1976 als erste Frau überhaupt ein GTZ-Projekt geleitet hatte; in einem Fragebogen der GTZ aus dem Jahr 1986 forderte sie „MEHR FRAUEN IN DIE PROJEKTE und auf Entscheidungsebenen““. ${ }^{12}$ In den Entsendepraktiken der DDR ist für den Fall Tansanias ein umgekehrter Trend der Maskulinisierung zu erkennen. Während in den 1960er und 1970er Jahren einige (z.T. alleinstehende bzw. allein ausgereiste) Frauen als Ärztinnen, Wirtschaftswissenschaftlerinnen oder Lehrerinnen nach Tansania ausgereist waren, handelte es sich in den 1980er-Jahren fast nur noch um „mitreisende Ehefrauen“. 1990 hieß es vom DDR-Botschafter ganz offen, dass der Einsatz einer Ärztin als Leiterin der Gewerkschaftsklinik „nicht in Betracht“ komme, da 90\% der Belegschaft und 80\% der Küstenbevölkerung muslimischen Glaubens seien und „eine Ärztin weder als Vorgesetzte noch als gleichberechtigte Person anerkennen würden“. ${ }^{13}$ Schon an dieser Gegenüberstellung zeigt sich, dass die Geschlechterbeziehungen in der Entwicklungsarbeit weder statisch waren noch linear auf einen höheren Frauenanteil zusteuerten.

waren, in denen in der BRD mehr Frauen tätig waren - Ärztinnen, Krankenpflegerinnen, Lehrerinnen - als in den bei GAWI und GTZ gefragten Bereichen von Ingenieuren, Volkswirten, Wirtschaftswissenschaftlern und Landwirtschaftsexperten. Erst mit dem Paradigmenwechsel von „Hardware“ auf „Software“, also von unangepassten technischen Fertiglösungen hin zu kulturell und sozial angepassten Prozessen, waren auch AbsolventInnen kultur- und sozialwissenschaftlicher Studiengänge gefragter - bei denen der Frauenanteil deutlich höher lag als in den Ingenieur- und Wirtschaftswissenschaften.

10 Haase, Zwischen Lenkung und Selbstbestimmung, S. 110. Allerdings hat sich der Anteil der Frauen fast halbiert und fiel von 38,8\% (1966) auf 21,7\% (1986).

11 Beginnend mit Esther Boserups Werk Women in Development (1970). Siehe für einen Überlick zur Thematik Ruth Pearson, The Rise and Rise of Gender and Development, in: Uma Kothari, Hg., A Radical History of Development Studies: Individuals, Institutions and Ideologies, Cape Town, London, New York 2005, S. 157-179.

12 Privatarchiv S. R., [Korrespondenz mit GTZ-HQ FB 221], Projektleiterin PESP, Beantwortung GTZ-Fragebogen zur Projektarbeit, o.O., o.D. [1986], Formatierung im Original.

13 BArch Berlin, DQ 1/12533, Schunke (DDR-Botschaft) an Müller (MfGE), Dar es Salaam, 15.1. 1990. Darüber hinaus könnten einer Frau die regelmäßigen Fahrten ins Landesinnere nicht zugemutet werden. Die erste DDR-Kraft, die die Gewerkschaftsklinik zwanzig Jahre zuvor geleitet hatte, war eine Frau gewesen - in ihren Berichten findet sich kein Hinweis auf die Probleme, die der Botschafter voraussah. 
Dieses Kapitel analysiert in erster Linie auf Egodokumente und Interviews zurückgreifend, wie das Entwicklungspersonal aus der BRD und der DDR den eigenen Einsatz wahrnahm und wie diese Wahrnehmungen in breitere sozioökonomische Verhältnisse und politische Debatten eingebettet waren. Drei Aspekte der persönlichen Erfahrungsberichte werden hier besonders betont. Erstens die Verflechtung von „Offiziellem“ und „Privatem“; zweitens die Konstitution und Begrenzung von Handlungsspielräumen sowie drittens die widersprüchlichen Selbst- und Rollenbilder, die situativ angepasst wurden und mit oft wenig praxistauglichen und bestenfalls ambivalenten Handlungsorientierungen einhergingen. Dabei zeigt sich, dass die ostdeutschen EntwicklungsarbeiterInnen, die „Auslandskader“ der DDR, keineswegs nur die beiden Pole „Republikflucht“ und „kompletter Gehorsam“ zur Handlungsorientierung kannten - wie etwa Jens Niederhuts fundierte Studie über DDR-Reisekader nahelegt ${ }^{14}$ - sondern sich auf vielfältige Weise kreativ mit den Verhältnissen in Tansania zu arrangieren wussten und dabei auch riskierten, in Ungnade $\mathrm{zu}$ fallen. Ambivalenzen lassen sich schon bei den Motiven feststellen. Zwar waren ostdeutsche EntwicklungsarbeiterInnen in ihren Spielräumen durch Devisenknappheit und die Reglementierung des Privatlebens in ihrer Bewegungsfreiheit eingeschränkter als ihre westdeutschen Pendants, gingen aber wie diese eigen-sinnig mit Vorgaben und vorgefundenen Bedingungen um. Vorgaben und Herrschaftsansprüche konnten damit „in bestimmten Handlungsfeldern unterlaufen und Bereiche des Aushandelns und der relativen Eigenständigkeit“ gesichert werden, ohne damit allerdings etablierte Hierarchien grundlegend infrage zu stellen. ${ }^{15}$

Dieses Kapitel beleuchtet zuerst die verschiedenen Motive, die DDR- und BRD-BürgerInnnen dazu führten, einen entwicklungspolitischen Einsatz in Tansania anzustreben, abzulehnen, zu absolvieren, zu verlängern und retrospektiv zu begründen. Es folgt eine Diskussion der Selektionsmechanismen und Vorbereitungsformen, mit denen die KandidatInnen für ihren Auslandseinsatz gewappnet - und diszipliniert - werden sollten. Der Blick in die Praxis setzt sich dann zuerst mit den Lebensumständen und Privilegien der Entsandten auseinander; aufbauend auf den skizzierten persönlichen Motiven und Einsatzbedingungen schließt das Kapitel mit einer ausführlichen Diskussion der Entwicklungsarbeit im engeren Sinne. Drei Dimensionen des Entwicklungshandelns, das Transferieren, Disziplinieren und Politisieren, werden hier unterschieden, um Handlungsspielräume und Dilemmata der Praxis greifbar zu machen.

14 Jens Niederhut, Die Reisekader. Auswahl und Disziplinierung einer privilegierten Minderheit in der DDR, Leipzig 2005.

15 Lindenberger, Die Diktatur der Grenzen, S. 25. 


\subsection{Motive: Anreize und Hürden}

Die persönlichen Motive für einen Auslandseinsatz waren in beiden deutschen Staaten durchaus vergleichbar: Er diente dazu, sozial- und entwicklungspolitisch tätig zu werden, aus dem Alltag auszubrechen, die eigene Persönlichkeit zu entwickeln und Karriere zu machen. Die Motive für einen Einsatz waren jedoch zeitabhängig; sie wandelten sich mitunter während des Auslandsaufenthaltes und in der retrospektiven Betrachtung, abhängig von der Einbettung der Entwicklungsarbeit in die jeweiligen historischen Opportunitätsstrukturen und Diskurse. Unter den Begriff des Motivs fallen dann nicht nur Interessen, die auf Objekte wie Statuspositionen oder Güter abzielen und dann in scheinbar zweckrationalem Handeln gipfeln, sondern auch die „diesen Handlungsweisen vorgelagerten Bedürfnisse, Emotionen und Identitäten“ ${ }^{16}$ Berthold Unfried hat verschiedene Typen der DDR-Auslandskader unterschieden und neben dem politisch geprägten Internationalisten und dem Abenteurer auch den Devisenverdiener postuliert; eine ähnliche Typologie ließe sich für westliches Entwicklungspersonal aufstellen. ${ }^{17}$ Aufgrund wirtschaftlicher Konjunkturen und gradueller Neuverortung der eigenen Identität und Tätigkeit waren diese Typen jedoch nicht in jedem Jahrzehnt in gleichem Maße anzutreffen. Zwischen den späten 1960er und den 1980er-Jahren verschoben sich die Motive von einer Betonung ideologischer Konflikte und politischer Wirksamkeit zu einer größeren Bedeutung individueller und ökonomischer Faktoren, wie im Folgenden anhand sechs verschiedener Motive dargelegt wird. Dabei ist lediglich das erste DDR- und nur das letzte BRD-spezifisch.

\section{Opportunität}

Das Opportunitätsmotiv ist eine Art Meta-Motiv der DDR-Auslandskadereinsätze. Die Möglichkeit einer Reise ins „Nicht-Sozialistische Wirtschaftsgebiet“ (NSW), also Ländern jenseits der Planwirtschaften sowjetischen Typs, stand vor und über allen anderen Interessen, die mit einem Auslandseinsatz verbunden sein mochten. Forschungen über DDR-Auslandskader sind sich einig darüber, dass diese im Vergleich zu anderen DDR-BürgerInnen Privilegierte waren bzw. spä-

16 Lindenberger, Die Diktatur der Grenzen, S. 25.

17 Unfried, Instrumente. 
testens im Zuge des Einsatzes Zugang zu Privilegien erhielten. ${ }^{18}$ Neue Privilegien erwuchsen aus der Möglichkeit, ins „NSW“ reisen und sich im Zuge dessen weiteres kulturelles, symbolisches, soziales, emotionales und ökonomisches Kapital aneignen zu können. Dieser Befund aus der Literatur stimmt mit der Selbstwahrnehmung der Entsandten weitgehend überein: Es habe sich, so ein entsandter Lehrer, um eine „einmalige Chance“ gehandelt. ${ }^{19}$ Für viele Auslandskader ebnete ein Gespräch mit Vorgesetzten den Weg zum Einsatz, wie etwa im Falle eines Wirtschaftsplaners, der sich erinnerte, „wie die Jungfrau zum Kinde“ zu seinem Einsatz als Regierungsberater in Tansania gekommen zu sein:

Und da fragte mich dann eines Tages mein Chef, ob ich da nicht Interesse für so etwas hätte. Und da habe ich gesagt, ja, natürlich habe ich dafür Interesse. Wer nicht, als junger Mensch, die Möglichkeit zu haben, mal ins sogenannte NSW, nicht-sozialistische Ausland, Wirtschaftsgebiet zu fahren, dort zu leben und Geld zu verdienen, war natürlich verlockend. [...] Voraussetzung war allerdings - das war ja nun wieder, weil das vom Ministerium war, bei den anderen war es vielleicht nicht ganz so schlimm [...], ich musste in die Partei eintreten. Na ja gut, scheiß drauf, ich habe hier gelebt, ich sage mal, wenn du was werden willst, entweder du hast da mitgemacht, bist da eingetreten, ansonsten hättest du die Chance wahrscheinlich nicht gehabt. ${ }^{20}$

In diesem Zitat werden mit dem Reiz der Auslandsreise und dem materiellen Verdienst zwei Aspekte angesprochen, die für den Einsatz sprachen. Der Eintritt in die SED um „etwas zu werden“, erscheint hingegen als Anpassungsleistung an die Machtstrukturen und wird als notwendiges Übel gewertet (und möglicherweise retrospektiv angesichts der vollständigen Delegitimierung dieser Partei nach 1989 überbetont). Auffällig ist die Abwesenheit von Solidaritätsmotiven, die in der offiziellen DDR-Rhetorik höchsten Stellenwert einnahmen. Die Erinnerungen des ehemaligen, unter anderem in Mosambik eingesetzten Auslandskaders Günter Mosler zeigen ebenfalls, wie in den Erinnerungen bisweilen anstelle von Solidaritätsgedanken in erster Linie Privilegien und sexualisierte Exotik mit einem Auslandseinsatz in Afrika assoziiert wurden:

18 Niederhut, Die Reisekader; Iris Christina Obernhummer, Macht und Herrschaft des MfS in der DDR - wie eigenständig war das MfS? Analyse anhand der Bestätigung oder Ablehnung von Auslandskadern, Diplomarbeit, Wien 2011; Iris Christina Obernhummer, Experten der „wissenschaftlich-technischen Zusammenarbeit“ der DDR in Afrika. Alltag und Lebensweisen zwischen DDR-Richtlinien und angespannter Sicherheitslage in den 1970er und 1980er Jahren, Diplomarbeit, Wien 2010; Wolle, Die heile Welt der Diktatur, S. 282-284.

19 Interview \#113, DDR-Lehrerexperte.

20 Interview \#21, DDR-Planungsberater. 
In Gruppengesprächen, besonders auf Baustellen, höre ich blöde Bemerkungen. „Da wirst du schwarze Weiber mit hängenden Tüten sehen. ... Diesmal bekommst du harte Währung, da könnt ihr im Intershop einkaufen. ... Du musst gute Beziehungen haben, dich schicken sie ständig ins Ausland, jetzt sogar nach Afrika, dort kommt kein Schwanz von uns hin.“21

Nur eine kleine Minderheit nutzte den Einsatz, um sich dauerhaft aus der DDR abzusetzen, aber selbst für diejenigen, die nicht an „Republikflucht“ dachten, stellte die „Endausreise“ aus Tansania eine einmalige Möglichkeit dar, die staatlichen Kontrollinteressen zu unterlaufen. Da die DDR nur die Urlaubsflüge, Tansania aber die erste Ein- und letzte Ausreise der DDR-Fachkräfte bezahlte eine Maßnahme zur Devisenersparnis seitens der DDR - wurde die Endausreise bisweilen bewusst über westliche Städte wie Amsterdam, Athen, Rom oder Wien organisiert, sodass ein mehrtägiger Zwischenaufenthalt „unvermeidlich“ war. Diese Reise hatte wiederum den Nimbus der Einzigartigkeit - „du kamst dir vor wie der König von Frankreich“ erinnerte sich ein Universitätsdozent - und angesichts des restriktiven Reiseregimes der DDR handelte es sich womöglich um die letzte Gelegenheit, selbst den Fuß in das nicht-sozialistische Ausland zu setzen, „denn wenn du zurück bist, ist für dich die Zeit zu Ende“. ${ }^{22}$ Der Einzigartigkeit und Gefahr entsprechend machen Beschreibungen der Rückreise, im Gegensatz zu Narrativen Westdeutscher, einen zentralen Teil vieler individueller Erinnerungen aus. In den Erzählungen wurde als integraler Teil der Reiseerfahrung immer auch die Angst vor der Staatssicherheit ausgedrückt, etwa in der Furcht, ,erwischt“ zu werden, weil man die Flugvorschriften umgangen und den Aufenthalt in Amsterdam eigenmächtig um ein oder zwei Tage verlängert hatte. Mit einem derartigen Fauxpas hätte man, so die Angst, die ganze Karriere, die eigene wie die der Familienmitglieder, in den Sand setzen können. ${ }^{23}$ Dass solche Risiken (einigen Kadern wurden verlängerte Transitaufenthalte tatsächlich als Disziplinarvergehen angekreidet ${ }^{24}$ ) trotzdem eingegangen wurden, zeigt einmal mehr die herausragende Bedeutung eines DDR-spezifischen Opportunitätsmotivs, das allen anderen Interessen übergeordnet und eingeschrieben war.

21 Günter Mosler, Als DDR-Auslandskader in Mosambik (1979-1982): Zwischen Dschungel, Taiga, Savanne, Wüste und Heimat, Leipzig 2013, S. 11.

22 Interview \#20, DDR-Universitätsexperte.

23 Am prominentesten finden sich die Motive in Interview \#17, DDR-Lehrerexperte; Interview \#20, DDR-Universitätsexperte; Interview \#21, DDR-Planungsberater. Siehe auch Hans Müller, Als DDR-Tierarzt in Tansania, in: Ulrich van der Heyden/Franziska Benger, Hg., Kalter Krieg in Ostafrika: Die Beziehungen der DDR zu Sansibar und Tansania, Berlin 2009, S. 99-110, hier: S. 109. 24 Siehe z. B. SAPMO BArch Berlin, DY 30/15207, Handelsrat Funke an Abt. Kader des MHF, Dar es Salaam, 14.9.1987. 


\section{Karriere und Komfort}

Die materiellen Rahmenbedingungen waren eine unabdingbare Voraussetzung für die Entsendung. Der Auslandseinsatz bot - das gilt im Wesentlichen für alle Entsandten - im Vergleich zu einer Tätigkeit in Deutschland ökonomische Akkumulationsmöglichkeiten. Dass sich, wie Hubertus Büschel meint, ein DDRAuslandseinsatz in finanzieller Hinsicht kaum auszahlte, ${ }^{25}$ wird z.B. dadurch widerlegt, dass sich viele Auslandskader mit Ersparnissen aus der Einsatzzeit ein Auto kaufen konnten. ${ }^{26}$ Die jeweilige tansanische Institution zahlte das Gehalt nicht an die Auslandskader, sondern an die DDR-Außenhandelsfirma Limex bzw. intercoop. Die DDR-Auslandskader wiederum erhielten einen Pauschalbetrag, der nicht von den Gehaltsbestimmungen auf tansanischer Seite, sondern von DDRRichtlinien abhing. Wenn dieser Pauschalbetrag nicht voll aufgebraucht wurde, ${ }^{27}$ konnte das Ersparte über die Auslandsvertretung in die DDR auf ein Valutakonto zurücküberwiesen bzw. gegen sogenannte Forumschecks umgetauscht werden. Mit diesen Valutaschecks konnten dann für den Großteil der DDR-Bevölkerung nicht zugängliche Konsumgüter in Intershops und Versandkatalogen wie den Genex-Katalog bezogen werden. All das wussten und erwarteten die meisten vor dem Einsatz, insbesondere in den Jahrzehnten nach den 1960ern.

Ökonomische Anreize sind jedoch keine naturgegebene Größe, sondern sozial und historisch bedingt. Dementsprechend bedeuteten sie nicht allen dasselbe. Während materielle Motive für manche DDR-Auslandskader zentral waren, stritten andere im Interview entschieden ab, dass diese in der Entscheidung zum Einsatz eine Rolle gespielt hätten. ${ }^{28}$ Materielle Interessen sind zudem nicht leicht aufzuspüren, denn sie wurden in der DDR als Zeichen der Entfremdung von sozialistischen Idealen und mögliches Fluchtmotiv gesehen und als Disziplinarfall gewendet, während moralische Imperative an den Altruismus während eines „Solidaritäts-“ bzw. „Entwicklungshilfeeinsatzes“ auch die offene Thematisierung in Interviews unwahrscheinlich machen. Materielle Motive gewannen zudem bisweilen erst im Verlauf des Aufenthalts an Bedeutung, als sich der Reiz des Neuen und eventuell vorhandene Ideale und Erwartungen abgenutzt hatten. So

25 Büschel, Hilfe zur Selbsthilfe, S. 240. Zur Attraktivität des Mehrverdiensts in der DDR siehe auch Axel Salheiser, Parteitreu, plangemäß, professionell? Rekrutierungsmuster und Karriereverläufe von DDR-Industriekadern, Wiesbaden 2009, S. 68.

26 BArch Berlin, DR 2/25496, Lehrergruppe Ifunda an MfV, Zur Einschätzung der Ereignisse in Ifunda durch das MfV, o.O., 31.3.1972, S. 3; Interview \#111, DDR-Experte im Ministry of Water and Energy.

27 Bols, Ende der Schweigepflicht, S. 157.

28 Interview \#119, FDJ-Brigadeleiter und FDJ-Freundschaftsbrigadistin. 
bettete der bereits erwähnte Planungsberater die Entscheidung zur Vertragsverlängerung narrativ in familiäre Strategien der Kapitalakkumulation ein. Als Ziel stellt sich hier die komfortable Ausgestaltung der eigenen privaten Nische der Periode des „sozialistischen Biedermeier“ ab Mitte der 1970er-Jahre. ${ }^{29}$

[W]enn man ein Jahr dort unten ist, man verdient ja auch nicht schlecht, muss man auch sagen. Wir konnten jeden Pfennig gebrauchen. Denn wir hatten ja noch nichts verdient. 1972 angefangen zu arbeiten, und bis ' 80 hatte ich gearbeitet. Dann haben wir noch ein Kind dazu gekriegt '78, meine Frau hat noch nebenher ein Fernstudium gemacht [...]. Und da überlegt man eben doch und sagt, wenn so eine Chance ist, noch ein Jahr zu machen, so 15.000, 20.000 Mark zu sparen, kannst du immer gebrauchen hinterher, wenn du dich einrichten willst. Wir hatten ja auch keine Einrichtung zu Hause. ${ }^{30}$

In den Interviews mit Westdeutschen wurden „Verdienst“ oder ein höherer Lebensstandard nicht als explizite Gründe für einen Auslandseinsatz in Tansania erwähnt (allerdings auch nicht explizit danach gefragt). Das Schweigen ist wenig verwunderlich, da Erwerbsabsichten den moralischen Imperativen des entwicklungspolitischen Feldes im Allgemeinen widersprachen. Gleichzeitig warben GAWI und GTZ offensiv mit einem (dank Steuerbefreiung, Spesen- und „Härtezulagen") außergewöhnlich hohen Gehalt, um Fachkräfte zu rekrutieren. ${ }^{31}$ Viele ExpertInnen empfanden die Höhe angesichts von „Entbehrungen“ und Karriererisiken als durchaus gerechtfertigt. Interviews zeigten, dass EntwicklungsexpertInnen mit ihren Ersparnissen aus mehrjährigen Einsätzen und eventuell folgenden Consulting-Aufträgen oft in Eigenheime in der BRD und Feriendomizile in wärmeren Gefilden investierten oder Hypotheken abzahlen konnten. Das stand einer postmaterialistischen Einstellung (der materielle Sorglosigkeit in der Regel vorausgeht) nicht entgegen.

EntwicklungshelferInnen zeichneten sich im Gegensatz zu ExpertInnen laut dem Entwicklungshelfergesetz von 1969 durch ihr ideelles Engagement und die Abwesenheit einer „Erwerbsabsicht“ aus. Bestimmte Berufsgruppen wie ÄrztInnen mussten deutliche Gehaltseinbußen hinnehmen, aber da sich der DED als Fachdienst verstand und entsprechende Bedingungen bieten musste, um erfahrenes Personal rekrutieren zu können, erhielten auch viele DED-Kräfte während des Einsatzes generell „mehr Geld als für eine vergleichbare Tätigkeit in

29 Wolle, Die heile Welt der Diktatur, S. 230.

30 Interview \#21, DDR-Planungsberater; ebenso Interview \#107, WTZ-Experte in Syrien.

311974 etwa erhielt ein GAWI-Experte mit Familie mindestens 4.550 DM monatlich (steuerfrei), mit weiteren Zusatzleistungen und Kaufkraftausgleich wurden die monatlichen Kosten für ExpertInnen meist in einem Rahmen von 9.000 bis 15.000 DM kalkuliert. Siehe BArch Koblenz, B 213/33043, BfE an ZAV, o.O., 24.1.1974; PAAA, ZW 114 925, Vorlage zur Entscheidung, S. 8a. 
Deutschland“, wie der DED-Beauftragte 1979 für Tansania konstatierte. ${ }^{32}$ Integrierte ExpertInnen hatten von allen westdeutschen Gruppen die materiell prekärste Lage zu verkraften. Sie bekamen - in der ersten Hälfte der 1970er-Jahre monatlich das für expatriates übliche Gehalt der jeweiligen tansanischen Institution in Höhe von ca. 700 DM sowie Zuschüsse, die in den gesichteten Fällen zwischen 350 und 1.800 DM betrugen. ${ }^{33}$ Ob das BMZ die Zuschusszahlungen bewilligte, hing jedoch von der „entwicklungspolitischen Relevanz“ der Tätigkeit ab, sodass z. B. EnglischlehrerInnen keinen Zuschuss zugesprochen bekamen, BiologielehrerInnen hingegen schon. Die „Relevanz“, und damit der Zuschuss, konnte vom BMZ auch von einem aufs nächste Jahr aberkannt werden. ${ }^{34}$

Ob der Einsatz karriereförderlich oder -abträglich war, hing nicht zuletzt vom Berufsfeld ab. Im entwicklungspolitischen Feld war jeder Projekteinsatz symbolisches Kapital und dementsprechend eine Investition in die weitere Laufbahn. Einige Angehörige der zweiten Generation schwammen auf der Einstellungswelle des goldenen Zeitalters der Entwicklung und durchliefen ihr ganzes Berufsleben in diesem Sektor: Man habe sich, so Beispiele aus zwei Interviews, im „ganzen Leben nie um einen Job beworben“, „immer Angebote bekommen“, „Jobs immer ausgesucht“ und „eigentlich auch selbst gebastelt“. ${ }^{35}$ Dabei ist freilich eher von prozesshaften und improvisierten als von starren Karrierevorstellungen auszugehen; in vielen Interviews mit Westdeutschen stellte der Auslandseinsatz eher eine Bruchstelle in der Biografie dar. Manche kehrten nach dem Einsatz der Entwicklungsarbeit desillusioniert den Rücken, andere etablierten sich auf dem Consulting- und Beratermarkt oder strebten in die Entscheidungszentren. Ein Ingenieur (und selbsterklärter „Achtundsechziger“) etwa machte als GTZ-Experte im Rahmen eines Dorfentwickungsprojektes die Erfahrung, wie sehr „ein paar Entscheidungen in Washington“ auf die Mikroebene des Projekts „durchschlagen“ konnten, was ihn dann dazu brachte, zwei Jahre in der Weltbank zu arbeiten „um mir das mal von innen anzusehen“. ${ }^{36}$

Die Fluktuation der Beschäftigungs- und Wirtschaftslage in der BRD beeinflusste die Motivlage, was gerade in konjunkturschwachen Phasen offensichtlich wurde, aber auch zu verschiedenen Strategien auf individueller Ebene

32 Günter Wöhlk, Zum Thema „Personelle Hilfe“, in: E+Z 1 (1979), S. 19-20, hier: S. 19. 33 Ein Arzt z.B. erhielt 1974 umgerechnet 1.135 DM brutto, wovon nach Besteuerung und Begleichung des Mietzinses für das Wohnhaus 705 DM übrig blieben, während ein Lehrer 1971 umgerechnet 700 DM bekam. BArch Koblenz, B 213/7679, Dr. V. J. S., Tätigkeitsbericht 1.12. 1972-31.12.1973, Tanga, 30.1.1974; ebd., Zahn (BMZ) an Referat III B/4, Bonn, 22.6.1971.

34 BArch Koblenz, B 213/7679, Drahtbericht der BRD-Botschaft, Dar es Salaam, 7.5.1975.

35 Interview \#27, GTZ-Projektleiter und Interview \#6, GTZ-Projektleiterin.

36 Interview \#24, GTZ-Experte. 
führte. Einerseits konnte ein Sicherheitsdenken einsetzen, demzufolge langfristige Karrierestrategien eindeutig gegen einen Auslandseinsatz sprachen. Auslandserfahrungen wurden in den meisten Zweigen der Privatwirtschaft wie im öffentlichen Dienst noch kaum honoriert, zusätzlich drohte Angehörigen innovationsabhängiger Berufsgruppen in der „fachliche[n] Windstille der Entwicklungshilfe“ den Anschluss an die rapide technologische Entwicklung zu verlieren“ und „hängenzubleiben“. ${ }^{37}$ Andererseits wurden z.B. durch Konkursanmeldungen von Ingenieurfirmen Mitte der 1970er Jahre auch Arbeitskräfte „freigesetzt“, die sich dann eher für einen Einsatz mit dem DED oder der GTZ interessierten; auch ältere Kandidaten, deren Karriere „einen Knick“ gemacht hatte, zogen in Zeiten des wirtschaftlichen Abschwungs Auslandseinsätze eher in Erwägung. ${ }^{38}$ Davon abgesehen gab es auch Personen, die sich, auch wenn dies Ratschlägen im beruflichen und privaten Umfeld widersprach, mit einem entwicklungspolitischen Einsatz bewusst „gegen die Karriere“ entschieden. ${ }^{39}$

Für AkademikerInnen einschlägiger Fachrichtungen lohnte sich ein Aufenthalt in Tansania, um karriererelevantes Wissen, Daten und Erfahrungen zu sammeln. Von manchen GTZ-Entsandten hieß es, sie seien lediglich nach Tansania gekommen, „um ihre Doktorarbeit zu schreiben“. ${ }^{40}$ DAAD-geförderte WissenschaftlerInnen bekamen wiederholt vorgeworfen, nur am Voranbringen der eigenen Forschungen interessiert gewesen $\mathrm{zu}$ sein und entwicklungspolitisch relevante Tätigkeiten wie den Aufbau neuer Studienprogramme vernachlässigt zu haben. ${ }^{41}$ Karriereüberlegungen spielten auch in Akademikerkreisen der DDR eine Rolle. Gerade hoch qualifizierte WissenschaftlerInnen waren oft nicht gewillt, Einsätze in Ländern wie Tansania überhaupt in Betracht zu ziehen. ${ }^{42}$ Die Aussicht, auf Grundlage der Auslandserfahrungen weitere Forschungsarbeiten zu verfassen, war bestenfalls ungewiss. ${ }^{43}$ Jegliche Forschungstätigkeit musste mit der delegierenden Stelle in der DDR abgesprochen werden und selbst wenn schon

37 Werner Dolph, Die ungeliebten Experten, in: Die Zeit, 15.6.1973; Interview \#28, GTZ-Projektleiter.

38 BArch Koblenz, B 213/33089, Tillmann, Stellungnahme zum Stand des Projektes für die GTZ, o.O., Januar 1981, S. 6.

39 Interview \#106, GTZ-Experte.

40 Ein Mitarbeiter des GTZ-Projekts in Ifakara zit. n. Der Spiegel 1979/19, Entwicklungs-Ruinen: „Das Geld ist weg“; vgl. auch Interview \#25, GTZ-Projektleiter; Interview \#94, GTZ-Projektleiter. 41 Interview \#106, GTZ-Experte; BArch Koblenz, B 212/59064, Niesel (DAAD), Vermerk über eine Besprechung mit deutschen Wissenschaftlern, die zur Zeit durch den DAAD gefördert an der University of Nairobi lehren, Nairobi, 28.1.1976, S. 9.

42 BArch Berlin, DR 3/2. Schicht/1512, Überlegungen zur Problematik der Auslandskaderreserve, o.O., o.D. [ca. 1985].

43 Interview \#121, DDR-Universitäsexperte. 
gesammeltes Material vorhanden war, konnte das Forschungsinteresse, wie ein ehemaliger Dozent in Politischer Ökonomie erzählte, zurückgewiesen werden mit dem Argument, dass „Hobbyforschung [...] nicht unterstützt“ werde. ${ }^{44}$ Am ehesten waren Auslandskader im technischen Bereich in der Lage, sich im Rahmen des Einsatzes mit internationaler Fachliteratur und aktuellen technologischen Entwicklungen (etwa den „modernsten Bohranlagen der Welt“45) vertraut machen zu können - also im Gegensatz zu westdeutschem Personal nicht den Anschluss an die technologische Entwicklung zu verlieren, sondern zu finden. Das ebnete mitunter den Weg zur Zunft der Außenhändler, da dieses Wissen im Rahmen kommerzieller Exportunternehmungen sehr gefragt war.

Auslandskader, denen disziplinarische Vergehen während des Einsatzes vorgeworfen wurden, mussten - wie in der DDR selbst - mit beruflicher Stagnation und Statusverlust rechnen. ${ }^{46}$ Wer sich hingegen während des Auslandseinsatzes „bewährte“, bekam einen Vertrauensvorschuss für einen zukünftigen Auslandseinsat $\mathrm{z}^{47}$ und hatte gute Aussichten den beruflichen Status und $\mathrm{Zu}$ gangsmöglichkeiten zu knappen Ressourcen wie Wohnraum zu verbessern. Schon während der Einsatzzeit wurden Zwischenaufenthalte in der DDR und Schriftwechsel von manchen verwendet, um den weiteren sozialen Aufstieg einzuleiten. ${ }^{48}$ Ein DDR-Lehrer schrieb 1970 einem seiner Vorgesetzten, dem Schulrat seines Kreises, aus Sansibar:

Wir sehen beide unsere Perspektive in einer Tätigkeit in [Stadt in der DDR], das heißt natürlich auch, dass wir in [Stadt in der DDR] gern wohnen möchten. Es ist sicher kein unverschämter Traum, wenn wir an eine Wohnung denken, die über die hygienische

44 Interview \#121, DDR-Universitätsexperte; siehe auch BArch Berlin, DR 3/2. Schicht/1514, Troisch (DDR-Botschaft) an Jacobs (TU Dresden), Dar es Salaam, 14.10.1986.

45 Interview \#111, DDR-Experte im Ministry of Water and Energy.

46 Die verschiedenen, vom Auslandseinsatz geprägten Lebensläufe wurden offensichtlich beim Treffen ehemaliger DDR-Entsandter in der Naupoldsmühle, dem der Autor am 5.9.2015 beiwohnte.

47 Bei einem Treffen ehemaliger DDR-Entsandter (die in Sansibar und Tansania-Festland eingesetzt worden waren) im Jahr 2014 gaben von insgesamt 39 - inklusiver mitausreisender EhepartnerInnen - nur 9 an, bereits zuvor einmal im „NSW“ gewesen zu sein. Fast die Hälfte (18) hingegen war später nochmals für die DDR im „NSW“ im Einsatz.

48 Privatarchiv E. W., E. W. an A. [SED-Kreisleitung], Sansibar, 7.7.1970; vgl. auch BArch Berlin, DR 3/2. Schicht/B 1514, P. K., Abschlußbericht über den Einsatz in der VR Tansania (September 82 bis Dezember 85), Zwickau, 3.2.1986. 
Mindestausstattung (Bad) verfügt. [...] Wir wissen, dass Du uns in dieser Frage bestimmt unterstützen wirst. $^{49}$

Die Karrieren verliefen manchmal geradlinig, in anderen Fällen waren sie bereits zuvor durch Brüche gekennzeichnet. Ein in Tansania tätiger Bildungsberater wurde nach seiner Rückkehr Sachverständiger beim Rat des Kreises und später beim Rat des Bezirks; auch infolge des Auslandsaufenthalts hatte sich jedoch sein politischer Horizont erweitert: Er habe seine „Genossen links überholt“, sei aus der SED ausgetreten und nach der Inhaftierung seiner Tochter durch das MfS in die BRD geflohen. ${ }^{50}$ Der Wert eines DDR-Auslandskadereinsatzes nach der Wiedervereinigung war ebenfalls nicht festgelegt und stark von den Perspektiven der jeweiligen EntscheidungsträgerInnen abhängig. Manche der Entsandten berichteten, ihnen sei der Einsatz als politischer Makel angelastet worden (etwa aufgrund der Annahme, alle Auslandskader wären „Stasi-Leute“ gewesen), während andere auf ihren Erfahrungen aufbauten und sich im staatlichen Rahmen von DED- oder GTZ-Engagements im entwicklungspolitischen Feld etablierten.

Die westdeutschen Entsandten, die nach Vertragsende „nicht aus dem ,Entwicklungsgeschäft ' ausdroppen, sondern irgendmöglich am Ball bleiben und den Kontakt zur GTZ nicht verlieren“ wollten, boten ihre Dienste auf dem Markt für Kurzzeiteinsätze und Consultingaufträge feil. ${ }^{51}$ Die Wiedereingliederung in den Arbeitsmarkt war oft schwierig; der Auslandsaufenthalt galt vielfach eher als Makel denn als Vorteil. Viele brauchten Monate und Jahre, um befriedigende Positionen zu erhalten, manche wären sogar „fast durchs Netz gefallen“, wie ein ehemaliger GTZ-Experte meinte. ${ }^{52}$ Das betraf auch die jeweiligen mitausgereisten PartnerInnen. Wie Interviews zeigten, war die Entscheidung über einen Auslandseinsatz oft kein individueller Prozess (wie psychologische Motivforschungen implizit oft nahelegen). Die Entscheidung für einen Auslandseinsatz, oder gegen eine Vertragsverlängerung, wurde oft als ein Aushandlungsprozess innerhalb der Kleinfamilie dargestellt, als eine Entscheidung, die im „Familienrat“ getroffen wurde..$^{53}$

49 Privatarchiv E. W., E. W. an A. [SED-Kreisleitung], Sansibar, 7.7.1970. Ein Interview mit dem Autor des Briefes hat gezeigt, dass Hoffnungen auf eine Verbesserung des beruflichen Status und der Lebensbedingungen erfüllt wurden.

50 Interview \#117, DDR-Polytechnikberater.

51 Privatarchiv S. R., [Korrespondenz mit GTZ-HQ FB 221], G.M. an GTZ FB 221, Tanga, 29.1.1988, S. 3; vgl. auch ebd., H. an S. R., o.O., 4.11.1986.

52 Interview \#106, GTZ-Experte.

53 Interview \#105, BRD-Dozent (Lokaler Vertrag mit GTZ-Gehaltsaufstockung). 


\section{Familie und Geschlechterbeziehungen}

Formulare in der DDR wie in der BRD gingen von einem androzentrischen Expertenbild und damit dem männlichen Norm-Experten aus, dem eine „mitausreisende Ehefrau“ angehörte. Die Bezeichnung „Mitausreisende Ehefrau“ stand sogar als „Beruf“ in den bundesdeutschen Dienstpässen. ${ }^{54}$ Dabei gab es durchaus auch Einzelfälle mitausreisender Ehemänner, und in vielen Fällen spielten Familie und PartnerIn eine zentrale Rolle bei der Entscheidung für oder gegen die Entwicklungsarbeit. Manchmal drängten sie als „die treibende Kraft“ darauf, „etwas anderes zu machen“; häufig führten PartnerInnen und Familie allerdings auch triftige Gründe ins Feld, die Möglichkeit eines Auslandseinsatzes fahren zu lassen. ${ }^{55}$ Viele geplante Einsätze scheiterten an inakzeptablen Bedingungen - vor allem fehlenden Beschäftigungsgarantien - für die mitausreisenden PartnerInnen. ${ }^{56}$ In beruflicher Hinsicht war der Einsatz für die mitausreisenden PartnerInnen, zumeist also Ehefrauen, ein ungleich größeres Karriererisiko. Selbst in Fällen, in denen Ehefrauen hoch qualifiziert waren und in Deutschland Positionen als Pharmazieingenieurin, Buchhalterin oder wissenschaftliche Mitarbeiterin innehatten, wurden sie zur Begleitung degradiert - ein Phänomen, das auch in rezenten Forschungen zu mobilen Eliten beschrieben wird. ${ }^{57}$ Eine Hauptursache für die Degradierung war die Schwierigkeit, eine Arbeitserlaubnis in Tansania zu beschaffen. Selbst wenn die Arbeitskraft der Ehefrauen in Anspruch genommen und entlohnt wurde, kam das in der Regel ebenfalls einer Abwertung gleich. 1973 berichtete die BRD-Botschaft, dass GAWI-Projektleiter qualifizierte Ehefrauen nur in „untergeordneter Tätigkeit“, als „Sekretärin des Ehemanns oder - was meist Anlass zu Schwierigkeiten [gab] - eines Kollegen“ einstellen wollten. ${ }^{58}$ Eine DDREntsandte, die den „Aufstieg“ von der „mitreisenden Ehefrau“ zur Laborassistentin schaffte, meinte, dass ihre Tätigkeit „weder das Prestige der Vollexperten“

54 Interview \#106, GTZ-Experte.

55 Interviews \#105 und \#106, GTZ-Experten.

56 BArch Berlin, DR 2/51009, Entwurf der Entsendeliste für Ablösung und Neuentsendung von Kadern in national befreiten Staaten 1986/87, o.O., o.D. [ca. 1986]; ebd., DR 3/2. Schicht/B1460/5b, MHF, Information für den Besuch des Botschafters der DDR in der VR Tansania - Prof. Dr. Matthes, Berlin, 25.5.1976; ebd., DR 3/2. Schicht/1514, DDR-Botschaft an MHF, Dar es Salaam, 18.9. 1981.

57 Anne Coles/Anne-Meike Fechter, Hg., Gender and Family among Transnational Professionals, New York 2008.

58 BArch Koblenz, B 213/7678, BRD-Botschafter Müllenheim an AA, Dar es Salaam, 19.7.1973. 
besaß, noch geeignet war „das Gefühl besonderer persönlicher Zufriedenheit zu entwickeln“. 59

Im DDR-,Kollektiv“ gab es wiederholt Auseinandersetzungen darüber, welche Ehefrauen die wenigen bezahlten Positionen übernehmen durften, zu denen administrative Posten in der Botschaft, aber auch das die Arbeit als Lehrerin in der Botschaftsschule und andere Funktionen in der DDR-Gemeinschaft gehörten. Die Vergabe dieser Posten verlief intransparent, zeigte allerdings eine offensichtliche Präferenz für die Ehefrauen des Botschaftspersonals und leitender Parteikader. ${ }^{60}$ Frauen, die bei der Vergabe dieser Posten keine Berücksichtigung fanden, verblieben wie auf BRD-Seite vorwiegend in der unbezahlten Reproduktionsarbeit im eigenen Haushalt oder dem näheren Umfeld. Wenngleich sich Ausnahmen finden lassen, ist diese Rollenaufteilung doch für beide deutsche Staaten augenfällig: Die Männer waren in der bezahlten Entwicklungsarbeit tätig, während das Handlungsfeld der Frauen durch Einkäufe, die Sorge um den Haushalt und eventuell die Betreuung der eigenen Kinder abgesteckt wurde. ${ }^{61}$ Die DDR-Botschaft setzte Frauen auch zu unbezahlten Arbeiten bei Empfängen ein, um Gäste zu bedienen. Eine Sprachlehrerin, die sich im Interview sehr verärgert über diese Pflicht zeigte, griff auf das Karriere- und Opportunitätsmotiv zurück: „[I]ch wollte meinem Mann nicht die Karriere versauen“, erklärte sie auf die Nachfrage, warum sie sich nicht direkt bei der Botschaft darüber beschwert hatte. ${ }^{62}$ In anderen Familien galt die Beschränkung der Frau auf den Haushalt nicht als Problem, sondern wurde als Normalität empfunden. ${ }^{63}$

Die Leistungen der Ehefrauen wurden, so ein DDR-Tierarzt, „kaum gewürdigt“, obgleich „die Sorge um die Kinder und das Wohl der Familie unter Bedingungen einer mehr als defizitären Versorgungssituation“ eine „ständige Herausforderung“ gewesen sei, zumal sich viele Ehefrauen - gerade auf DDR-Seite „autodidaktisch zwei Sprachen aneignen [mussten], um das tägliche Leben zu

59 SAPMO BArch Berlin, DY 30/15207, Diskussionsbeitrag A. B. zur Wahlversammlung [1987], B1. 52 .

60 Privatarchiv E. W., E. W. an A. [SED-Kreisleitung], Sansibar, 8.10.1968; BArch Berlin, DR 3/2. Schicht/1514, DDR-Botschafter Schedlich an Nast (MHF), Dar es Salaam, 18.9.1981; Bols, Ende der Schweigepflicht, S. 161.

61 Vgl. hierzu auch Markus Zürcher, Ausgehandelte Entwicklung: Widersprüche und Konflikte im Alltagsleben eines Schweizer Ehepaars in Ruanda um 1970, in: Sara Elmer u.a., Hg., Handlungsfeld Entwicklung. Schweizer Erwartungen und Erfahrungen in der Geschichte der Entwicklungsarbeit, Basel 2014, S. 19-44, hier: S. 26-27.

62 Interview \#93, DDR-Deutschlehrerin und mitreisende Ehefrau.

63 Interview \#111, DDR-Experte im Ministry of Water and Energy; Aussagen verschiedener DDREntsandter auf dem Ehemaligentreffen in der Naupoldsmühle, Eisenberg, 5.9.2015. 
meistern“.64 In einem Fall bat ein DDR-Universitätsdozent nach ,jahrelange[r] erzwungene[r] Untätigkeit“ seiner Ehefrau, seinen Einsatz abzubrechen - was allerdings so ungewöhnlich war, dass hierfür sogar ein eigener Ministerbeschluss eingeholt werden musste. ${ }^{65}$ Die These jüngerer Migrationsforschungen, dass die Unzufriedenheit mitreisender PartnerInnen einen Hauptgrund für den Abbruch von Auslandseinsätzen darstellt, findet sich auch sonst durch Interviews und Archivmaterialien nicht bestätigt. ${ }^{66}$ Frustrationen und Spannungen, die sich u.a. auf die divergenten Karriereverläufe zurückführen lassen, waren allerdings keine Seltenheit. Eine ehemalige GTZ-Expertin vermerkte, dass „[w]egen dieser erzwungenen jahrelangen Untätigkeit der Frau[en] viele Ehen während des Auslandseinsatzes [zerbrachen]“.${ }^{67}$

Über diese Fragen hinaus beanspruchten manche der mitausreisenden Ehefrauen der BRD für sich die Rolle eines „entwicklungspolitischen Gewissens“ oder veranstalteten Wohltätigkeitsevents. Auf DDR-Seite gab es in politisierter Variante die „Solidaritätsbasare“ zur Unterstützung antikolonialer Befreiungsbewegungen oder des „vietnamesischen Volkes“. Durch einen intensiveren persönlichen Kontakt mit Hauspersonal und Nachbarschaft sowie ihre „Insider“-Wahrnehmung von Versorgungsproblemen konnten manche der mitreisenden Ehefrauen ihren Ehemännern zudem bei der kulturellen Übersetzung helfen und neue Interpretationen und Lösungsansätze für Probleme anbieten, die in der entwicklungspolitischen Praxis auftraten. ${ }^{68}$

\section{Eskapismus}

Eine Grundfrage entwicklungspolitischer Auslandseinsätze ist, warum das Handlungsfeld nicht „daheim“, sondern im (zumeist postkolonialen und als unterentwickelt gedachten) Ausland gesucht wird. Das Eskapismus- oder Fluchtmotiv erklärt diese Verortung unspezifisch mit Bezug auf Resignations- und Frustrationserfahrungen mit der eigenen Gesellschaft und dem eigenen Leben. Der Auslandseinsatz erscheint als Ausweg aus einer existenziellen Sackgasse. Das Fluchtmotiv lässt sich für beide deutsche Staaten konstatieren; positiv gewendet

64 Müller, Als DDR-Tierarzt in Tansania, S. 99-110.

65 BArch Berlin, DR 3/2. Schicht/1514, S. B. via Rektor der KMU L. Rathman an MHF, Leipzig, 25.5. 1982.

66 Anne M. Braseby, Adaptation of Trailing Spouses: Does Gender Matter?, PhD Thesis, Miami 2010.

67 E-Mail einer ehemaligen GTZ-Projektleiterin an den Autor, 27.5.2017.

68 Interview \#115, GTZ-Projektleiter und mitausreisende Ehefrau. 
könnte man es Abenteuermotiv nennen, was aber die Ausgangsbedingungen in den Hintergrund rückt. ${ }^{69}$ Der Wunsch, mit dem grauen Alltag in Deutschland zu brechen, konnte sich als allgemeine Langeweile, „Sinnsuche“, Abenteuerlust, Drang zum „Aussteigen“ oder zur „Selbstfindung“ äußern. Angesichts der starken Definition der Persönlichkeit in Industriegesellschaften über die berufliche Tätigkeit spielte auch die Frustration über die Arbeit eine große Rolle. Die „Arbeit in der Dritten Welt“ stellte eine „Alternative zu der unbefriedigenden beruflichen Situation hier [in der BRD]“ dar, wie zwei Ingenieure retrospektiv schrieben. ${ }^{70}$ Unter den InterviewpartnerInnen begründeten einige AkademikerInnen, die z.T. bereits auf gesicherten Assistentenstellen an Universitäten beschäftigt waren, ihren Auszug aus dem Elfenbeinturm mit dem Wunsch, wirksam zu werden, Theorie in Praxis umzusetzen und der Langeweile an der Uni zu entkommen. ${ }^{71}$ Die Entwicklungsarbeit - oder auch schon der Auslandseinsatz an sich - stand damit für die Entsandten im Gegensatz zu Vorstellungen des „normalen“ Lebens. ${ }^{72}$

In der BRD wie der DDR fachten exotisierende Wissensbestände und koloniale Vorstellungswelten die Abenteuerlust an. Von einigen Interviewpartnern der DDR-Seite wurden Lektüreerfahrungen als prägend für den Wunsch eines Auslandsaufenthalts hervorgehoben, darunter Abenteuer- und Reisegeschichten, Karl May-Romane, Hans Schomburgks in der DDR millionenfach verlegte AfrikaReiseberichte wie Meine Freunde im Busch (1954) oder selbst die Erinnerungen von Paul von Lettow-Vorbeck (ehemaliger Kommandeur der Schutztruppe für Deutsch-Ostafrika während des Ersten Weltkriegs, der erst zu einem „Kolonialhelden“ stilisiert und dann zu einem der aktivsten Vertreter der kolonialrevisionistischen Bewegung wurde). ${ }^{73}$ Bei diesen Referenzpunkten in den Erzählungen über den eigenen Auslandseinsatz überrascht es auch nicht, wenn die Aussicht auf einen Einsatz in „Afrika“ für den in Tansania eingesetzten DDR-Tierarzt Hans Müller nicht in erster Linie Gedanken an antiimperialistische Solidarität hervorgerufen hatte: „Dschungel, Feuchtigkeit, Hitze und wilde Tiere, vielleicht auch ein bisschen Gebiet für Pioniere“74 heißt es bei Müller, während das Entwicklungshelferbild einer DED-Physiklehrerin sich im androzentrischen Klischee von

69 Friedrich Heckmann, Entwicklungsdienst: Hilfe für die „Unterprivilegierten“? Subjektive und objektive Momente der Tätigkeit von Entwicklungshelfern, in: Gerhard Wurzbacher, Hg., Störfaktoren der Entwicklungspolitik, Stuttgart 1975, S. 15-35, hier: S. 29.

70 V. K./B. W., Praxiserfahrungen aus der Arbeit als Entwicklungshelfer in Tansania, in: Blätter des iz3w 381 (1979), S. 11-15, hier: S. 11; siehe auch Krebs, Ein tansanisches Tagebuch, S. 6-8. 71 Besonders prononciert in Interviews \#26 und \#27, GTZ-Experten.

72 Roth, The Paradoxes of Aid Work, S. 45.

73 Interview \#114, Leiter einer Freundschaftsbrigade; Interview \#117, DDR-Polytechnikberater.

74 Müller, Als DDR-Tierarzt in Tansania, S. 99-100. 
„hartgesottene[n] Burschen [...], die sich [...] durch den Urwald schlugen“ erschöpft hatte. ${ }^{75}$

Anekdotische Archivbelege legen nahe, dass auch Beziehungskrisen oder der Wunsch, aus geordneten und als übermäßig reguliert und einengend empfundenen Sexual- und Familienverhältnissen auszubrechen, eine Rolle spielten. In der Betrachtung abstrakter, von der konkreten Biografie losgelöster „Motive“ bleiben solche egozentrischen Aspekte zwangsläufig unterbelichtet, einzig im Genre der Auto-Ethnographien ${ }^{76}$ und Einschätzungen von außen treten sie vereinzelt an die Oberfläche. Auffällig an einem Bestand abgelehnter Bewerbungen des DDR-Ministeriums für Gesundheit aus den Jahren 1965 bis 1969 ist, dass ein bedeutender Anteil der Bewerbungen von (zumeist unverheirateten) Frauen stammt, darunter sowohl Krankenschwestern als auch Ärztinnen, von denen sich einige noch in der Ausbildung befanden. ${ }^{77}$ Womöglich war hier die biografische Erwartung ausschlaggebend, aus beruflichen und familiären Gründen bald weniger Mobilitätsmöglichkeiten zu haben. Als explizite, aber durchwegs wenig konkrete Motive findet sich in diesem Bestand nicht nur der Wunsch, der (nicht näher spezifizierten) Bevölkerung zu helfen, sondern auch das Vorhaben, das eigene Wissen durch das Kennenlernen Afrikas und der ,jungen Nationalstaaten“ zu erweitern. Zwei Beispiele lassen vermuten, dass patriarchale und heteronormative Geschlechterbeziehungen und Eskapismus eng verknüpft waren: Eine Krankenschwester, die ihrem Arbeitgeber schon durch ihr „burschikoses Auftreten“ und das häufige Kundtun einer eigenen Meinung negativ auffiel, bewarb sich für einen Auslandseinsatz, aber meinte auch, ihr zukünftiger Mann sei „sowieso dagegen““ ${ }^{78}$ Über einen Bewerber hieß es mit augenscheinlich kritischem Ton, seine Ehefrau sei lesbisch, das Paar habe sich bereits auseinandergelebt. ${ }^{79}$ Der DED wiederum stellte mit Bezug auf einen Generationenkonflikt fest, dass viele BewerberInnen eigentlich nicht an Entwicklungshilfe interessiert seien, sondern eher die „Flucht aus einem strengen Elternhaus“ anstrebten. ${ }^{80}$ Da derartige biografische Fluchtmomente sowohl in Ost- als auch in Westdeutschland als Hinweis

75 Inge Landmann, Aufgeben oder Durchhalten? Physikunterricht in Tansania, in: Willi Erl, Hg., Betrifft: Zusammenarbeit: 25 Jahre Deutscher Entwicklungsdienst, Berlin 1988, S. 191-196, hier: S. 191.

76 Laurie L. Charlés, Intimate Colonialism. Head, Heart, and Body in West African Development Work, Walnut Creek, CA 2007.

77 BArch Berlin, DQ 1/23939, E. E. an MfG, Abt. Auslandseinsatz [sic], Halle, 12.12.1964.

78 BArch Berlin, DQ 1/22733, Poliklinik Neustrelitz, Beurteilung der Krankenschwester G. E., Neustrelitz, 20.4.1965.

79 BArch Berlin, DQ 1/22733, Dr. G. H., „Kaderreserve für Auslandseinsatz“, o.O., o.D.

80 Büschel, Hilfe zur Selbsthilfe, S. 348. 
auf eine illegitime egozentrische Motivlage und eine instabile Lebenssituation gelesen wurden und einem produktiven Auslandseinsatz als abträglich galten, wurden BewerberInnen, bei denen es Anzeichen für partnerschaftliche Konflikte oder andere Formen des Eskapismusmotives gab, ausgesiebt. ${ }^{81}$ Als legitimes und wünschenswertestes Motiv galt den Entsendeinstitutionen das Wirksamkeitsmotiv, das eng mit der offiziellen Rhetorik verschränkt war.

\section{Wirksamkeitsprojektionen}

In der DDR, so erinnerten sich gerade ehemalige Entsandte der früheren Generationen, begann die Solidaritätswelle bereits mit der Kenntnisnahme der afrikanischen Unabhängigkeiten 1960 und ihrer Einordnung in einen globalen Entwicklungsprozess. ${ }^{82}$ Hinzu kamen im selben Jahr Proteste gegen das Massaker im südafrikanischen Sharpeville ${ }^{83}$ und antiimperialistische Massendemonstrationen infolge der Ermordung des kongolesischen Premierministers Patrice Lumumbas in vielen Metropolen von Mexiko-Stadt bis Leipzig und Belgrad Anfang $1961 .^{84}$ Ein DDR-Bildungsexperte identifizierte diese Proteste Anfang der 1960er-Jahre als Katalysator für seinen Wunsch, am globalen Fortschritt aktiv mitzuwirken:

Die Personen, die mich auch mitgeprägt haben, nicht nur Nyerere sondern auch Nkrumah. Sékou Touré, und andere. Insbesondere aber auch Lumumba. [...] Damals war Lumumba, das war eine Welle, es gab hier in Leipzig internationale Solidaritätsbekundungen [nach der Ermorderung Lumumbas, Anm. EB] noch und noch, das war ein internationales Ereignis. ${ }^{85}$

Mit Rückgriff auf Alessandro Portellis Unterscheidung dreier verschiedener Erzählregister, dem politischen, gemeinschaftlichen und persönlichen, ist deutlich

81 Haase, Zwischen Lenkung und Selbstbestimmung, S. 123; Niederhut, Die Reisekader, S. 51. 82 Interviews \#23, \#27, DDR-Experten; Interview \#24, DDR-Kulturattaché.

83 Hans-Georg Schleicher, GDR Solidarity: The German Democratic Republic and the South African Liberation Struggle, in: South African Democracy Education Trust, Hg., The Road to Democracy in South Africa, Pretoria 2004, S. 1069-1153, hier: S. 1103.

84 Slobodian, Foreign Front, S. 62. Neben Aufmärschen in Kairo, London, Neu Delhi, Lagos, Caras und vielen anderen Orten waren auch in Ost-Berlin 15.000 Menschen - darunter viele ausländische Studierende - auf die Straßen gegangen, in westdeutschen Städten immerhin einige Hundert.

85 Interview \#31, DDR-Universitätsexperte. Er und ein anderer Interviewpartner seiner Generation waren auch hauptverantwortlich dafür, dass 2011 das Lumumba-Denkmal in Leipzig - zu diesem Zeitpunkt das einzige in Deutschland - nach seiner mutwilligen Zerstörung 1997 wiedererrichtet wurde. 
die enge Verflechtung aller drei Ebenen festzustellen. ${ }^{86}$ In den Interviews verknüpften mehrere Angehörige dieser Generation ihren Einsatz direkt mit internationaler Solidarität und Unterstützung von Befreiungsbewegungen, wie es auch mit dem letzten der 1958 von Walter Ulbricht propagierten 10 Gebote für den neuen sozialistischen Menschen gefordert wurde: „Du sollst Solidarität mit den um nationale Befreiung kämpfenden und den ihre nationale Unabhängigkeit verteidigenden Völkern üben.“ Das Motiv der Solidarität besaß eine identitätsstiftende Komponente und war somit nicht nur außenpolitisch funktional, sondern diente auch der Legitimierung der Gesellschaftsordnung nach innen, indem es die Zugehörigkeit zur DDR zur moralisch überlegenen (und wachsenden) antikolonialen Welt betonte. ${ }^{87}$ DDR-BürgerInnen bewarben sich auf Auslandseinsätze, um „dem Afrikanischen Volk [sic] tatkräftig zur Seite zu stehen“. ${ }^{88}$ Das Gefühl, epochemachende Entwicklungen in Afrika und im globalen Maßstab nicht nur mitzuerleben, sondern mitgestalten zu können, betonte ein DDR-Auslandskader, der in den 1960er-Jahren als Lehrer in Sansibar und später als Bildungsexperte in Äthiopien tätig war. Seine Retrospektive auf den Sprung vom „Dorfschullehrer“ in die Weltgeschichte rekurriert auf mehrere Umbrüche in den 1960er-Jahren:

Wir haben die Afrikaner für die Besseren gehalten. Es wurde ein Staat nach dem anderen gebildet. Sieg über den Kolonialismus. Martin Luther King in den USA. Die Achtundsechziger in der BRD traten auf den Plan. Und wir hatten die Gelegenheit, vom Dorfschullehrer praktisch in die große Politik mit reinzukommen. Es war echt eine Begeisterung. [...] Dieses Gefühl! Etwas in der Welt mitbewegen zu können! Wir leisten einen Beitrag, wir haben die Chance, da hineinzukommen! ${ }^{89}$

In den Wirksamkeitsvorstellungen war die Grenze zwischen (offen politisierter) Solidarität und (apolitisch gedachter) Hilfe meist fließend. Zwischen Solidaritätsund Hilfspraktiken lässt sich zwar theoretisch unterscheiden ${ }^{90}$, aber beide gli-

86 Alessandro Portelli, The Death of Luigi Trastulli and Other Stories: Form and Meaning in Oral History, Albany 1990, S. 21.

87 Angela Brock, Producing the „Socialist Personality“? Socialisation, Education, and the Emergence of New Patterns of Behaviour, in: Mary Fulbrook, Hg., Power and Society in the GDR, 1961-1979: The „Normalisation of Rule“?, New York 2009, S. 220 -252, hier: S. 223.

88 BArch Berlin, DQ 1/23939, V.F. an MfG, Albertsberg, 16.4.69.

89 Interview \#113, DDR-Lehrerexperte.

90 Ein Unterscheidungskriterium ist, ob die Unterstützung als Interaktion unter „Gleichen“ konzeptualisiert wird oder ob eine hierarchische Beziehung mit einseitigen Transfers als kognitiver Ausgangspunkt dient. Ein solidarischer Handlungsimpetus zeichnet sich hingegen dadurch aus, dass die eigene Wirksamkeit im Kontext einer Bewegung gedacht wird: Die eigene Person wird Teil einer progressiven Bewegung und stützt diese. Der Hilfsgedanke verlagert die imaginierte Handlungsmacht auf das Selbst und unterscheidet viel stärker zwischen einem agierenden 
chen sich im Anspruch, eigene Handlungsmacht auszuüben, ebenso wie im Fehlen konkreter Gedanken, wie die eigene Tätigkeit tatsächlich aussehen würde. DDR-Entsandte späterer Jahre betteten ihre Entsendung nicht in einen derartigen globalen, geradezu heroischen Fortschrittsprozess ein; bei ihnen finden sich häufiger emotionsarme Verweise auf bilaterale Abkommen zwischen der DDR und Tansania, in deren Rahmen der eigene Einsatz realisiert wurde. ${ }^{91}$

In den Narrativen vieler BRD-Entsandter, die in den 1970er und frühen 1980er ihre Berufslaufbahnen begannen, bietet die Gemeinschaft der Achtundsechziger einen wichtigen Deutungsrahmen für die eigenen Wirksamkeitsprojektionen. Die Erzählungen umfassten ein breites Spektrum von Aktivitäten vor dem Tansaniaeinsatz, die von politisch riskantem Engagement (z.B. Untergrundaktivität im Widerstand in Chile) über verschiedene Formen des Aktivismus (z. B. das Spenden für antikoloniale Befreiungsbewegungen wie die SWAPO und lokales Engagement im eigenen Viertel in Westberlin) bis hin zum Mitläufertum (wie das „uninformierte“ Mitmarschieren auf Demos als „langhaariger Student“) reichten. ${ }^{92}$

Die Verlagerung der Tätigkeit in die ,jungen Nationalstaaten“ bzw. in die „Dritte Welt“ versprach, eine Handlungsmacht zu erlangen, von der sich in der eigenen Gesellschaft nicht einmal träumen ließ. Ein GTZ-Experte erzählte, dass er 1973 von seinem Doktorvater auf eine Einsatzmöglichkeit an der Ingenieursfakultät hingewiesen wurde. Für ihn, einen selbst ernannten Achtundsechziger, war das die Möglichkeit, „,aus der Stagnation“ und dem „muffige[n] Berlin“, wo trotz politischer Bewegungen nichts weitergegangen sei, herauszukommen und nun endlich ,anzupacken“ und etwas zu verändern, statt weiter mit dem Promotionsvorhaben ,in der Sandkiste“ zu arbeiten. ${ }^{93}$ Hier offenbart sich das Wirksamkeitsmotiv als Spiegelbild des Eskapismusmotives. Die Beziehung zwischen imaginierter Handlungsmacht einerseits und der geografischen Verlagerung in die „Dritte Welt“ andererseits blieb häufig, aber nicht immer unreflektiert:

Denn zum ersten Mal könnten wir als Ingenieure umfassender arbeiten und unsere politische Einstellung dazu einsetzen, wie man etwas plant, organisiert, ausführt und vermittelt. Dies ist eine große Erfahrung, vergleicht man die Bedingungen, unter denen man als Techniker in der BRD arbeitet. $^{94}$

Subjekt und einem passiven Objekt - etwa eine statische, fremde Kultur - die überhaupt erst einmal in Bewegung versetzt werden muss.

91 Im Fall anderer Entsendeländer wie Mosambik oder Angola könnten politisierte Solidaritätsmotive jedoch auch in späteren Jahren durchaus prominent gewesen sein.

$92 \mathrm{Zu}$ Spenden für Befreiungsbewegungen siehe auch Hein, Die Westdeutschen, S. 235.

93 Interview \#122, GTZ-Experte.

94 K./W., Praxiserfahrungen, S. 15. 
Die Hoffnungen dieser beiden Ingenieure, ,in der Dritten Welt direkter politisch tätig sein“ und zur „Überwindung der Abhängigkeit und der Folgen des Kolonialismus“ beitragen zu können, sind ein klares Beispiel für eine (gleichermaßen spezifische wie unkonkrete) räumliche Verortung des Wirksamkeitsmotivs. ${ }^{95}$ Die Projektion der eigenen Handlungsmacht in die Dritte Welt wurde in den Texten von BRD-EntwicklungshelferInnen aber bisweilen auch hinterfragt: Wäre es nicht effektiver und sinnvoller, „Alten, Behinderten, Kranken und Gastarbeitern“ in der eigenen Gesellschaft beizustehen ${ }^{96}$ In der DDR bereitete diese Problematik den politisch Motivierten kein Kopfzerbrechen, schließlich wurden Fachkräfte auch in der DDR von „Brennpunkten des Aufbaus des Sozialismus“ (Ausbildungsstätten, wissenschaftlichen Projekten, Industrialisierungsvorhaben) abgezogen: Der individuelle Beitrag zur Weltrevolution konnte in der DDR theoretisch genauso gut wie im Ausland geleistet werden, zumindest im offiziellen Diskurs. ${ }^{97}$ Wie bereits anhand von Initiativbewerbungen gezeigt (siehe Eskapismus), war die Verknüpfung von Hilfsgedanken und postkolonialer Welt aber auch in der DDR verbreitet.

Nur wenige BRD-Entsandte distanzierten sich im Interview explizit von idealistischen Beweggründen, darunter ein Gesprächspartner, der den Landwirtschaftsfachmann Hans Ruthenberg zitierte, bei dem er auch studiert hatte. Ruthenberg habe von seinen Studierenden verlangt, nicht aus ideologischen Gründen, sondern aus „sachlicher Notwendigkeit“ in die Dritte Welt zu gehen gerade in Afrika sei der Bildungsstand noch niedrig, während gleichzeitig die Nahrungsmittelproduktion nicht mit der „Bevölkerungsexplosion“ mithalten könne. ${ }^{98}$ Während das Motiv nüchtern-sachorientiert anmutet, reiht es sich doch ein in die Tradition der white man's burden und noblesse oblige. Religiöse Motive blieben in den Interviews von untergeordneter Bedeutung oder wurden explizit zurückgewiesen; gerade im Rahmen der Entwicklungsarbeit der Kirchen in Tansania wären entsprechende Diskurse aber ebenfalls zu erwarten.

Wenngleich sich der Hilfsimperativ politisch, religiös oder technokratisch kleiden konnte, gehen alle diese Ausformungen doch auf gemeinsame Wurzeln zurück. Barbara Heron hat argumentiert, dass sich der innere Drang zu helfen den sie „Entwicklungsbegehren“ (desire for development) nennt - historisch als

95 K./W., Praxiserfahrungen, S. 11.

96 Krebs, Ein tansanisches Tagebuch, S. 7.

97 SAPMO BArch Berlin, DY 24/19211, Brigadeleiter Pabst, Aktennotiz über eine Grundsatzaussprache mit dem Generalsekretär der ASPYL und anderen Funktionären in Bambi, Sansibar, 16.9. 1970.

98 Interview \#102, GTZ-Experte und Projektleiter. 
ein spezifisch „bürgerlicher“ und „weißer“ Imperativ herausgebildet habe. ${ }^{99} \mathrm{Mi}$ chael Cowen und Robert Shenton verorten in ähnlicher Weise die Geburtsstunde des Entwicklungsgedankens mit dem Entstehen des Konzepts einer „Treuhandschaft“ (trusteeship): Bestimmte Gruppen von Personen sahen sich im Europa des 19. Jahrhunderts als berechtigt, aufgrund ihres Wissens als „Treuhänder“ für die Menschheit $\mathrm{zu}$ agieren und $\mathrm{zu}$ intervenieren. ${ }^{100}$ Die Anthropologin Tania Li wiederum hat gezeigt, dass die mit der „Treuhandschaft“ verbundenen Techniken von der Etablierung von Anreizstrukturen bis hin zur Ausübung von Zwang sowohl von Kolonialbeamten als auch von EntwicklungsexpertInnen angewendet wurden. ${ }^{101}$

Drei Aspekte sind diesen historisierenden Thesen hinzuzufügen. Erstens ist das Selbstverständnis, mit dem Ziel der „Entwicklung“ intervenieren zu können und zu dürfen, auch in der tansanischen Elite weit verbreitet gewesen, es war also keinesfalls (mehr) auf expatriates beschränkt. Es ist fraglich, inwiefern dieses Selbstbild analytisch noch als „weiß“ zu fassen ist, es bleibt aber jedenfalls mit privilegierten Machtpositionen und Fortschrittsvorstellungen verbunden. Zweitens ist davon auszugehen, dass dieses Wirksamkeitsmotiv allgemeine Anerkennung genoss und persönliche, als weniger legitim erachtete Motive in den Hintergrund rücken sollte. Anders ließe sich kaum erklären, dass Menschen, die sich ihr Leben lang relativ wenig sozial und politisch engagiert haben, dies plötzlich taten - etwa DDR-Auslandskader, die vor ihrem Einsatz keinerlei „Solidaritätspraktiken“ ausgeübt hatten, wenn man von den mehr oder weniger obligatorischen Spenden und dem Kauf von „Soli-Marken“ absieht. ${ }^{102}$ Auch auf BRD-Seite finden sich Entsandte, die weniger an „Zielgruppen“ und „Entwicklung“ und mehr an „Abenteuer“ oder Verdienst interessiert waren. Drittens wurden Wirksamkeitsfantasien nicht nur auf „afrikanische Zielgruppen“ projiziert, sondern auch in andere Bezüge gebracht: Ein DDR-Lehrer meinte kurz vor seiner Abreise aus Sansibar 1970 stolz, ,dass wir doch ein kleines Kapitelchen in unserer Außenpolitik mitschreiben oder mitgestalten durften“. ${ }^{103}$ Hier stand die verbesserte Position der DDR im Zentrum. Ein Universitätsdozent resümierte im Interview,

99 Barbara Heron, Desire for Development. Whiteness, Gender, and the Helping Imperative, Waterloo 2007.

100 Cowen/Shenton, Doctrines of Development, S. 5.

$101 \mathrm{Li}$, The Will to Improve.

102 Interview \#119, Interview mit Leiter einer Freundschaftsbrigade und Freundschaftsbrigadistin. Solidaritätsmarken wurden monatlich vom FDGB - in einer Mischung aus Freiwilligkeit und moralischem Druck - an die Werktätigen verkauft. Die erzielten Einnahmen flossen in den Solidaritätsfonds des FDGB, mit dem dieser u.a. seine internationale Arbeit finanzierte.

103 Privatarchiv E. W., E. W. an die SED-Kreisleitung Querfurt, Sansibar, 9.10.1970. 
dass er während seines Tansania-Einsatzes in den 1980er-Jahren „in drei Jahren so viel geschafft“ habe, wie er sein „ganzes Leben nie wieder schaffen konnte und geschafft habe“ - hier stand die persönliche Leistung, nicht das Ergebnis für die DDR (oder Tansania) im Vordergrund. ${ }^{104}$ Wirksamkeit war also Teil verschiedener diskursiver Register, von denen nicht alle auf einer Externalisierung beruhten.

Feststellbar ist auch - teils als Resultat der Auslandseinsätze - das Ziel, in der BRD selbst Veränderungen zu bewirken. Neben einem fortgesetzten Engagement in der Dritte-Welt-Bewegung und Versuchen, mit Bildungsarbeit zu einem Bewusstseinswandel in der Bevölkerung beizutragen, vollführte eine Reihe westdeutscher Entsandter nach dem Auslandseinsatz in Tansania den programmatischen „Marsch durch die Institutionen“. Sie besetzten zunehmend höhere Positionen in der Entwicklungsbürokratie, stießen dort Reformen an und trugen zum Bedeutungsgewinn sozialpolitischer Kriterien als Maßstab entwicklungspolitischer Maßnahmen bei. ${ }^{105}$ Sie setzten sich teils im Rückgriff auf ihre Auslandserfahrungen für neue Förderungsfelder wie die kleinbäuerliche Landwirtschaft oder Grundschulbildung ein, die nun $\mathrm{zu}$ den Großprojekten in Infrastruktur, Industrie und Landwirtschaft hinzukamen. ${ }^{106}$ Ujama war eine wichtige Inspiration für diese Neuausrichtung.

\section{Tansaphilie}

In der BRD genoss Tansania in einem breiten Spektrum der Linken den Ruf als besonderes Einsatzland, das - so fanden drei bundesdeutsche Ärzte 1977 - ,immer wieder den festen politischen Willen zum sozialistischen Aufbau“ bewiesen hatte und mit Angola und Mosambik im Zuge sei, „den ersten Baustein für ein sozialistisches Panafrika zu legen““. ${ }^{107}$ Wie nur wenige Länder konnte Tansania mit einer antiimperialistischen und entwicklungspolitischen Ausrichtung punkten, die aller Widersprüche und praktischen Probleme zum Trotz gerade in linken Kreisen anschlussfähig war. Wie ein DED-Entwicklungshelfer 1981 treffend analysierte, war die tansanische Politik ,einerseits antikapitalistisch, aber gleichzeitig auch antikommunistisch“:

104 Interview \#20, DDR-Universitätsdozent.

105 Zum Beispiel Interview \#26, GTZ-Experte.

106 E-Mail einer ehemaligen GTZ-Projektleiterin an den Autor, 27.5.2017.

107 Wolfgang Bichmann u.a., „Westliche“ Medizin in Ländern der Dritten Welt. Am Beispiel Tansania: Ein Trojanisches Pferd des Neo-Kolonialismus, in: Wolfgang Fritz, Hg., Jahrbuch für kritische Medizin: Band 2, Hamburg 1977, S. 170 -192, hier: S. 174. 
[S]ie proklamiert die sozialistische Planwirtschaft und praktiziert kapitalistische Marktwirtschaft; sie ist von dem Glauben an die grundsätzliche Vereinbarkeit von Gegensätzen durchsetzt, wie auch jeder gute Sozialdemokrat glaubt, dass Arbeit und Kapital an einem Strang zu ziehen haben [...]; sie ist gegen die bundesdeutsche Südafrikapolitik, aber auch gegen die sowjetische Afghanistanpolitik; sie ist nicht klerikal, aber doch christlich. ${ }^{108}$

Freilich gab es Anfang der 1980er-Jahre bereits „neue“ Ziele für die westliche Linke, die sich weitaus besser für die Projektion von Hoffnungen eines alternativen Sozialismus jenseits von Kommunismus und Sozialdemokratie und das Entfachen einer Aufbruchsstimmung eigneten - beispielsweise das sandinistische Nicaragua. Aber auch Tansania blieb (angesichts der Bürokratisierung und Aushöhlung des Afrikanischen Sozialismus erstaunlich lange) ein „Mekka linker Polittouristen“. ${ }^{109}$ Das war selbst noch der Fall, als das Ujamaa-Bild Risse in wohlgesonnenen Publikationen wie dem $i z 3 w$ bekam und (neo-)marxistische Kreise ab Mitte der 1970er-Jahre verstärkt Kritik am halbherzigen Reformismus, der korrupten „Staatsklasse“ und der ungenügenden Beachtung des Klassenkampfs übten. ${ }^{110}$ Eine DED-Entwicklungshelferin, die erstmals 1980 nach Tansania ausreiste und in der Folge auch einen zweiten Einsatz absolvierte, hob im Interview die ideologische Attraktivität Tansanias hervor:

[D]a ich Politologie studiert hatte, hat mich so der Afrikanische Sozialismus interessiert. Also bei mir war's wirklich ein politischer Grund. Und da war ja noch Nyerere in Tansania und das hat mich alles interessiert. Und deshalb hatten wir uns beim Deutschen Entwicklungsdienst beworben. ${ }^{111}$

Auch GAWI- und GTZ-ExpertInnen erinnerten sich, dass sie „da wirklich fest dran geglaubt [haben], was Nyerere in schönen Worten gepredigt hat“. ${ }^{112}$ Ujamaa und self-reliance galten für ihre Arbeit als zentrale Orientierungspunkte. Diejenigen, die dem Afrikanischen Sozialismus gegenüber von vorneherein kritisch eingestellt waren, verschwiegen ihre Meinung in den Selektionsverfahren.

108 Jäger, Shida kweli, S. 51.

109 Isolde Schaad, Die Komfortzelle im Busch, in: Dietmar Dirmoser u.a., Hg., Mythos Entwicklungshilfe: Entwicklungsruinen: Analysen und Dossiers zu einem Irrweg, Giessen 1991, S. 175-184, hier: S. 180. Zu Nicaragua siehe Christian Helm, Botschafter der Revolution. Das transnationale Kommunikationsnetzwerk zwischen der Frente Sandinista de Liberación Nacional und der bundesdeutschen Nicaragua-Solidarität 1977 - 1990, Berlin 2018.

110 Hofmeier, Möglichkeiten und Grenzen, S. 216.

111 Interview \#18, DED-Entwicklungshelferin; ähnlich Interview \#68, DED-Entwicklungshelfer. 112 Interview \#28, Integrierter Experte im Planungsministerium; vgl. auch Interview \#26, GTZExperte; Interview \#6, GTZ-Projektleiterin; Interviews \#27 und \#28, GTZ-Experten. 
In der DDR bildete sich - mit Ausnahme einiger Ujamaa-Interessierter im akademischen Bereich sowie vereinzelter RückkeherInnen aus Tansania - keine spezifische Tansaphilie heraus. Eine Serie negativer Bewerbungsbeurteilungen aus dem Bestand des DDR-Ministeriums für Gesundheit aus den Jahren 1965 bis 1969 zeigt, dass das Tansaniabild sowie die Vorstellungen vom postrevolutionären Sansibar äußerst unscharf waren. ${ }^{113}$ Die BewerberInnen schrieben, dass sie über Medienberichte, private Kontakte - etwa vom Kreisarzt oder von einem befreundeten Paar, das gerade von Sansibar aus im DDR-Heimaturlaub weilte - oder aus DDR-Publikationen über ,junge Nationalstaaten“ und Hilfeleistungen in den verschiedensten Gebieten von der Einsatzmöglichkeit Kenntnis bekommen hatten. In einigen Fällen sind die Bewerbungen geografisch spezifisch. Afrika und Sansibar kommen wohl auch aufgrund der Berichterstattung häufiger vor; vereinzelt werden andere „,befreundete“ Länder wie Ägypten, Kuba, Mali, Iran, Irak und Algerien genannt. Manche BewerberInnen wollten aber auch schlicht ins außereuropäische Ausland ,egal auf was für einem Erdteil““.114 Alle diese BewerberInnen fanden jedoch keine Berücksichtigung. Im Folgenden wird erklärt, wie die Selektionsprozesse in den beiden deutschen Staaten abliefen.

\subsection{Direktiven: Selektion und Vorbereitung}

Hubertus Büschel hat Vorbereitung und Selektion von DDR- und BRD-EntwicklungsarbeiterInnen bereits ausführlich beschrieben, sodass hier der Fokus nur auf jenen Aspekten liegt, die für die Handlungsspielräume während des Einsatzes von Bedeutung erscheinen. Büschels These, dass weder DDR noch BRD es sich leisten konnten, „besonders wählerisch“ bei der Auswahl von ExpertInnen zu sein, scheint besonders für die von ihm behandelten 1960er-Jahre zutreffend. ${ }^{115}$ Selbst für die 1970er und 1980er-Jahre aber finden sich Belege dafür, dass weder der „freie Arbeitsmarkt“ der BRD noch die „Kaderplanung“ der DDR die gewünschte Zahl von EntwicklungsarbeiterInnen rechtzeitig bereitstellen konnte. ${ }^{116}$ Unterschiede zwischen BRD und DDR sowie innerhalb der verschiedenen Entsendemodi gab es aber doch: Kulturelles Kapital - vor allem spezifische Fach-

113 BArch Berlin, DQ 1/22733; ebd., DQ 1/23939.

114 BArch Berlin, DQ 1/22733, R.G. an MfG, Ueckermünde, 7.9.1965.

115 Büschel, Hilfe zur Selbsthilfe, S. 239. Siehe auch Sandra Mass, „Eine Art sublimierter Tarzan“. Die Ausbildung deutscher Entwicklungshelfer und Entwicklungshelferinnen als Menschentechnik in den 1960er Jahren, in: WerkstattGeschichte 42 (2006), S. 77-89.

116 Siehe dazu z. B. eine Reihe von Briefwechseln und Aktenvermerken in PAAA, MfAA, C 773/74; außerdem Matthes, Zur Entwicklung, S. 84-85. 
kenntnisse in zweiter Linie auch Beherrschung von Fremdsprachen - war in beiden deutschen Staaten ein entscheidendes Kriterium. Politische Auswahlkriterien blieben in der DDR freilich allen anderen Aspekten übergeordnet; in der Expertenentsendung der BRD hingegen spielten bestehende Netzwerke und damit soziales Kapital eine wichtige Rolle in der Rekrutierung. Auf Freiwilligenebene galt der DED zeitweilig als Ventil und Angebot der Bundesregierung, die unter jungen Menschen weitverbreitete Unzufriedenheit und den individuellen Tatendrang in eine entwicklungspolitisch relevante Tätigkeit zu kanalisieren. Die DDR war gerade bestrebt, dieses Ventil zu versiegeln: Die Unzufriedenen durften keinesfalls gehen.

Versuche, erwünschtes Verhalten während des Entsendezeitraums zu gewährleisten, gingen über die Selektion hinaus. Spezifische Vorbereitungsprogramme dienten ab Anfang der 1960er-Jahre dazu, nicht nur Sprachkenntnisse zu vermitteln, sondern auch den Habitus - also die in der Alltagspraxis wirksamen Handlungsorientierungen und Beurteilungsschemata ${ }^{117}$ - der Ausgewählten zu formen. Für die Ausreisenden beider Staaten galt, dass sie ihr Verhalten an neue Situationen in der Entwicklungsarbeit anzupassen hatten. Keinesfalls sollten einfach die Maßstäbe und Verhaltensrichtlinien aus dem eigenen Land unverändert mitgenommen und übertragen werden. ${ }^{118}$ Von Entsandten beider Länder gab es Beschwerden über die Unzulänglichkeit der Vorbereitungsprogramme. In der DDR lag ein Fokus auf der Vermittlung politischer Verantwortung und von Bedrohungsszenarien. In der BRD spielten in manchen Kursen die Deutung kultureller Differenzen und der Umgang mit Andersartigkeit eine zentrale Rolle, in anderen hingegen die Vermittlung eines historisierenden und politisierten Verständnisses globaler Ungleichheiten.

\section{Die Privilegierung der Gefälligen}

Im Zuge des Mauerbaus reglementierte die DDR-Regierung „Westreisen“ zunehmend restriktiv; ausführliche geheimdienstliche Überprüfungen wurden ein fester Bestandteil der (Auslands-)Kaderpolitik, die sich an den machtpolitischen Interessen der SED orientierte. ${ }^{119}$ Tatsächlich war über das MfS hinaus eine Reihe weiterer staatlicher Stellen in die Personalentsendung involviert. Zuständig für das Angebot, die Selektion und die materielle Betreuung von „Projektanten“,

117 Zum Habitus siehe z. B. Reichardt, Bourdieus Habituskonzept.

118 Vgl. zur Frage des Habitus in transnationaler Perspektive Kelly/Lusis, Migration.

119 Niederhut, Die Reisekader, S. 14 
„Experten“ oder „Spezialisten“ der DDR war in der Regel das staatliche Außenhandelsunternehmen für den Export immaterieller Leistungen Limex (später intercoop). Die jeweiligen Fachministerien wiederum waren angehalten, die für den immateriellen Export notwendige Auslandskaderreserve aufzubauen und die jeweiligen KandidatInnen vorzuschlagen. ${ }^{120}$ Der planmäßige Aufbau einer „Auslandskaderreserve“ für den Einsatz in den ,jungen Nationalstaaten“ stieß allerdings auf handfeste demografische Probleme. Vor dem Mauerbau war ein Sechstel der DDR-Bevölkerung in den Westen abgewandert, darunter mit vielen VertreterInnen der „Intelligenz“ - ÄrztInnen, IngenieurInnen und auch nach dem Zweiten Weltkrieg ausgebildete „NeulehrerInnen“ - gerade Angehörige jener Gruppen, die für Einsätze im globalen Süden besonders gefragt waren.

In vielen Fällen wurden Kaderanforderungen von den Ministerien auf die Bezirks- und Kreisebene bis in die einzelnen Schulen, Betriebe oder Universitätssektionen weitergereicht, wo Vorgesetzte gezielt MitarbeiterInnen ansprachen und für Auslandseinsätze zu gewinnen versuchten. ${ }^{121}$ Offenbar schlugen die Kaderabteilungen, die in erster Linie an einem reibungslosen Ablauf in der eigenen Institution und weniger an den außenpolitischen Motiven interessiert waren, nicht immer geeignete KandidatInnen vor. In Bezug auf einen Bankberater, den die sansibarische Regierung zurück in die DDR reisen ließ, hieß es vom Außenministerium, man sollte „Auffassungen, DDR-Kader wären auch dann noch für Afrika bzw. Sansibar gut genug, entgegentreten“. ${ }^{122}$ Für Freundschaftsbrigaden konnten Organe der FDJ, der anderen Massenorganisationen und der SED „Kadervorschläge“ einreichen, auch die Möglichkeit der persönlichen Bewerbung war - die Zustimmung der jeweiligen FDJ-Leitung vorausgesetzt - in der Direktive vorgesehen. ${ }^{123}$ Manche DDR-BürgerInnen übermittelten ihre Bewerbungen - und das ist ein den bisherigen Forschungen entgegenstehender Befund - aus Eigeninitiative und ohne die vorherige Absegnung obiger Stellen. ${ }^{124}$ Die „top-down“--

120 In Fällen, in denen staatliche Grundabkommen noch nicht möglich waren - und das war während der 1960er in fast allen Ländern Afrikas der Fall - wurden auch die Abkommen für die Entsendung von Entwicklungspersonal von Limex geschlossen. BArch Berlin, DR 2/24452, Gespräch DDR-TAN über Stand der ZA im Bildungsbereich, Aktenvermerk über ein Gespräch mit dem Principal Secretary des Ministry of Education der VR Tansania, F.K. Burengelo; Dar es Salaam, 8.7. 1968.

121 Interview \#21, DDR-Planungsberater.

122 BArch Berlin, DC 20/11525, Büttner (MfAA) an Dambor (Ministerrat), Berlin, 30.10.1967, Bl. 286.

123 SAPMO BArch Berlin, Direktive für die Auswahl und den Einsatz von Mitglieder der „Brigaden der Freundschaft“ der FDJ, Berlin, 1.7.1968, S. 5-7.

124 Kategorisch jede Möglichkeit der Bewerbung für Freundschaftsbrigaden verneint z. B. Ulrich van der Heyden, FDJ-Brigaden der Freundschaft aus der DDR - die Peace Corps des Ostens?, in: 
Rekrutierung war also der übliche Weg, aber Initiativbewerbungen hatten ebenfalls Chancen, wenngleich diese von der Staatssicherheit immer mit besonderem Misstrauen begutachtet wurden. ${ }^{125}$

Wie in anderen kommunistischen Staaten wurde auch in der DDR die Bedeutung des politischen Kapitals auf Kosten anderer Kapitalarten in den Vordergrund gestellt. Die zu entsendenden „Kader“ sollten sich nicht nur durch ihre fachliche Qualifikation, sondern auch durch Übereinstimmung mit der SED-Linie auszeichen, was die Zahl der in Frage kommenden Fachkräfte weiter reduzierte. Wie Aufstiegs- und Erwerbschancen in der DDR-Gesellschaft allgemein war auch der Auslandskaderstatus stark abhängig von politischer Loyalität und Aktivitäten und Mitgliedschaften, die unter dem Begriff „gesellschaftliches Engagement“ subsumiert wurden. ${ }^{126}$ Der Status als Auslandsreisekader war zeitlich begrenzt und musste periodisch neu bestätigt werden, was den Disziplinierungseffekt verstetigte. Außerdem konnte er bei Beanstandungen - etwa wegen politisch inopportuner Äußerungen, Eheproblemen, Verstößen gegen Weisungen - jederzeit wieder entzogen werden, womit er Privileg und Konformierungsinstrument zugleich darstellte. ${ }^{127}$ Einen wichtigen Indikator für das politische Kapital stellte der „Klassenhintergrund“ dar. Mehrere Interviewpartner gehörten zu der Generation, die über die nur bis 1963 existierenden Arbeiter- und Bauernfakultäten (ABF) den Aufstieg aus bescheidenen familiären Hintergründen in die „Intelligenz“ geschafft hatten und beschrieben sich z.T. selbst als „klassische Arbeiterkader“. Diese kurzzeitige Schleusenöffnung für den Bildungsaufstieg unterprivilegierter „Arbeiterkinder“ war das Instrument der SED, um einerseits den Zusammenhang von Bildung und sozialer Ungleichheit zu durchbrechen und andererseits neue, parteitreue Eliten heranzubilden. ${ }^{128}$ Die teils überzogen loyal wirkenden Ausdrucks- und Handlungsweisen mancher DDR-Kader in Tansania sollten dabei nicht nur an Disziplinierungsmodi vor Ort, sondern auch an die Lebensgeschichten rückgebunden werden. Ein Interviewpartner, der den Aufstieg vom Sohn einer mittellosen heimatvertriebenen Familie zum Neulehrer (,das ganz große Los“), Auslandskader und promoviertem Bildungsforscher geschafft hatte, sah seine Biografie als generationstypisch an:

Berthold Unfried/Eva Himmelstoss, Hg., Die eine Welt schaffen: Praktiken von „Internationaler Solidarität“ und „Internationaler Entwicklung“, Leipzig 2012, S. 99-122, hier: S. 101-102.

125 Interview \#113, DDR-Lehrerexperte; Interview \#114, Freundschaftsbrigadistin.

126 Salheiser, Parteitreu, S. 56

127 Niederhut, Die Reisekader, S. 61; Wolle, Die heile Welt der Diktatur, S. 282-283.

$128 \mathrm{Zu}$ den Arbeiter- und Bauernfakultäten siehe Ingrid Miethe, Bildung und soziale Ungleichheit in der DDR. Möglichkeiten und Grenzen einer gegenprivilegierenden Bildungspolitik, Opladen 2007. 
Wenn man ein Leben mit null beginnt und mit 18 noch vor dem Nichts steht, dann hütet man jedes Stückchen, was man gewinnt, und das gibt man nicht so schnell auf. Und von der Biografie her bin ich keine Einzelheit. Wir sind die Nachkriegsgeneration. 1930 geboren. ${ }^{129}$

Wichtig ist der nur implizit enthaltene Hinweis, dass das bereits „Gewonnene“ jederzeit wieder verloren gehen konnte - und dementsprechend „behütet“ werden musste. Diese „Gegenseitigkeit von Loyalität und Protegierung“ kam daher besonders bei jenen Kadern zum Tragen, die ihren Aufstieg den DDR-spezifischen Selektionskriterien zu verdanken hatten. ${ }^{130}$ Ein anderer ehemaliger Auslandskader vermutete, dass er für einen Einsatz unter anderem deswegen in Betracht gezogen wurde, weil sein Großvater ein Mitbegründer der Kommunistischen Partei in Thüringen gewesen war und er als Enkel noch von diesem politischen Kapital zehren konnte. ${ }^{131}$

Auswahlprozess und -kriterien blieben für die Entsandten intransparent, sodass solche Annahmen auf Vermutungen beruhten. Allen betroffenen Interviewten war bewusst, dass „die Leute da im Ministerium“132 oder andere Gremien die Entscheidung trafen und dass ein „Durchleuchten“ stattfand, aber „[m]an hat [...] nicht gefragt, warum man zu den Auserwählten gehörte. “133 Die Überprüfung und Informationseinholung über Volkspolizei und „inoffizielle Mitarbeiter“ (IM) des MfS erstreckten sich meist über einen Zeitraum von drei bis sechs Monaten, bisweilen auch deutlich länger. ${ }^{134}$ Neben der Staatssicherheit gaben auch leitende Kader der Arbeitsstelle - DirektorInnen, Kaderabteilungsleitung, Partei und Betriebsgewerkschaft - ihre Einschätzung zur Eignung der BewerberInnen ab. ${ }^{135} \mathrm{Sie}$ bewerteten nicht nur die fachliche Qualifikation, die charakterliche „Reife“, das „gesellschaftliche Engagement“ und die Freizeitgestaltung sowie das Verhalten im „Kollektiv“, sondern gaben auch Hinweise auf eventuell vorhandene Verwandtschaft ersten Grades in West-Berlin oder der BRD. Am Ende stand die

129 Interview \#113, DDR-Lehrerexperte.

130 Salheiser, Parteitreu, S. 56.

131 Interview \#117, DDR-Bildungsberater.

132 Interview \#21, DDR-Planungsberater; Interview \#17, DDR-Lehrerexperte.

133 Weiser, DDR-Lehrer nach Sansibar, S. 223; Obernhummer, Experten, S. 51. Einige InterviewpartnerInnen berichteten, dass sie bei Einsicht in ihre Stasi-Akten nach der Wiedervereinigung negative Einschätzungen fanden, die damalige unverständliche Abreiseverzögerungen oder Reisesperren erklärten.

134 Niederhut, Die Reisekader, S. 55.

135 Diese für die Reise- und Auslandskaderauswahl zuständigen Gremien wurden nach einem Ministerratsbeschluss im Jahr 1970 als Beratungs- und Kontrollgruppen (BKG) bezeichnet. Für eine genauere Beschreibung der Tätigkeit der BKGs und ihrer Zusammenarbeit mit dem MfS siehe Niederhut, Die Reisekader, S. 48; Obernhummer, Experten, S. 51-52. 
Entscheidungsempfehlung, die nicht selten eine Ablehnung nahelegte. VertreterInnen von Krankenhäusern oder Universitäten argumentierten bisweilen auch, dass die KandidatInnen unabkömmlich seien.

Im Falle einer Empfehlung führte die Staatssicherheit vor der tatsächlichen Aufnahme neuer KandidatInnen in die Auslandskaderreserve die ,sicherheitspolitische Überprüfung“ bei der betreffenden Person sowie auch bei Angehörigen durch. ${ }^{136}$ Familienverbindungen und sonstige aktive Kontakte nach Westdeutschland waren das wichtigste Ausschlusskriterium. Die „politische Zuverlässigkeit“ während des Auslandseinsatzes schien zudem keinesfalls gegeben bei Personen, bei denen „individualistische Ziele“ oder Anzeichen einer Sympathie für „westliche Ideologie“ identifiziert wurden. Als ein derartiges Anzeichen galt etwa die kolportierte Ansicht eines Arztes, dass „einige westliche Präparate doch wesentlich besser wirkten als die gleichartigen Präparate der DDR“. ${ }^{137}$ Ausschlussgründe wurden oft in kumulierter Form angeführt: „, $[u]$ ngenügende politische Festigkeit, Geltungsbedürfnis, Schwatzhaftigkeit, Alkoholmissbrauch, Bestechlichkeit und Amoralität“. ${ }^{138}$ Diese - offensichtlich nicht auf fachlicher Qualifikation beruhenden - Ausschlusskritieren sollten sicherstellen, dass sich BewerberInnen während des Auslandseinsatzes ins „Kollektiv“ einordneten und als lenkbar erwiesen. Negative Urteile über den Charakter („Undiszipliniertheit“, „schwere Lenkbarkeit“, „Starrsinn“, „Eigenwilligkeit“, „Hang zur Überheblichkeit“, „zeigt sich spöttisch“, „wiederholt gegen Beschlüsse des Leitungskollektivs“) zeigen, dass Qualitäten wie Berechenbarkeit und Gehorsam in der Überprüfung durch das MfS besondere Bedeutung beigemessen wurden.

Das Ziel, „einen hohen Anteil von Genossen in der Reisekaderreserve zu sichern“, erreichte die DDR nicht. ${ }^{139}$ Gerade im medizinischen Bereich waren viele der Entsandten keine SED-Mitglieder. Eindeutig (wenngleich aufgrund der begrenzten Fallzahl nicht zu verallgemeinern) hingegen ist die Tendenz, dass jene, die weitere Karrieresprünge machen und auch weitere Auslandseinsätze absolvieren wollten, für SED-Anwerbungsversuche vor und während des Einsatzes empfänglich waren. In der Freundschaftsbrigade in Sansibar waren 197014 von 21

136 Der Auswahlprozess ist dargestellt in Niederhut, Die Reisekader, S. 48-63; Obernhummer, Experten, S. 53-55.

137 BArch Berlin, DQ 1/22733, Rat des Kreises Sonneberg, Beurteilung von Dr. med. A.J., 7.12.1965. 138 Sabine Gries, Die Pflichtberichte der wissenschaftlichen Reisekader der DDR, zit. nach Obernhummer, Experten, S. 55.

139 Das wurde z.B. an der Humboldt-Universität umgesetzt; hier waren 1984 77,5\% aller neu aufgenommenen Reisekader SED-Mitglieder. Siehe BArch Berlin, DR 3/2. Schicht/339, Wilde (HU Berlin), Bericht zur weiteren Entwicklung der Reisekaderreserve im Hochschulbereich einschließlich Studenten in der Zeit vom 31.8.82 bis 31.12.83, Berlin, 17.2.1984. 
Brigademitgliedern „Genossen“, drei von ihnen befanden sich noch im ersten Jahr ihrer SED-Mitgliedschaft. ${ }^{140}$ Bei wem keine aktive, über Beitragszahlung hinausgehende Mitgliedschaft in den gelenkten Massenorganisationen wie dem FDGB oder der Gesellschaft für Deutsch-Sowjetische Freundschaft nachgewiesen werden konnte, dem wurde mangelndes „gesellschaftliches Engagement“ angekreidet. Offen gelebter christlicher Glaube und Aktivität in kirchlichen Gemeinden hingegen waren für die Karriere allgemein und die Aufnahme in die Auslandskaderreserve im Besonderen hinderlich.

All diese angewandten Kriterien waren nicht spezifisch für einen Auslandseinsatz, sondern entsprachen den üblichen Unterscheidungsmerkmalen der „Kaderplanung“ zur Absicherung der SED-Herrschaft. Zunehmend betont wurden aber angesichts der Einsatzdauer, vor allem „geordnete Familienverhältnisse“, zumal enge familiäre Bindungen eine Rückkehrgarantie darstellten. ${ }^{141}$ Grundlegend falsch wäre, aus der übergeordneten Bedeutung politischer Kriterien den Umkehrschluss zu ziehen, dass die entsandten DDR-Kader unqualifiziert gewesen wären. Fachliche Eignung blieb ein zentrales Selektionskriterium. Die „Treue zum Arbeiter- und Bauernstaat“ stand zwar an erster Stelle und tatsächlich gab es auch Beschwerden über Fehlvermittlungen und unqualifizierte Entsandte, aber zumindest im Falle Tansanias scheint der Großteil der Auslandskader für die anstehenden Aufgaben fachlich gerüstet gewesen zu sein. ${ }^{142}$

Die über fachliche Kriterien hinausgehende Absicht, nur Personen mit „festem Klassenstandpunkt“ und stabilen Familienverhältnissen zu entsenden, war eindeutig verbunden mit dem Bedrohungsszenario vom „NSW“ - dem „NichtSozialistischen Wirtschaftsgebiet“ - als Ort der Versuchungen und ideologischen Irrwege, die zur Entfremdung von der DDR führen konnten. Aus staatlicher Sicht war das Aussiebverfahren effektiv. Nur in Einzelfällen - Jens Niederhut nennt für die 1970er und 1980er-Jahre Quoten zwischen 0,03 und 0,14 Prozent der Gesamtzahl der Reisekader ${ }^{143}$ - kehrten die Entsandten nicht zurück. So auch in Tansania. Während sich im Jahr 1969 zwei DDR-Paare und 1975 ein Veterinär aus Tansania absetzten, sind aus den folgenden anderthalb Jahrzehnten keine weiteren Fälle von „Republikflucht“ überliefert. ${ }^{144}$ Die verantwortlichen DDR-Insti-

140 SAPMO BArch Berlin, DY 24/19211, APO V BdF Sansibar, Einschätzung des politisch-ideologischen Bewußtseinsstandes der APO, o.O., November 1970.

141 Obernhummer, Experten, S. 51.

142 Vgl. hierzu auch Obernhummer, Experten, S. 52; Niederhut, Die Reisekader, S. 48-53.

143 Niederhut, Die Reisekader, S. 57-58.

144 Die Fälle aus dem Jahr 1969 sind dokumentiert in PAAA, MfAA, B 271/74; der Fall aus dem Jahr 1975 ist z. B. erwähnt in BArch Berlin, DR 3/2. Schicht/B 1449/1b, Dr. B. K., Abschlußbericht, Berlin, 1.4.1975. 
tutionen reagierten auf solche Ereignisse - die natürlich nicht nur einen Prestigeund Fachkraftverlust für die DDR und Unruhe unter den DDR-BürgerInnen, sondern auch die Verstimmung der betroffenen tansanischen Stellen zur Folge hatten - mit einer weiteren Verschärfung der „Sicherheitsbestimmungen“. ${ }^{145}$

DDR-SpezialistInnen, -Berater und -BrigadistInnen in Tansania absolvierten oft zum ersten Mal einen längeren Auslandseinsatz. ${ }^{146}$ Vor allem in sprachlicher Hinsicht - erste Fremdsprache in der Schule war das in afrikanischen Ländern wenig hilfreiche Russisch - war der Aufbau der Auslandskaderreserve ein aufwendiges Unterfangen. Zu Beginn der 1960er-Jahre war der Bedarf an LehrerInnen so groß, dass Sprachkenntnisse ein Hauptkriterium der Selektionsprozesse darstellten. ${ }^{147}$ Die erste Gruppe von DDR-LehrerInnen, die sich 1965 nach Sansibar begab, bestand überwiegend aus Männern, die sich ihr Englisch nicht in der Schule, sondern im Laufe der Kriegsgefangenschaft angeeignet hatten. ${ }^{148}$ Während Mitglieder von Freundschaftsbrigaden bis Ende der 1980er Jahre nur eine sprachliche „Schnellbesohlung“149 erhielten, verbesserten sich die Sprachvorbereitungen für die Berater und ExpertInnen sukzessive. Im Vergleich mit der Sowjetunion etwa schien die DDR in Sachen Fremdsprachenkompetenz daher besser aufgestellt. ${ }^{150}$ Sprachschwierigkeiten konnten freilich trotzdem nicht abgestellt werden.

\section{Bedrohungsszenarien und Direktiven}

Die Vorbereitungsprozedur war je nach Entsendeinstitution und sogar Person unterschiedlich. Die Feststellung, dass auf DDR-Seite einzig FreundschaftsbrigadistInnen eine mehrmonatige Vorbereitung durchlaufen mussten, während ExpertInnen „lediglich eine Vorbereitung an universitären Instituten“ erhielten, ist

145 So wurden z.B. Reisepässe nach den Ereignissen 1969 unter Verschluss gehalten. PAAA, MfAA, B 271/74, DDR-Vizekonsul, Einschätzung der Republikflucht Dr. P. und Frau, Sansibar, 28.5. 1969.

146 BArch Berlin, DR 2/51008, Einschätzung der Effektivität des Experteneinsatzes in Tansania 1988 (Auszug).

147 Weiser, DDR-Lehrer nach Sansibar.

148 Interview \#112, DDR-Lehrerexperte.

149 Interview \#114, Leiter einer Freundschaftsbrigade.

150 Die 1955 gegründete sowjetische Außenhandelsfirma Technopromexport etwa musste (laut einem BRD-Bericht) jeden 1964 nach Tanganjika entsandten Veterinär von einem Dolmetscher begleiten lassen, ein Luxus, den sich die DDR nur in den wenigsten Fällen leistete. BArch Koblenz, B 213/7657, BRD-Botschaft an AA, Dar es Salaam, 13.8.1964. 
mit Blick auf die späteren Jahre zu differenzieren. ${ }^{151}$ Während Angestellte des Ministeriums für Volksbildung, die auf mittlerer Ebene als Lehrkräfte eingesetzt werden sollten, einen ,zentralen Lehrgang zur politisch-ideologischen, schulpolitischen und länderspezifischen Qualifizierung“ und mit der Zeit deutlich effektiver werdende Sprachkurse absolvierten, wurden für höherrangige Kader, die für Schlüssel- und Beratungspositionen vorgesehen waren, sogar langfristige und individuell zugeschnittene Programme eingeführt. ${ }^{152}$

Der Fall eines in Tansania tätigen Planungsberaters steht exemplarisch für die Vielfalt und teils bemerkenswerte Sorgfalt der Vorbereitungsmethoden. Der Planungsberater wurde Mitte der 1970er-Jahre von seinem Vorgesetzten angesprochen, ob er an einem Auslandseinsatz interessiert wäre. Er bejahte, trat in die SED ein und fuhr 1977 als einer von 30 Interessenten zu einem „Info-Tag“ der Plankommission nach Berlin. Nach dem „Durchleuchten“ - einem Euphemismus für die Überprüfung durch die Staatssicherheit - verblieb eine Gruppe von sechs Personen, die dann von ihren beruflichen Pflichten freigestellt wurden und über mehrere Monate Einblicke in die höchsten Ebenen des DDR-Planungssystems erhielten und eine intensive Sprachausbildung absolvierten. Erste Mitglieder dieser Gruppe wurden 1979 in verschiedene afrikanische Länder entsendet, der Tansania-Einsatz des Planungsberaters begann nach mehrmaligen Verschiebungen erst 1981, nachdem die entsprechenden bilateralen Abkommen geschlossen worden waren. ${ }^{153}$ An diesem Beispiel zeigt sich eine langfristige, fachliche genauso wie sprachliche und politische Vorbereitung auf den Einsatz für Experten, die auf Beraterebene eingesetzt wurden.

Insgesamt jedoch wappneten die Vorbereitungsprogramme die DDR-Auslandskader nur spärlich für ihren Einsatz. ${ }^{154}$ In den obligatorischen Abschlussberichten übten Auslandskader Kritik an der Vorbereitung. Über zweieinhalb Jahrzehnte hinweg forderten sie konkretere landesspezifische Einweisungen, eine Verbesserung des Englischunterrichts, die Einführung von Swahilikursen sowie die Einrichtung einer Institution, die sich auf die Betreuung der Kader im Ausland spezialisieren sollte. ${ }^{155}$ Ein „noch nicht zufriedenstellend gelöstes Problem“ sah

151 Büschel, Hilfe zur Selbsthilfe, S. 251.

152 BArch Berlin, DR 2/50607, Vorbereitungsmaßnahmen für die Auslandskader der Kategorien II und III - Entsendung im Schuljahr 1983/84.

153 Interview \#21, DDR-Planungsberater.

154 Matthes, Zur Entwicklung, S. 85.

155 Ein Beispiel, in dem alle Forderungen zusammentreffen: BArch Berlin, DR 3/2. Schicht/B 1449/1b, B. (Parteisekretär GO Tabora) und G. (Staatl. Leiter der Spezialistengruppe Tabora) an Limex, MHF u. a., Tabora, 26.7.1971. 
das DDR-Konsulat 1967 auch in der „Vorbereitung auf die Psyche, Mentalität, die Kontaktfreudigkeit, den psychologisch richtigen Umgang mit Afrikanern“ - eine Formulierung, die mit ihrem essenzialistischen Gehalt selbst als Beleg für eine problematische Haltung gelten kann. ${ }^{156}$ Tatsächlich jedoch fehlte vielen Entsandten die Gesprächskompetenz für informelle Unterhaltungen an der Türschwelle und lockeren Small Talk bei Cocktail-Partys genauso wie praktische Alltagswendungen, wie sich ein Veterinär erinnerte: „[P]olitische Erklärungen konnten wir perfekt abgeben und die Vorzüge der DDR erläutern. Bei Autopannen war es schwieriger. “157 Gerade die DDR-Entsandten, die an Sekundarschulen und der Universität unterrichteten, mussten bei ihrer Ankunft viel Zeit und Energie aufwenden, um ihre Englischkenntnisse auf ein akzeptables Niveau zu steigern. Als die DDR bei Teilen der sansibarischen Führungsschicht in Ungnade fiel, wurden fehlende Sprachkenntnisse sogar als Vorwand für Abberufungen und die Nichtverlängerung von Verträgen herangezogen. ${ }^{158}$ Die Sprachausbildung der Kader des Ministeriums für Volksbildung wurde dann schon in der zweiten Hälfte der 1960er Jahre auf ein ganzes Jahr ausgedehnt. ${ }^{159}$

Ein weiterer Schwerpunkt der Vorbereitung lag darauf, jedem Auslandskader seine Rolle als „Repräsentant der DDR im Ausland“160 einzuschärfen und die ideologischen und außenpolitischen Positionen - zu deren Verbreitung die Entsandten beitragen sollten - zu vermitteln. Retrospektive Erfahrungsberichte legen nahe, dass die Selbstwahrnehmung tatsächlich durch eine starke Identifikation mit dieser Repräsentationsfunktion geprägt war. Sie thematisieren häufig die politischen Rahmenbedingungen (z. B. das Streben der DDR nach diplomatischer Anerkennung) und enthalten Verweise auf bilaterale Abkommen zwischen der DDR und Tansania. Die Auslandskader verorteten ihre Tätigkeit explizit in diesem Rahmen. Die Doppelrolle als Fachkraft und Proto-Diplomat war durchaus fordernd, wie ein Entsandter des Volksbildungsministeriums aus Sansibar schrieb: die Tatsache, „dass man nicht nur Lehrer sein“ könne, „sondern immer der Repräsentant [sic] eines sozialistischen Landes“ sei, mache „alles eben viel komplizierter“. ${ }^{161}$

156 BArch Berlin, DC 20/11525, Büttner (MfAA) an Dambor (Ministerrat), Berlin, 30.10.1967, Bl 286.

157 Müller, Als DDR-Tierarzt in Tansania, S. 100-101.

158 Weiser, DDR-Lehrer nach Sansibar, S. 244.

159 Interview \#113, DDR-Lehrerexperte; Aussagen verschiedener DDR-Entsandter auf dem Ehemaligentreffen in der Naupoldsmühle, Mühltal/Eisenberg, 5.9.2015.

160 Obernhummer, Experten, S. 55.

161 Privatarchiv E. W., E. W. an A. und Familie, Sansibar, 25.8.1969. 
Neben der Repräsentationsfunktion wurden in der Vorbereitung auch Bedrohungsszenarien vermittelt, die das nichtsozialistische Ausland und damit auch Tansania zu einem Ort beständiger Gefahr stilisierten, an dem es jederzeit zu „Provokationen“ oder gar Abwerbungsversuchen durch den „Klassenfeind“ kommen konnte. ${ }^{162}$ „Bei allen Kontakten“, so ein Schulungsmaterial zur Vorbereitung von Auslandsreisen aus dem Jahr 1988, sei „grundsätzlich davon auszugehen, dass sie zur Ausforschung, Aufklärung und Beeinflussung der Kader und damit zur Schaffung von Voraussetzungen für ihren Missbrauch zu Verrats- oder anderen die DDR [...] schädigende Handlungen genutzt werden können“. ${ }^{163}$ Die in der DDR wie auch während des Einsatzes wiederholt vorgenommene Einimpfung von Bedrohungsszenarien sollte offiziell die Sicherheit der Entsandten gewährleisten, diente aber ebenso dazu, die Auslandskader zu disziplinieren und ihre Handlungen in gewünschte und vorhersagbare Bahnen zu lenken. In einem Bericht der SED-Grundorganisation in Dar es Salaam wurden disziplinarische Anforderungen an Auslandskader durch die Gegenüberstellung einer Geborgenheit und Sicherheit gebenden DDR einerseits und dem gefährlichen Ausland andererseits gerechtfertigt:

Viele Genossen sind das erste Mal im Einsatz im Ausland. Sie kommen aus der DDR, wo wir relativ abgeschirmt und von vielen Dingen verschont, in Sicherheit und Geborgenheit aufgewachsen sind und gelebt haben. Daraus resultiert eine wichtige Erkenntnis [...]: wir leben und arbeiten hier unter anderen, feindlichen Bedingungen, im direkten Kontakt mit dem Klassengegner, oftmals kapitalistischen Lebens- und Umweltbedingungen. ${ }^{164}$

Als Hauptaufgabe sollte Auslandskadern die Realisierung der vereinbarten Verträge gelten. Kennzeichnend für die wirtschaftliche Krise der DDR ist die neue Aufgabe in den 1980er-Jahren, der DDR-Außenwirtschaft mit Marktanalysen unter die Arme zu greifen, Tenderausschreibungen zu sammeln und im Gastland über die „Exportangebote von immateriellen Leistungen“ der DDR zu informieren. ${ }^{165}$ Die dieser Aufgabe nachgeordnete Direktive der „Auslandsinformation“ - die politischen Positionen der DDR und der „,sozialistischen Staatengemeinschaft“ zu

162 Obernhummer, Macht und Herrschaft des MfS, S. 64-69; dies., Experten, S. 58.

163 BStU, MfS, ZOS 2382, Arbeitsgruppe für Organisation und Inspektion beim Ministerrat Abt. Auslandsdienstreisen, Schulungsmaterial zu den „Grundsätzen und Hinweisen für die Vorbereitung dienstlicher Reisen und für das Verhalten von dienstlich im Ausland weilenden Bürgern der DDR“, Berlin, 1.9.1988, Bl. 27

164 SAPMO BArch Berlin, DY 30/15206, Rechenschaftsbericht der Leitung an die Wahlberichtsversammlung der GO der SED Dar es Salaam, 25.11.1985, Bl. 174.

165 BArch Berlin, DR 3/2. Schicht/1512, Böhme (MHF), Rahmendirektive, Berlin, 26.6.1984, S. 2. 
propagieren - hatte in den 1960er und 1970er-Jahren noch deutlich mehr Gewicht besessen.

Die disziplinarischen Erfordernisse umfassten aber nicht nur die Vertragserfüllung, also die Arbeit an sich, sondern auch die Sphären des Konsums, der privaten Kontakte und der Freizeitgestaltung. ${ }^{166}$ Die Unterordnung unter den Botschafter wurde ebenso gefordert wie die Eingliederung in das DDR-,Kollektiv“ vor Ort und ein bescheidenes, möglichst vorbildhaftes Auftreten, das auch persönlichen Verzicht erfordern konnte. Kontakte über das DDR-,Kollektiv“ hinaus waren insbesondere mit Entsandten anderer RGW-Länder und den jeweiligen, möglichst hochrangigen ArbeitskollegInnen und Vorgesetzten erwünscht. Fanden diese Begegnungen außerhalb der Arbeitszeit statt, waren jedoch selbst sie berichtspflichtig: Auch das Private war politisch. „Letztlich“, so ein stellvertretender Minister auf einem Weiterbildungslehrgang für Experten im Jahr 1981, gehe es „darum, daß der Experte, durch seine Arbeit, seine Haltung und sein Auftreten Freunde für die DDR, die sozialistische Staatengemeinschaft gewinnt. “167

Die Reaktionen auf die Durchdringung professioneller sowie privater Bereiche mit dem Kriterium des Politischen fielen unterschiedlich aus. In mancher Hinsicht lastete ein schweres Gewicht auf der täglichen Arbeit, weil jedes Missgeschick als Anzeichen für eine mangelhafte politische Einstellung gedeutet werden konnte. So betonte ein FDJ-Funktionär in einem Schreiben an den Brigadeleiter auf Sansibar, dass der „Bau eines Hauses“ und selbst „einer Treppe [...] eine politische Angelegenheit“ darstelle. ${ }^{168}$ Pragmatische Entsandte hingegen deuteten - entgegen der Logik leitender FunktionärInnen - die Anforderung so, dass die Erfüllung des Arbeitsvertrages mit der tansanischen Institution bereits den Hauptteil der politischen Aufgabe darstelle und darüber hinausgehende Tätigkeiten von der Hauptaufgabe, also der Erfüllung des Vertrages, ablenken würden. Dieser Rückzugsraum war wichtig, denn vor Handlungen, die als „Einmischung in innere Angelegenheiten“ Tansanias interpretiert werden konnten, wurden die Entsandten bereits in der Vorbereitung gewarnt. Für das Ausbalancieren dieses Imperativs der Nichteinmischung mit der Anforderung, politische Meinungsänderungen zu bewirken oder sozialen Wandel anzustoßen, gab es allerdings keine allgemeingültigen Handlungsorientierungen, sodass die Navigation auf diesem Terrain den Einzelnen überlassen blieb. Das galt, wenn auch mit

166 Ein Beispiel für alle diese Punkte ist BArch Berlin, DR 3/2. Schicht/1512, Heidorn (MHF), 10 Grundsätze für jeden Experten, 28.7.1981.

167 Ebd.

168 SAPMO BArch Berlin, DY 24/19211, Böhme (FDJ) an Pabst (Leiter BdF Sansibar), Berlin, 10.9. 1970 
einem weniger engen politischen und disziplinarischen Korsett als im Fall der DDR-Auslandskader, ebenso für Entsandte der BRD.

\section{Freier Arbeitsmarkt und Netzwerke}

Während die DDR-Personalentsendung weitgehend von Entstehung neuer wissenschaftlicher Institutionen abgekoppelt war, entstanden in der BRD eine Reihe entwicklungspolitischer Studiengänge und Kaderschmieden, die das wahrgenommene „Expertendefizit“ beheben sollten. ${ }^{169}$ Abschlüsse von Postgraduiertenstudien des Deutschen Instituts für Entwicklungspolitik, des Seminars für ländliche Entwicklung an der FU Berlin oder des aus einer ehemaligen Schule für den Kolonialdienst hervorgegangen Deutschen Instituts für tropische und subtropische Landwirtschaft waren wertvolles, feldspezifisches, symbolisches Kapital. Die AbsolventInnen dieser Einrichtungen hatten eine Eintrittskarte für die Expertenlaufbahn so gut wie sicher; das gleiche galte für jene, die Weiterbildungsprogramme oder Einsätze als „beigeordnete Sachverständige“ mit multilateralen Organisationen durchlaufen hatten. ${ }^{170}$ Spezifische „Entwicklungsländerforschungen“ und Bildungsangebote entwickelten sich auch an Universitäten und Hochschulen in Bielefeld, Göttingen, Bochum, Dortmund, Hohenheim und anderen Standorten mit meist disziplinär oder sektoral spezifischen Angeboten in Entwicklungssoziologie, Entwicklungsethnologie, Entwicklungsökonomie und Entwicklungspolitologie bzw. Regional- und Entwicklungsplanung, Tropischer Landwirtschaft, Veterinärmedizin oder Ländlicher Entwicklung. ${ }^{171}$ ProfessorInnen wie der Agrarwissenschaftler Hans Ruthenberg - der auch in Tansania

169 Thomas Hüsken, Der Stamm der Experten. Rhetorik und Praxis des Interkulturellen Managements in der deutschen staatlichen Entwicklungszusammenarbeit, Bielefeld 2006, S. 125-126. 170 Nicht weniger als 81\% der AbsolventInnen des postgraduellen Programms am SLE haben „den überwiegenden Teil ihres Berufslebens in der Entwicklungszusammenarbeit verbracht.“ 2011 durchgeführte Befragung aller SLE-Abgänger seit 1962, sle-berlin.de/index.php/de/studium/ karrierechancen (Zugriff 20.10.2015). Vgl. auch Interview \#26, Ehemaliger GTZ-Experte (BRD); Interview \#63, Ehemaliger GTZ-Experte (Tansania), beide Absolventen des Seminars für Ländliche Entwicklung der TU Berlin. Zur institutionellen Ebene siehe auch Manfred Glagow u. a., Ausbildung, Dialog, Politikberatung. Zur Organisation und Tätigkeit der Deutschen Stiftung für Internationale Entwicklung (DSE), der Carl-Duisberg-Gesellschaft (CDG) und des Deutschen Instituts für Entwicklung (DIE), Saarbrücken 1985. Zu multilateralen Programmen siehe: Interview \#102, GTZ-Experte.

171 Für einen detaillierten Überblick siehe DSE, Die dritte Welt als Studienfach entwicklungsorientierte Studienangebote an Hochschulen in der Bundesrepublik Deutschland einschließlich Berlins (West), 2., völlig überarb. und erw. Aufl, Bonn 1980. 
forschte - veranlassten Scharen von Studierenden, ihr Forschungs- und Betätigungsfeld in der „Dritten Welt“ zu suchen. ${ }^{172}$

Nichtsdestoweniger klagten Verantwortliche des DED wie auch der GAWI und der GTZ über unbefriedigende Bewerbungsrückläufe auf Werbung und Stellenanzeigen. ${ }^{173}$ Beim DED waren die materiellen Einsatzbedingungen Anfang der 1960er Jahre äußerst unattraktiv. Die Beschränkung auf Ledige verkleinerte den Interessentenkreis weiterhin. ${ }^{174}$ Hohe Ansprüche wie die projektspezifische Auswahl und Ausbildung wurden schon Mitte der 1960er wieder aufgegeben, sodass die EntwicklungshelferInnen oft erst kurz vor ihrer Entsendung über ihren Einsatzort in Kenntnis gesetzt wurden. Insgesamt konnten Westdeutsche persönliche Wünsche bei der Länderwahl jedoch deutlich effektiver durchsetzen als DDRAuslandskader. ${ }^{175}$

Die Personalrekrutierung auf dem freien Arbeitsmarkt durch die Bundesstelle für Entwicklungshilfe (BfE), die GAWI, die GTZ und die von der GTZ beauftragten Consulting-Firmen (z. B. Ingenieurbüros oder das Africa Bureau Cologne) hatte ebenfalls ihre Tücken. Nur wenige BewerberInnen konnten alle Ansprüche an Qualifikation, Berufs- und Auslandserfahrung und die Bereitschaft, sich tansanischen Arbeits- und Lebensbedingungen anzupassen, erfüllen. ${ }^{176}$ Die GTZ-Zentrale konnte „innerhalb von zwei Jahren keinen Feld-, Wald- und Wiesenvolkswirt“ rekrutieren, sodass sich ProjektleiterInnen ihr Personal bisweilen selbst suchten, weil sie erwarteten, dass „von der Personalabteilung [...] sowieso nichts [kommt]“. ${ }^{177}$ In Tansania reisten vereinzelt GAWI- und GTZ-Experten an, die sich als „Psychopath[en]“ oder „Messerstecher“ entpuppten, zutiefst rassistische oder anderweitig sozial absolut inakzeptable Verhaltensweisen an den Tag legten und postwendend wieder ausreisen mussten. ${ }^{178}$ Hier mag es sich um Einzelfälle gehandelt haben, aber Qualität und Eignung des Personals wurden in manchen Projekten als generell niedrig und unbefriedigend eingeschätzt. Einem Veteranen des BRD-Entwicklungssektors zufolge habe es bei der GTZ „einen Bodensatz gescheiterter Existenzen“ gegeben, der mit unbefristeten Verträgen „mitgeschleift“

172 Interview \#102, Ehemaliger GTZ-Experte und Student bei Hans Ruthenberg.

173 Die Selektionsverfahren der bundesdeutschen Entsendeinstitutionen inklusive ihrer psychologischen Tests sind bereits an anderer Stelle ausführlich beschrieben worden: Haase, Zwischen Lenkung und Selbstbestimmung, S. 119-24; Büschel, Hilfe zur Selbsthilfe, S. 241-251.

174 Hein, Die Westdeutschen, S. 84, S. 86-87.

175 Ebd., S. 87.

176 Allgemein dazu: Pollvogt, Zur Anatomie, S. 69; spezifisch für Tansania: BArch Koblenz, B 213/33080, Metschies (GTZ), Vermerk (Anlage an das Schreiben an das BMZ vom 21.1.1980), o.O., 21.1.1980, S. 28.

177 Interview \#94, GTZ-Projektleiter.

178 Interviews \#27 und \#96, GTZ-Projektleiter. 
worden sei. Diese Personen seien trotz bekannter Alkoholprobleme oder psychischer Störungen noch zu Auslandseinsätzen entsandt worden. ${ }^{179}$ Der GTZ-Projektleiter an der Ingenieurwissenschaftlichen Fakultät in Dar es Salaam vermerkte 1974 resigniert, dass unter Zeit- und Ergebnisdruck nun einmal „genommen werden muß, was sich anbietet“. ${ }^{180}$

Da der rasch anwachsende Bedarf durch die entwicklungspolitischen Ausbildungsinstitutionen nicht gedeckt werden konnte und der Rücklauf auf Werbekampagnen von GAWI, GTZ und DED enttäuschend blieb, nahmen persönliche Netzwerke stets eine zentrale Rolle in der Rekrutierung ein. ${ }^{181}$ Ab Mitte der 1970erJahre scheinen Entsandte, von denen ein stetig wachsender Anteil bereits Auslandserfahrungen vorweisen konnte, häufiger den Vorstellungen der ProjektleiterInnen entsprochen zu haben. Die GTZ griff zunehmend auf einen „Stamm von Experten“ und „Projekthoppern“ zurück: GTZ-ExpertInnen konnten einfach von einem Projekt oder Land ins andere „umgetopft“ werden, was für die GTZ nicht nur wirtschaftlich war, sondern auch Eignung und Handlungsweise der Entsandten berechenbarer machte. ${ }^{182}$ Neulingen hingegen bereitete die Gewöhnung an Verfahren, Zuständigkeiten, Rechenschafts- und Berichtspflichten der GTZ immer wieder Probleme. ${ }^{183}$

Da Personalakten für Entsandte der BRD-Seite nicht einsehbar waren, lassen sich keine definitiven Aussagen über die angewandten Kriterien und Überprüfungsverfahren treffen. In den 1960er Jahren wurden BewerberInnen einer „politischen Überprüfung “ unterzogen und noch 1972 fragte der Personalfragebogen der BfE nach Verwandten im „kommunistischen Machtbereich“ und der Mitgliedschaft in kommunistischen Organisationen; vor 1927 Geborenen wurden

179 Telefonisches Interview mit Wolfgang Schneider-Barthold, 26.8.2015. Schneider-Barthold war ehemaliger leitender Mitarbeiter des DIE, der GTZ und des BMZ. Er relativierte seine Aussage mit dem Zusatz, dass ein solcher „Bodensatz“ in jeder Institution zu finden sei.

180 BArch Koblenz, B 213/7680, Wolfgang Kreuser, Aufbau der Ingenieurfakultät Dar es Salaam, Stand 1.10.1974, S. 9.

181 Büschel, Hilfe zur Selbsthilfe, S. 242. Interviews mit GTZ-ExpertInnen legen nahe, dass einerseits die GTZ-Zentrale die Entscheidungen über Entsendungen traf, während andererseits ProjektleiterInnen auf bestehende Netzwerke zurückgriffen oder persönlich nach Eschborn reisten, um die Auswahl vorzunehmen. In einigen Fällen nahmen auch die tansanischen Counterparts Einfluss auf die Auswahl der deutschen Fachkräfte, die ihnen während BRD-Reisen vorgestellt wurden. Siehe z. B. BArch Koblenz, B 213/33080, Metschies (GTZ), Vermerk (Anlage an das Schreiben an das BMZ vom 21.1.1980), o.O., 21.1.1980, S. 28.

182 Hüsken, Stamm der Experten; Interview \#122, GTZ-Experte; s. z. B. die Lebensläufe in BArch Koblenz, B 213/33065.

183 E-Mail einer ehemaligen GTZ-Projektleiterin an den Autor, 27.5.2017. 
zudem Angaben über die Entnazifizierung abverlangt. ${ }^{184}$ Spätestens ab Mitte der 1970er-Jahre scheinen diese politischen Aspekte keine Rolle mehr gespielt zu haben, interviewte GTZ-Entsandte konnten sich zumindest an keine politischen Überprüfungen oder Einweisungen erinnern, die über allgemeine Prinzipien wie „Nichteinmischung in die Angelegenheiten des Gastlandes“ und die „Wahrung bundesdeutscher Interessen“ hinausgingen. Nicht zuletzt aufgrund verschiedener Berufsprofile und Netzwerke blieb es jedoch dabei, dass es zumeist konservativ und wirtschaftsliberal eingestellte Experten waren, die Posten in der Wirtschaftsberatung besetzten, während AnhängerInnen linker Strömungen insbesondere im DED und in Projekten mit primär sozialen Zielsetzungen zu finden waren.

\section{Einsatzvorbereitung zwischen Tansaphilie und Rassismus}

Im Gegensatz zu DDR-Auslandskadern verstanden sich die meisten Entsandten der BRD nicht vordergründig als VertreterInnen Westdeutschlands oder ihrer Entsendeinstitution. Für die entsandten ExpertInnen, von denen die meisten ja nur mit einem befristeten Vertrag ausgestattet waren, war „die GTZ“ (bzw. zuvor die GAWI) nicht sie selbst, sondern in erster Linie die Zentrale in Eschborn. ${ }^{185}$ Die Anforderung, ein Land oder gar ein ganzes politisches System zu vertreten, spürten sie weitaus weniger. In Interviews mit BRD-ExpertInnen standen im Gegensatz zu DDR-KooperantInnen konkrete „Felderfahrungen“ und Tätigkeiten im Vordergrund, nicht der geopolitische Rahmen oder die Repräsentationsfunktion für die BRD oder gar für den kapitalistischen Westen - und wenn diese Aspekte thematisiert wurden, dann nicht in affirmativer, sondern eher in kritischer Absicht.

Die Vorbereitung im Umfang von üblicherweise drei Monaten beinhaltete entwicklungspolitische, landeskundliche und sprachliche Kenntnisse (auch Swahili). ${ }^{186}$ In der BRD war die Institutionalisierung der entwicklungspolitischen

184 BArch Koblenz, B 102/121668, Vermerk Mörtl, Bundesamt für gewerbliche Wirtschaft, Frankfurt/Main, 29.7.1964; ebd., B 213/7661, Förderung der Ingenieur-Fakultät Dar es Salaam Heft 6, BfE, Einstellungsauftrag Prof. Dr.-Ing. H. W., Frankfurt/Main, 31.10.1972, S. 8, 10 -11.

185 Köhler, Mittler zwischen den Welten, S. 63.

186 Die 1959 gegründete Deutsche Stiftung für Entwicklungsländer (DSE) war verantwortlich für die Vorbereitung von deutschen EntwicklungsarbeiterInnen (u. a. der GTZ und des DED) vor ihren Auslandseinsätzen und führte „Aus- und Fortbildungsprogramme für Fach- und Führungskräfte aus Entwicklungsländern“ durch. Als Vorbilder hatten zwei Nachkriegsinstitutionen gedient das britische Wilton Park und die deutschen Evangelischen Akademien - deren Hauptaufgabe 
Vorbereitung eine Reaktion auf das Verhalten von westdeutschen Experten, die beim Aufbau des Stahlwerks Rourkela in Indien rassistische und arrogante Verhaltensweisen an den Tag gelegt hatten. Skandalberichte über die „RourkelaDeutschen“ in der indischen, westdeutschen und internationalen Presse führten zu Forderungen nach besserer Selektion und Vorbereitung der Entsandten. ${ }^{187}$ Die Vorbereitungsprogramme waren zeitweise stark durch die Achtundsechziger-Bewegung beeinflusst; die Experimente mit freien und selbstbestimmten Ausbildungsformen beim DED wurden jedoch ab Anfang der 1970er-Jahre, nicht zuletzt aufgrund von Beschwerden der TeilnehmerInnen wieder durch konventionellere Methoden ersetzt. Ein Hang zu sozialistischen Konzepten und Tansaphilie blieb in den Vorbereitungsstätten jedoch bestehen. Ujamaa und self-reliance waren klassische Themen in entwicklungspolitischen Bildungsmaterialien und in der DED-Vorbereitung; das Referat Öffentlichkeitsarbeit des BMZ zeigte über Jahre hinweg den Film Ujamaa - Tansanias Weg zum Sozialismus, der 1975 in den Verdacht geriet, ein $\mathrm{zu}$ „rosiges, die Lage verharmlosendes Bild der aktuellen Verhältnisse“ zu zeichnen. ${ }^{188}$ Ein DED-Entwicklungshelfer forderte 1981, dass die Widersprüche der tansanischen Realität, die so weit vom sozialistischen Idealbild entfernt war, schon in der DED-Vorbereitungsstätte in Wächtersbach zur Sprache gebracht werden sollten, um böse Überraschungen und Desillusionierungen zu vermeiden. ${ }^{189}$

Kurzzeit-ExpertInnen und über Consulting-Firmen rekrutierte Fachkräfte absolvierten die vorgesehenen Vorbereitungen meist gar nicht erst, und wenn doch, dann manchmal mit exorbitanten Gehaltsforderungen für die Zeit in der BRD. ${ }^{190}$ Bei der Entsendung von „normalen“ GTZ-Kräften führte Termindruck bisweilen zu einer Hektik, die es nicht opportun erscheinen ließ, ihnen noch den Luxus einer länder- und aufgabenspezifischen Vorbereitung angedeihen zu lassen. Manche ExpertInnen landeten folglich in einem Land, das ihnen nicht nur praktisch,

gewesen war, Diskussionen um die moralische und politische Neuorientierung Deutschlands anzustoßen. In der DSE ging es nun nicht mehr (nur) darum, die Denkweisen der deutschen Nachkriegsbevölkerung zu transformieren, sondern auch, Expertise und Wissen zu exportieren. 187 Jan Bodo Sperling, Die Rourkela-Deutschen. Probleme der Verhaltensweisen deutscher Techniker auf einer Grossbaustelle in Indien, Dissertation, Aachen 1965.

188 BArch Koblenz, B 213/7682, Tansania Allgemeines Bd. 13, Kenneweg an Referat 116, Bonn, 18.4.1975.

189 Jäger, Shida Kweli.

190 Ingenieure, die über Consultingfirmen für ein GTZ-Projekt rekrutiert worden waren, stellten im Fall eines Projektes Gehaltsforderungen von 8.600 bis 10.600 DM pro Monat für drei bis sieben Monate in der BRD, wobei diese Zeit offenbar nur teilweise für die Vorbereitung genutzt wurde. Das BMZ erkannte diese Kosten allerdings nicht an. BArch Koblenz, B 213/33089, Hanusch (GTZ), Mitteilung bzgl. NECO, Eschborn, 22.9.1978. 
sondern auch theoretisch gänzlich unbekannt war. ${ }^{191}$ Immer wieder beschwerten sich ProjektleiterInnen zudem über die miserablen Fremdsprachenkenntnisse der Entsandten, gerade im Fall von Ingenieuren. ${ }^{192}$

In Vorbereitungskursen für GTZ-ExpertInnen bzw. DED-EntwicklungshelferInnen unterrichteten auch TansanierInnen, die in der BRD studierten bzw. studiert hatten. Sie wurden vor allem im Bereich „Landeskunde“ (Ostafrika) eingesetzt. Die Festschreibung auf die Rolle der interkulturellen VermittlerInnen und das Näherbringen von Do's und Don'ts wurde bisweilen als einschränkend empfunden. Ein tansanischer Interviewpartner sah seine Aufgabe eher darin, die dichotome Denkweise von afrikanischer Hilfsbedürftigkeit und deutscher, unpolitischer Hilfe mitsamt den einhergehenden paternalistischen Haltungen aufzubrechen. ${ }^{193}$ In einigen Vorbereitungskursen wurden solche Haltungen aber auch eingeübt und stabilisiert, wie der bereits erwähnte tansanische Arzt Matomora Matomora (siehe Kap. 4) erfahren musste und in einem Bericht über das entwicklungspolitisch ausgerichtete Programm mit mit dem Titel „Medizin in Entwicklungsländern“ festhielt. Der Kurs, angeboten von der Zentralstelle für Arbeitsvermittlung, richtete sich in erster Linie an deutsche medizinische Fachkräfte, die kurz vor einem „Entwicklungshilfeeinsatz“ standen. ${ }^{194}$ Er steht damit nicht repräsentativ für die Vorbereitungen, die beim DED und der DSE für ganze Generationen von Entsandten durchgeführt wurden, aber gibt gerade dadurch einen wertvollen Einblick in die Kluft zwischen verschiedenen Formaten und Zielgruppen.

Die Zielsetzung des Kurses, die Arzttätigkeit in ein soziales, ökonomisches und kulturelles Umfeld einzubetten, war Matomora zufolge sehr positiv einzuschätzen. Genau diese Einbettung geschehe jedoch, wie er in einem ersten Kritikstrang anmerkte, in völlig unzureichender Manier: „Begriffe wie Neokolonialismus und Imperialismus, unerlässlich für jede seriöse Diskussion über die III. Welt“, seien „im Kurs tabu“ gewesen, während historische Aspekte wie die Kolonialvergangenheit und globale Produktionsstrukturen komplett verschwiegen worden seien (was bei den Kursen anderer Institutionen, die von den

191 BMZ, B 213/63790, Tansania Allgemeines Heft 5, BRD-Botschaft, Entwicklungspolitischer Zweijahresbericht, Dar es Salaam, August 1987, S. 11.

192 BArch Koblenz, B 213/7672, BRD-Botschaft an AA, Dar es Salaam, 9. 8.1969, S. 7; ebd., B 213/ 7680, Wolfgang Kreuser, Aufbau der Ingenieurfakultät Dar es Salaam, Stand 1.10.1974, S. 9; ebd., B 213/33089, Wiegmann (BMZ) an Sinn (GTZ), o.O., 4.11.1980.

193 Interview \#14, tansanischer Doktoratsstudent in der BRD; siehe auch Interview \#15, tansanische Studentin in der BRD und spätere GTZ-Expertin und -Verwaltungsangestellte.

194 BArch Koblenz, B 213/7683, Wichelmann (BMZ) an Zentralstelle für Arbeitsvermittlung, Bonn, 28.4.1976, Bericht: 11.6.1976. 
Achtundsechzigern beeinflusst waren, nicht der Fall war). ${ }^{195}$ Das Konzept der medizinischen Entwicklungshilfe sei gänzlich unhinterfragt geblieben. Matomora selbst gehörte, worauf er in diesem Bericht nicht explizit verwies, zu jenen, die in einer Perspektive der Kritischen Medizin forschten und publizierten. ${ }^{196}$ Deutsche KollegInnen zitierten ihn z.B. in einem Beitrag mit dem eindeutigen Titel „Westliche“ Medizin in Ländern der Dritten Welt. Am Beispiel Tansania: Ein Trojanisches Pferd des Neo-Kolonialismus. ${ }^{197}$ Matomoras zweiter Kritikstrang galt rassistischen Strukturen und Repräsentationsweisen und den „so eloquent und selbstsicher vorgetragenen Schlussfolgerungen, die von uns Ausländern nicht so hingenommen werden [können]“:

Zum Beispiel empfinde ich es als sehr beleidigend, wenn ein namhafter Referent die These vertritt, dass die Afrikaner traditionell ihre Kinder so [...] erziehen, dass wenn diese von der traditionellen Gesellschaft ,entwurzelt‘ aufwachsen zu großer Oralität neigen (deshalb würden die Neger so viel essen! die Westafrikaner kauen deshalb den ganzen Tag Holzspäne!!!), oder zu großer Gier neigen (deshalb hätte Haile Selasie [sic] selbst im hohen Alter sich nicht gescheut, seinem hungernden Volk 25 Milliarden Dollar zu entwenden!) [...] Referenten aus den von Weißen beherrschten Ländern bedienten sich der Propaganda dieser rassistischen Regime und meinten, weil angeblich bestimmte Stämme früher ,Krieger gewesen wären, würden sie heute noch dazu neigen, kriminelle Handlungen zu begehen. ${ }^{198}$

Matomora bedauerte, dass der Kurs eine Bühne bot für Referenten, „die ihr [...] reiches Erfahrungsspektrum [im] Dienst einer primitiven, engherzigen und vorurteilsbeladenen Ideologie“ einsetzten. ${ }^{199}$ Seine Vorschläge für eine Rundumerneuerung der Vorbereitungsseminare betrafen folgerichtig neben einer Generalüberholung und Politisierung der Inhalte auch eine Änderung der personellen Zusammensetzung und der Form. Es brauche mehr Diskussions- statt Referierzeit und mehr ausländische ReferentInnen und TeilnehmerInnen. ${ }^{200}$ In manchen Fällen, etwa bei der DSE, wurde das umgesetzt, wobei wie erwähnt auch tansanische Studierende und AbsolventInnen eingesetzt wurden, die damit auf EntwicklungsarbeiterInnen einwirkten, die ihnen dann in Dar es Salaam oder Tanga wieder begegnen sollten. Kulturalistische Erklärungen wurden jedoch, zulasten

195 Ebd., S. 4.

196 Matomora Matomora, Die tansanische Gesundheitspolitik und die politische Grundlage der medizinischen Versorgung, in: World University Service, Hg., Medizinische Versorgung in der Dritten Welt und Ausländerstudium in der Bundesrepublik, Bonn 1976.

197 Bichmann u.a., „Westliche“ Medizin.

198 BArch Koblenz, B 213/7683, Matomora Matomora, Mein Erfahrungsbericht des Kurses Medizin in Entwicklungsländern, Zur Vorlage bei der ZAV, Heidelberg, 11.5.1976, S. 3-4.

199 Ebd., S. 4.

200 Ebd., S. 5. 
von marxistisch inspirierten Ansätzen, die Machtasymmetrien und materielle Ungleichheiten ins Zentrum stellen, in der GTZ weiterhin tradiert. ${ }^{201}$ Das entsprach auch dem Interesse vieler KandidatInnen, die Modelle über interkulturelle Begegnungen auf persönlicher Ebene für die Praxis als hilfreicher empfanden als eine Makrokritik globaler Machtungleichheiten, die die eigene Präsenz in kritischem Licht erscheinen ließ und eher als Lähmung der eigenen Handlungsfähigkeit erfahren wurde. ${ }^{202}$

Allgemein beschränkten sich Disziplinierungstechniken für das westdeutsche Personal weitgehend auf eine Pädagogisierung. Beim DED wurde der anfängliche „Maulkorberlass“, der jegliche Kritik am Gastland verbot, fallen gelassen und durch das allgemeinere Prinzip der Nichteinmischung ersetzt. ${ }^{203}$ Die gängelnden Regelungen der „Mutter DED“, die das Privatleben der EntwicklungshelferInnen reglementierte (darunter das Verbot, mit Personen des anderen Geschlechts zusammenzuleben, Meldepflicht bei jeder Entfernung vom Arbeitsort oder der Wohnung und sogar eine Obergrenze von 1,20 Meter für die Bettenbreite) wurden Ende der 1960er-Jahre ebenfalls gelockert oder abgeschafft. ${ }^{204}$ Während das Privatleben der westdeutschen Entsandten damit formell tatsächlich zur Privatsache wurde, blieben die individuelle Lebensführung und der Umgang mit Ungleichheiten stets ein Streitpunkt.

\subsection{Lebensbedingungen: Zwischen Kollektiv und Privilegien}

Während viele BRD-Entsandte sich als Teil einer internationalen, vorwiegend westlichen expatriate community verstanden, ${ }^{205}$ waren DDR-BürgerInnen angehalten, eng in die von anderen Nationalitäten weitgehend abgeschottete DDREnklave eingebunden zu bleiben. Ihr Alltag ist deswegen aber keinesfalls als abgeschottet erfahren worden, weil der Auslandsaufenthalt im Vergleich zum Leben in der DDR zahlreiche neue Kontakt- und Erfahrungsmöglichkeiten über diese Enklave hinaus bot. Zwar wurden Regeln und Rituale aus der DDR nach Tansania verlagert, was diese zum Teil rigider machte und verstärkte, in anderen Fällen aber auch lockerte und Schlupflöcher eröffnete. Die jeweilige lokale DDR-

201 Hüsken, Der Stamm der Experten.

202 Siehe E-Mail einer ehemaligen GTZ-Projektleiterin an den Autor, 27.5.2017.

203 Hein, Die Westdeutschen, S. 91.

204 Ebd. Die Bezeichnung „Mutter DED“ findet sich bei Lothar Beblo u. a., Bei Allah! Das ist doch eine Ungerechtigkeit! Mitarbeiter erinnern sich, in: Willi Erl, Hg., Betrifft: Zusammenarbeit: 25 Jahre Deutscher Entwicklungsdienst, Berlin 1988, 45-50, hier: S. 49.

205 Siehe Erik Cohen, Expatriate Communities, in: Current Sociology 24/3 (1977), S. 5-90. 
Enklave war nur einer von mehreren Räumen, in denen sich die Auslandskader bewegten. Für Mitglieder des „DDR-Kollektivs“ wie der „BRD-Kolonie“ stellt sich die Frage, wie diese in die tansanische Gesellschaft und die dort ansässige expatriate community eingebettet waren - und inwiefern sich in den beiden Fällen überhaupt von Gemeinschaften reden lässt.

\section{Das DDR-,,Kollektiv“}

1985 befanden sich insgesamt 110 DDR-BürgerInnen in Tansania. Bei den meisten handelte es sich um Entwicklungs- und Botschaftspersonal sowie deren Angehörige; auch in Vorjahren waren es nie bedeutend mehr gewesen. Es handelte sich damit um eine recht übersichtliche Gruppe, die nach Einsatzort und Status in weitere „Kollektive“ unterteilt war. Die fern von Dar es Salaam (bzw. während der 1960er Jahre Sansibar-Stadt) eingesetzten Auslandskader genossen tendenziell größere Freiräume, während das Netz der DDR-expatriate community in Dar es Salaam engmaschig geknüpft war. Die Mitglieder kannten sich, unterhielten häufig einen regen persönlichen Kontakt, tauschten sich aus und halfen einander, aber konkurrierten auch um Ressourcen (z. B. die Benutzung von Fahrzeugen) und Anerkennung in einem komplexen Beziehungsgeflecht, das berufliche, staatliche, parteiliche, familiäre, nachbarschaftliche und freizeitliche Interaktionsmuster umfasste.

Die zentrale Institution zur Aufrechthaltung einer DDR-Identität außerhalb der DDR war die Botschaft mit den ihr untergeordneten politischen und wirtschaftlichen Abteilungen sowie der Schule für die mitausgereisten Kinder. ${ }^{206}$ Machtzentren waren die lokalen Grundorganisationen der SED sowie die jeweilige diplomatische Vertretung des Staates (Botschaft, Konsulat). Das machtpolitische Problem, ob Partei oder Botschaft das Sagen im „Kollektiv“ hatten, wurde dadurch entschärft, dass der Parteileiter das „Prinzip der Einheit von staatlicher und parteimäßiger Leitungstätigkeit“ zu achten und sich mit dem Botschaftspersonal abzusprechen hatte, was der Botschaft den ersten Rang einräumte. ${ }^{207}$ Zusätzlich war das Botschaftspersonal von Angehörigen der Staatssicherheit durchsetzt, zeitweise stellten sie sogar die größte Gruppe der Botschaftsangehörigen (wobei die Entsandten, so zeigten Interviews, nur vermuten konnten, wer der Staatssi-

206 Kinder durften mit ausreisen, wenn sie maximal die vierte Klasse erreicht hatten und so noch in der DDR-Botschaftsschule beschult werden konnten. Ältere Kinder verblieben in der DDR, entweder bei Verwandten oder einem speziellen Internat in Königs-Wusterhausen.

207 SAPMO BArch Berlin, DY 30/15205, DDR-Botschaft, Beurteilung des Genossen L. H., Dar es Salaam, 20.5.1983. 
cherheit angehörte und wer nicht). ${ }^{208}$ Außerhalb von Dar es Salaam fanden an den Einsatzorten, wo mindestens zwei oder drei SED-Parteimitglieder präsent waren - was nicht überall der Fall war - regelmäßige Sitzungen der SEDGrundorganisation statt, an denen oft auch die parteilosen DDR-BürgerInnen teilnahmen. ${ }^{209}$ Wenn die Parteilosen kein Pflichtgefühl zur freiwilligen Teilnahme an den Tag legten, wurde die Freiwilligkeit eingefordert. ${ }^{210}$ Die „freiwillige“ Teilnahme war auch bei gemeinsamen Arbeitseinsätzen vorgesehen, wobei diese „Subbotniks“ genau wie die Parteisitzungen und andere Rituale aus der DDR bekannt waren, aber in Tansania die Umgehungsmöglichkeiten oft geringer waren, wie ein ehemaliger Kulturattaché der Botschaft beschrieb:

Anfangs habe ich das als eine Art „Subbotnik“ oder „freiwilliger Arbeitseinsatz“ gesehen, wie es ja auch in der DDR seit langem zu verschiedenen Anlässen üblich war [...]. Im Grunde war diese Tätigkeit in Tansania also nicht ungewöhnlich, eher die Exotik des Ortes. So etwas kannte man „von Zuhause“. Je nach den konkreten Umständen „zu Hause“ beteiligte man sich daran oder auch nicht, konnte man sich es „leisten“, nicht an kollektiven Aktivitäten teilzunehmen oder auch nicht. Im Ausland war das übersichtlicher und wegen der Vorauswahl der Auslandskader eine ungeschriebene Regel. ${ }^{211}$

Symbolische Auszeichnungen durch Abzeichen und Medaillen (,Verdienter Aktivist“, „Kollektiv der sozialistischen Arbeit“, „Verdienstmedaille der DDR“, „Pestalozzi-Medaille“) und Beurteilungen durch die Vorgesetzten trugen der fachlichen Tätigkeit wie auch dem Engagement außerhalb der Arbeit Rechnung. Weitere aus der DDR exportierte Rituale wurden zu einer Vielzahl staatlicher Feiertage und feierlicher Anlässe begangen, darunter der Internationale Frauentag, der Kampftag der Arbeiterklasse, der Tag der Republik, Fasching, das „Neptunfest“ (eine Spaßtaufe für Kinder), Weihnachtsfeiern, Kennenlernpartys, Abschiedsfeiern und Geburtstage. „Eine Feier löste die andere ab“, hieß es etwa in einem privaten Fotoalbum eines Lehrerehepaars. Diese Inszenierungen der DDR in Tansania dienten der Aufrechterhaltung eines Gemeinschaftsgefühls und waren auch von politischen Ereignissen durchzogen. So folgte der Kinderweihnachtsfeier 1972 mit Kaffee und Dresdner Stollen ein „Bürgerabend“, in dessen Rahmen die Anerkennung der DDR durch Tansania - nunmehr mit reichlich Alkohol - zelebriert wurde. ${ }^{212}$

208 Bols, Ende der Schweigepflicht, S. 161.

209 SAPMO BArch Berlin, DY 30/15205, Sekretär GO DSM an Abt. Int. Verbindungen der SED, Dar es Salaam, 11.10.1983.

210 Interview \#17, DDR-Lehrerexperte.

211 E-Mail des ehemaligen DDR-Kulturattachés an den Autor, 27.6.2016.

212 Eintrag zum 23.12.1972 im Fotoalbum ehemaliger Entsandter, Privatbesitz. 
Während der ehemalige Kulturattaché die Botschaft als „eine Art Gravitationszentrum, Kraftquell für die DDR-Bürger“ beschrieb und darauf hinwies, dass die meisten Freizeitaktivitäten „nicht nur mit Kenntnis und Billigung“, sondern in der Regel auch „mit Unterstützung und häufig unter Federführung der Botschaft“ stattfanden, stellten manche ExpertInnen diese Doppelfunktion von identitätsstiftender Versorgung und Disziplinierung widersprüchlicher dar. Ein ehemaliger Bildungsberater beschrieb die Botschaft retrospektiv als die „große Glucke“, die sich um das „materielle Wohlergehen“ gekümmert, aber auch „immer [...] den Finger drauf [hatte]“, wenn es um die Loyalität zur DDR ging. ${ }^{213}$ In der beruflichen Praxis der Bildungsberatung habe er hauptsächlich mit seinem tansanischen Counterpart zu tun gehabt und „Narrenfreiheit“ genossen. In „den eigenen Reihen“, so meinte er weiter, „musste [man] sehr vorsichtig agieren“, da „jedes krumme Wort gewichtet“ wurde.

Gerade die Einbindung in die Entwicklungsarbeit jedoch eröffnete Distanzierungsmöglichkeiten zu den Kontrollinstanzen: Im Kontrast zu Erfahrungsberichten (v.a. von Botschaftsangehörigen), die das DDR-„Kollektiv“ als homogene Einheit beschwören, betonten mehrere ExpertInnen im Interview, dass sie „fachlich, räumlich, zeitlich ziemlich voneinander getrennt“ von anderen Expertengruppen $^{214}$ gelebt und als „Einzelkämpfer“ agiert hatten: „Wir mussten morgens früh da sein und kamen abends spät nach Hause“, dementsprechend konnten sie an DDR-spezifischen Veranstaltungen nur selten teilnehmen. ${ }^{215}$ Die wichtigsten Kontakte dieser ExpertInnen, von denen manche bewusst Distanz zu anderen DDR-BürgerInnen hielten, waren andere expatriates und TansanierInnen. Ein Universitätslektor meinte, er habe „einen ganz engen Kontakt zu allen afrikanischen Kollegen, zu allen Ausländern und vor allem den westlichen und weniger zu DDR-Bürgern gesucht“, und „je mehr das aus dem westlichen Ausland welche waren, war mir das lieb, weil ich davon nur profitieren konnte““.216 Neben manchen DDR-InterviewparterInnen beschrieben auch deren damalige tansanische KollegInnen solche Distanzierungsbemühungen. Ein Professor der Rechtswissenschaften etwa erinnerte sich an seine früheren DDR-KollegInnen, ein „Paar aus Leipzig“, als „sozial und gesprächig, aber reserviert im Umgang mit anderen aus der BRD und der DDR“. ${ }^{217}$

213 E-Mail des ehemaligen DDR-Kulturattachés an den Autor, 27.6.2016; Interview \#117, DDRPolytechnikberater.

214 Interview \#31, DDR-Universitätsexperte.

215 Interview \#111, DDR-Experte beim Ministry of Water and Energy.

216 Interview \#20, DDR-Universitätsexperte.

217 Interview \#14, Tansanischer Professor an der Rechtsfakultät, Übersetzung E. B. 
Die Bewegungs- und Kontaktregelungen waren weithin internalisiert und wurden von manchen rationalisiert und womöglich gar nicht mehr als Einschränkung empfunden. Manche InterviewpartnerInnen, darunter ein entsandter Lehrer, bewerteten das Pochen der Botschaft auf Einhaltung der „Sicherheitsheitserfordernisse“, etwa die Abmeldung bei Reisen, als „gut und sinnvoll“; er meinte auch, dass „man [...] sich frei bewegen“ konnte: „Gab’s niemanden, der einem irgendwas vorgeschrieben hat, ging auch gar nicht“. ${ }^{218}$ In anderen Erinnerungen nehmen Regulierungen der alltäglichen Mobilität jedoch einen zentralen Platz ein. ${ }^{219}$ Gleichzeitig wendeten die Entsandten - darunter auch der zitierte Lehrer selbst - Taktiken an, um die Botschaftskontrolle zu umgehen. Einige Entsandte testeten die Grenzen und ungeschriebenen Regeln immer wieder aus. Partei, Botschaft oder die „Staatlichen Leiter“ der jeweiligen Expertengruppen wiederum beäugten derartige Grenzüberschreitungen kritisch und konnten jederzeit Empfehlungen abgeben, wann jemand „mal wieder richtigen DDR-Wind“ zu spüren bekommen solle. ${ }^{220}$ Gleichzeitig gab es immer wieder Personen, die sich den Disziplinierungsbemühungen nicht unterwarfen. Ein Beispiel dafür ist ein junger Schneider, der in einer Brigade der Freundschaft der FDJ in Sansibar arbeitete. Fachlich voll anerkannt, fiel der Brigadeleitung sein privates Verhalten wiederholt negativ auf. Er gab, so der Bericht, sein Geld ,völlig unkontrolliert“ aus, „pflegte Kontakte mit einer hier unerwünschten Musik-Band“ (im Rahmen der sansibarischen „Kulturrevolution“ wurden manche Arten von Kapellen als imperialistische Erscheinung gebrandmarkt), stahl von einem anderen Brigademitglied und ,übertrat auch die Weisung, keine Beziehungen zu Mädchen zu unterhalten“. In den wiederholten Aussprachen erkannte der Gescholtene die „Kritik des Kollektivs - wie das bei ihm immer üblich ist - voll an“, änderte sein Verhalten aber nicht. ${ }^{221}$ Er wurde für zukünftige Einsätze als zu unreif erachtet, gleichzeitig nahm die Brigadeleitung (aus Furcht vor einer möglichen „Republikflucht“ des noch ledigen jungen Mannes) davon Abstand, ihn vor der Rückreise über die Aberkennung des Auslandskaderstatus zu unterrichten. In

218 Interview \#17, DDR-Lehrerexperte.

219 So etwa Interview \#21, DDR-Planungsberater: ,[D]u kannst dich an den Strand legen, [aber] in die Stadt gehen, so wie hier, flanieren, kannst du nicht. Teilweise darfst du's auch nicht, das ist also verboten gewesen, stand auch so etwas in der Direktive darin. Hat der auch immer noch mal erzählt, der Handelsrat und der Botschafter, was da alles erlaubt und nicht erlaubt ist.“

220 BArch Berlin, DR 2/50722, Das Bildungswesen im Sozialistischen Äthiopien - Kurzinformation (Sept. 1982), 6.10.1982, Anlage 1: Information zur weiteren Entwicklung des Experteneinsatzes im Sozialistischen Äthiopien.

221 SAPMO BArch Berlin, DY 24/19211, o.A., Kaderfragen, o.O., o.D. [1970], S. 2. 
seinem wie auch in anderen Fällen wurde die Information erst beim nächsten geplanten DDR-Aufenthalt übermittelt.

\section{Tabu „Westkontakte“}

Angesichts von An- und Abreisen und wechselnden Einsatzbedingungen war das in DDR-Berichten viel beschworene „Kollektiv“ keine stabile Größe. Es musste stattdessen immer wieder neu hergestellt werden und war daher mehr Imperativ, Zielvorstellung oder vorgespiegelte Eintracht als Wirklichkeitsbeschreibung. Ein zentraler Kristallisationspunkt der Disziplinierungsstrategien waren die Kontaktvorschriften - mit denen ebenfalls eigen-sinnig umgangen wurde. Für DDRAuslandskader gab es zwei Kategorien persönlicher Beziehungen: Offiziell erwünschte Kontakte und solche, die meldungspflichtig waren und insbesondere bei ausbleibender Meldung Disziplinarverfahren nach sich ziehen konnten. $\mathrm{Zu}$ den gewünschten Kontakten gehörte der Austausch mit (1) anderen Kadern aus der DDR und den übrigen RGW-Staaten, insbesondere der Sowjetunion, um den Zusammenhalt der „sozialistischen Länder“ zu demonstrieren, (2) ein gutes, aber rein professionelles Verhältnis mit tansanischen KollegInnen und EntscheidungsträgerInnen sowie (3) Angehörigen „progressiver“ Bewegungen. Kontakte mit TansanierInnen und anderen Personen aus dem „NSW“, dem Nicht-Sozialistischen-Wirtschaftsgebiet, die nicht genehmigt waren bzw. über die nicht berichtet wurde, führten immer wieder zu disziplinarischen Maßnahmen, die von Verwarnungen bis zum erzwungenen Einsatzende, Streichung aus der Auslandskaderreserve und einer Reisesperre reichten. 1970, als gerade der Besuch des DDR-Außenministers bevorstand und die DDR auf die diplomatische Anerkennung durch Tansania hoffte, wurde gar eine ganze Lehrergruppe abberufen, weil eine DDR-Bürgerin - als mitausreisende Ehefrau nach Tansania gekommen - mit einem Westdeutschen „fraternisiert“ und der lokale SED-Parteisekretär nicht eingegriffen hatte. ${ }^{222}$

Die Signalwirkung solcher Sanktionen an die verbliebenen DDR-Entsandten war eindeutig: Jeder potenziell „gefährliche“ Kontakt sollte gemieden, anderenfalls gemeldet werden. In diesem Modus wurden die Kontakte dann in den Berichten auch immer wieder dargestellt. Im Alltag waren Beziehungen aber nicht so fein säuberlich trennbar wie in den Berichtvorlagen. Die Grenzen zwischen Privatund Arbeitsbeziehungen waren fließend, und was war, wenn die anderen den

222 BArch Berlin, DR 2/25493, Informationsbericht des Staatlichen Leiters der Lehrergruppe an MfV, Dar es Salaam, 29.4.1970, S. 4. 
Kontakt suchten? Angesichts der diversifizierten Fachkräfterekrutierung Tansanias - oft gab es Westdeutsche an derselben Schule oder in einer Institution, mit der man kooperieren musste - war ein striktes „Kontaktverbot“ unpraktikabel. Ein vollständiges Unterlassen „verdächtiger“ Kontakte war angesichts der Bedingungen und der internationalen Zusammensetzung vieler Wohn- und Arbeitsorte ebenso unmöglich wie deren vollkommene Kontrolle. Am Technical College Dar es Salaam etwa, an dem 1974 trotz „Afrikanisierung“ noch über 20\% des Personals aus dem Ausland stammten, wimmelte es aus offizieller DDR-Perspektive nur so von „Klassenfeinden“: 55 Freiwillige und ExpertInnen aus der BRD, den Niederlanden, Dänemark und anderen westlichen Ländern - während Angehörige osteuropäischer Staaten mit insgesamt gerade einmal fünf Lehrern aus der DDR, der Sowjetunion und Bulgarien deutlich in der Unterzahl waren. ${ }^{223}$ Die DDR-Entsandten sollten in solchen Situationen die Beziehungen auf „ein sauberes dienstliches Verhältnis“ beschränken. ${ }^{224}$

Kontakte mit Westdeutschen waren die heikelsten von allen, trotz der strikten Richtlinien gab es sie - allerdings nur in geschützten Räumen, im Geheimen oder in Notfällen. Das Kontaktverbot wurde missachtet bei Aufeinandertreffen im Swimmingpool der Universität oder weit draußen im Indischen Ozean, in der Wohnung von Dritten, wie z.B. befreundeten tansanischen Familien oder von jenen DDR-Entsandten, die einen Sonderstatus genossen. Mehrere ehemalige Auslandskader erinnerten sich daran, dass sie sich deutsch-deutsche Kontakte nur in Notfällen erlaubten (wenn z. B. eigene Angehörige oder die Frau eines BRDExperten schnell ins Krankenhaus gefahren werden mussten) und selbst dann noch von der Botschaft ermahnt wurden. Persönliche Interaktionen blieben somit immer ein „heißes Eisen“, und wenn sich ein Auslandskader den „Kontakt mit Tod und Teufel“ erlaubte, gehörte das in den Bereich der Geheimnisse, die nicht mit anderen DDR-Kadern geteilt wurden, zumal die Staatssicherheit ihre Augen und Ohren immer in der Nähe haben konnte. ${ }^{225}$ Die Strategie der meisten Entsandten war also, die eigenen Kontakte „nicht an die große Glocke [zu] hängen“ und auch den anderen keine dahin gehenden Fragen zu stellen. ${ }^{226}$ Tatsächlich tauschten sich - so erzählten mehrere Entsandte auf einem Ehemaligentreffen 2014 - viele erst nach 1990 offen darüber aus, mit welchen Personen sie während ihrer Tansania-Aufenthalte tatsächlich verkehrt hatten.

223 Staatlicher Leiter der Lehrergruppe G. R., Bericht über die Tätigkeit der Lehrergruppe in Dares-Salaam im 1. Halbjar 1974, Dar es Salaam, 15.7.1974, BArch SAPMO/DR 2/60785, S. 7.

224 BArch Berlin, DR 2/25493, Informationsbericht des Staatlichen Leiters der Lehrergruppe an an MfV, Dar es Salaam, 29.4.1970, S. 8.

225 Interview \#93, DDR-Deutschlehrerin und mitreisende Ehefrau.

226 Interview \#24, Kulturattaché der DDR-Botschaft in Tansania. 
Die staatliche Regulierung der sozialen Interaktionen, Ver- und Misstrauen, Verheimlichung und Denunziation waren damit in der DDR-Gemeinschaft für den Umgang untereinander und die weiteren Karrierewege von weit größerer Bedeutung, als es für jegliche westliche expatriate community denkbar wäre. Die Kontaktgebote hingen wie ein Damoklesschwert über dem Alltag. Das heißt nicht, dass sie stets in den Gedanken präsent waren. Der Umgang damit stellte aber einen wichtigen Teil des DDR-spezifischen Habitus dar. Die sprachliche Unsicherheit im Verbund mit fehlender Auslandserfahrung und den Kontaktverboten ließ einen guten Teil der Ostdeutschen in der internationalen community als ungelenk erscheinen,sodass umso mehr ins Auge fiel, wenn sich unter den ExpertInnen oder Diplomaten doch einmal jemand mit einer lockeren und weltgewandten Umgangsweise fand. ${ }^{227}$

Viele DDR-BürgerInnen fanden sich während ihres Aufenthaltes keinesfalls einfach mit der frustrierenden Kluft zwischen Regeln und Realität, zwischen offiziellen und eigenen Erwartungen ab. Manche Auslandskader warben in Berichten offensiv um Verständnis für ihre Situation, da die rigiden Verhaltensvorschriften keine umsetzbaren Handlungsmodelle für die komplexere Realität bereithielten. ${ }^{228}$ Der Vertrag mit einer tansanischen Institution und die ja auch von DDR-Seite betonte Pflicht, auf tansanische Interessen einzugehen, erweiterten den Spielraum und ermutigten manche auch zur Verteidigung einer gewissen Autonomie gegenüber DDR-Obrigkeiten. Ein Lehrer erinnerte sich an einen Weiterbildungslehrgang für seine gesamte Institution, der in Kooperation mit dem Personal einer US-amerikanischen Universität durchgeführt wurde. Auch die DDR-Lehrer sollten einige Kurse leiten:

\footnotetext{
Das sah dann unsere Botschaft nicht ganz so gern. Aber was sollten sie machen. Da haben dann mein Kollege und ich uns beteiligt und da kam es natürlich auch zu recht freundlichen Kontakten zu den amerikanischen Kollegen. Und war eine schöne Zeit eigentlich.Wir wurden dann auch eingeladen von denen, das durfte man also nicht so groß breittreten. Aber es entwickelten sich recht gute Kontakte. 229
}

Im offiziellen Skript im Bericht für das Ministerium für Volksbildung im Jahr 1987 hieß es über diese Veranstaltung, die drei vertretenen DDR-Lehrer seien vom tansanischen Rektor mit der Weisung eingesetzt worden, die „Durchsetzung der tansanischen Interessen gegenüber proamerikanischer Propaganda“ zu gewährleisten; schon zuvor habe man „Versuchen, dem Lehrgang ein US-amerikanisches

227 Kilian, Hallstein-Doktrin, 218-219; Interview \#99, DDR-Universitätsexperte.

228 BArch Berlin, DR 2/25494, Jahresbericht 1971 Ifunda, o.O., o.D. [1971].

229 Interview \#17, DDR-Lehrerexperte. 
Gepräge zu geben, [...] unmissverständlich Widerstand entgegengesetzt“. Während des Lehrgangs hätten sich die US-Amerikaner ,jeder direkten politischideologischen Polemik“ enthalten, sodass es nicht zu Konfrontationen gekommen sei; alle Gespräche seien rein fachlicher Natur gewesen. ${ }^{230}$ Zwischen der Ost-WestKonfliktrhetorik des Berichts und der Betonung freundschaftlicher Kontakte im Interview klafft dennoch eine Lücke, die sich dadurch erklären lässt, dass die Lehrer ihre Teilnahme in ideologisch und vertraglich (im Auftrag des Rektors) sanktionierte Formulierungen kleideten und so ihren eigenen Spielraum vor Interventionen verteidigten. Im Interview wiederum wurden die Kontakte zu den US-amerikanischen Kollegen womöglich besonders betont, um die individuellen Handlungsspielräume hervorzuheben und dem Narrativ einer rein ideologisch motivierten DDR-Entwicklungspolitik entgegenzuwirken.

\section{Die BRD-,Kolonie“}

Auch die BRD-,,Kolonie“, wie die westdeutsche Bevölkerung in Tansania von der Botschaft manchmal genannt wurde, war anhand räumlicher und statusmäßiger Kriterien unterteilt und geschichtet, allerdings offener, heterogener und um ein Vielfaches größer als auf DDR-Seite. Die westdeutsche „Kolonie“ umfasste Mitte der 1970er-Jahre etwa 1.500 Personen, von denen ein großer Teil in kirchlichen und wirtschaftlichen Institutionen und damit über das staatliche entwicklungspolitische Feld hinaus tätig war. Die BRD-Botschaft in Dar es Salaam verfügte zu diesem Zeitpunkt über mehr Personal als alle anderen bundesdeutschen Auslandsvertretungen auf dem afrikanischen Kontinent. ${ }^{231}$ Aus Sicht der Entsandten übte sie trotzdem nicht annähernd so eine zentrale Funktion aus wie die DDRVertretung. Sie war weder ein vergleichbares Machtzentrum noch Hort der Identitätsstiftung, gerade beim Entwicklungspersonal der unteren Ebenen gab es kaum oder gar keine Berührungspunkte während des Einsatzes. Nur zu den wichtigsten Anlässen und Nationalfeiertagen veranstaltete die Vertretung Zusammenkünfte, außerdem lud der Botschafter (bzw. zeitweise die Botschafterin) abhängig vom Jahr regelmäßig oder nur gelegentlich - zu „Projektleitertreffen“, an denen die GTZ-ExpertInnen teilnahmen und über den status quo ihrer Arbeit berichteten. ${ }^{232}$ Für ProjektleiterInnen war es jedoch essenziell, einen guten Draht

230 BArch Berlin, DR 2/50566, Lehrergruppe der DDR in der VR Tansania, Abschlussinformation über Weiterbildungslehrgang am CE DSM, 1987.

231 Röhnelt, Die bundesdeutsche Entwicklungshilfe, S. 40.

232 BArch Koblenz, B 213/33081, Berater S.-F., 10. Vierteljahresbericht (Februar, März, April 1979), o.O., o.D., S. 20. 
zur Botschaft aufrecht zu erhalten, da BotschafterIn und EntwicklungshilfereferentInnen Projektauswahl, -gestaltung und -überwachung sowie entwicklungspolitische Verhandlungen beeinflussten, also z.B. Empfehlungen über die Fortführung von Projekten und damit auch über Karriereverläufe gaben. Engere Kontakte beim DED gab es im Rahmen von Jahresversammlungen (ab 1967) und Fachgruppentreffen.

Die im Alltag relevanten Privatkontakte wurden vor allem mit anderen expatriates geschlossen, was ursprünglichen Integrationsabsichten entgegenstehen mochte. In einem ostentativ selbstkritischen Bericht bekannte DED-Entwicklungshelfer Helmut Jäger, dass ihm der Aufbau von Beziehungen und Freundschaften zu TansanierInnen mühsame Verständigungsarbeit abnötigte und, wenn er nicht an einem abgelegenen Ort, sondern in Dar es Salaam wohnen würde, auch er „kulturelle Inzucht“ betrieben und „mit Holländern und Amis rumgehockt [...] und nur gelegentlich Ausflüge in afrikanische Hütten gemacht hätte“.233 Er widersprach allerdings der unter expatriates gängigen Meinung, man könne mit TansanierInnen unmöglich Freundschaften unterhalten. In Jägers Schilderung dringt hier die materielle Ebene in die - von deutscher Seite mit Erwartungen der „Immaterialität“ belegten - Kategorien von Freundschaft und Liebe ein. Der weitverbreiteten Ansicht, Liebesbeziehungen mit „Afrikanerinnen“ würden unweigerlich auf „Prostitution“ in Form von „Sex für Jeans“ hinauslaufen, hielt er eigene Erfahrungen entgegen: Seine Beziehung zu seiner (tansanischen) Freundin sowie $\mathrm{zu}$ einem (tansanischen) Freund habe allen Seiten viel abverlangt, um Vorurteile und Berührungsängste zu überwinden, aber, „obwohl ich reich und weiß bin“, sei es gelungen, ein auf Gegenseitigkeit beruhendes Vertrauensverhältnis aufzubauen. Andere „Weiße“, so Jäger, unkten freilich nach wie vor, das schlimme Erwachen werde auch bei ihm noch kommen. ${ }^{234}$

Intime Liebes- und Vertrauensverhältnisse wurden (im Gegensatz zur DDRSeite) auch in den Interviews thematisiert. Entsandte suchten Rat oder waren selbst Vertrauenspersonen. Sie redeten mit KollegInnen, NachbarInnen und StudentInnen über Eheprobleme und ungewollte Schwangerschaften, tauschten sich also gerade über solche Probleme aus, die im eigenen Familien- oder Bekanntenkreis tabu waren. Mitunter ging es hier auch darum auszuloten, welche Reaktionen kulturell akzeptabel waren. Auf BRD-Seite waren es vor allem die Junggesellen, die ein „bestimmtes Milieu“ von Hotels und Bars frequentierten ${ }^{235}$ und länger- oder kurzfristige Beziehungen mit tansanischen Frauen unterhielten,

233 Jäger, Shida Kweli, S. 50.

234 Ebd.

235 Interview \#122, GTZ-Experte. 
in einigen Fällen auch heirateten und in Tansania blieben. Die GTZ-Experten an der Universität Dar es Salaam hatten sich beim tansanischen Kollegium den Ruf eingehandelt, Umgang mit zahlreichen girlfriends $\mathrm{zu}$ pflegen. ${ }^{236}$

Ein Gemeinschaftsgefühl, das zwischen verschiedenen Kategorien wie „(west-)deutsch“, „europäisch“, „ausländisch“ und „weiß“ oszillierte, wurde vor allem dann beschworen, wenn die Sicherheitslage sich verschärfte. Generell gewann die „BRD-Kolonie“ als identitätsstiftende Gemeinschaft und Quelle sozialen Kapitals am ehesten in Krisensituationen an Bedeutung. Kriminalität wurde insbesondere dann zum Gesprächsthema, wenn auch die Räume, die expatriates zuvor als sicher empfunden hatten - etwa die Badestrände von „State House bis Oyster Bay“ - zu unsicheren Gebieten erklärt wurden; als die allgemeine Sicherheitslage in Dar es Salaam so angespannt war, dass nach der Dämmerung laut Botschaft nur noch „,öllig mittellose Afrikaner oder unerfahrene Neulinge zu Fuß auf den Straßen“ unterwegs waren. ${ }^{237}$ Der Wahrnehmung verengter Räume folgte dann eine Kontraktion und Betonung von Identitätskategorien. Konjunkturen der Unruhe und Panik sorgten dafür, dass die eigene nationale Identität einerseits wie auch das eigene „Weißsein“, der Status als „Europäer“ in „Afrika“ zu sein, an Bedeutung gewannen. Bedrohungsgefühle wurden weniger über die Berichterstattung in den Medien, sondern mehr über die Zirkulation von Berichten und Gerüchten über Einbrüche und Überfälle in den jeweiligen communities geschürt.

Vereinzelt in den 1970er und verstärkt in den 1980er-Jahren waren Botschaftsund Expertenberichte von BRD- und DDR-Seite voll von entsprechenden Meldungen (so wurden z. B. im ersten Halbjahr 1988 zehn Einbrüche bzw. Überfälle im DDR-„Kollektiv“ registriert oder drei Übergriffe im Zeitraum von zwei Monaten auf BRD-Botschaftsangehörige 1976). ${ }^{238}$ Ein Bericht aus dem Jahr 1976 vermerkte, dass Diebstahl und Raub in der Presse ,als Relikte des Kapitalismus [...] gebrandmarkt" und oft in Zusammenhang mit Korruption und Vergeudung öffentlichen Eigentums gebracht wurden, ohne dass etwas unternommen wurde; Anzeigen würden keine Konsequenzen nach sich ziehen. ${ }^{239}$ Während der Umgang auf DDR-Seite mit den gestiegenen Kriminalitätsraten relativ pragmatisch erscheint und die Berichte kein allzu großes Bedrohungsgefühl erkennen lassen (wenngleich auch hier Sicherheitsfenster eingebaut und Wachmänner eingestellt wurden), legten sich einige BRD-Entsandte sogar Schusswaffen zu und trugen, wie ein GTZ-Experte berichtete, „dauernd eine gewisse Angst mit sich herum“,

236 Interview \#33, Tansanischer Dozent.

237 BArch Koblenz, B 213/7683, Heft 2, Albers (BRD-Botschaft) an AA, Dar es Salaam, 23.12.1976.

238 BArch Berlin, DR 3/2. Schicht/1514, Dr. G. O., Abschlussbericht, Leipzig, 19.8.1988, S. 2.

239 BArch Koblenz, B 213/7683, Heft 2, Albers (BRD-Botschaft) an AA, Dar es Salaam, 23.12.1976. 
was ihn dazu führte - was ihm „während der vergangenen 2 1/2 Jahre nie in den Sinn gekommen wäre“ - ,sein Gartentor permanent unter Verschluß“ zu halten. ${ }^{240}$ Ein derart ausgeprägtes Bedrohungsgefühl war nicht zuletzt oft die Kehrseite einer privilegierten Lebensweise.

\section{„Billigkonkurrenz“ aus Fernost: Die Hinterfragung der Privilegien}

Entwicklungsarbeit umfasst, wie bereits gezeigt, ein breites Spektrum von un- bis hochbezahlten Positionen und damit einhergenden Lohnnebenleistungen. Die Lebensbedingungen erstreckten sich ebenfalls auf einer Skala von spartanisch bis luxuriös. ${ }^{241}$ Für die meisten DDR-Entsandten bot Tansania in mancher (wenn auch nicht in jeder) Hinsicht bessere materielle Lebensbedingungen als im Herkunftsland, während die Erfahrungen von BRD-Entsandten stark von den konkreten Einsatzbedingungen und zum Teil auch den eigenen materiellen und moralischen Ansprüchen abhingen.

Uma Kotharis Einsicht über den Zusammenhang von Herkunft und Status „that being from, or of, the West whether as a representative of colonial or donor power ascribes status“ 242 - wurde ähnlich auch von InterviewpartnerInnen aus der BRD (nicht jedoch der DDR) formuliert. Sie betonten, dass ihnen viele TansanierInnen mit einer gewissen Distanz begegneten und vermuteten hier einen direkten Zusammenhang mit der Hautfarbe. Den Begriff expatriate, so ein ehemaliger GTZ-Experte, habe er in Tansania als „einerseits ein Schimpfwort, andererseits [...] ein Autoritätsmerkmal“ aufgefasst. ${ }^{243}$ Expatriateness war in Tansania eine Qualität, die auch TansanierInnen mit Auslandserfahrung zugesprochen werden konnte; einerseits in einem positiven Sinne als Prestige und

240 BArch Koblenz, B 213/33081, Berater H.M. S.-F., 11. Vierteljahresbericht (Mai, Juni und Juli 1979), o.O., o.D., S. 9; ebd., Berater H. M. S.-F., 12. Vierteljahresbericht (August, September und Oktober 1979), o.O., o.D., S. 6. Zu den Schusswaffen siehe BArch Koblenz, B 213/33088, Berater S.F., 13. Vierteljahresbericht (November 1979-Januar 1980), o.O., o.D., S. 20; Interview \#25, GTZProjektleiter; BArch Koblenz, B 213/33081, Berater H. M. S.-F., 11. Vierteljahresbericht (Mai, Juni und Juli 1979), o.O., o.D., S. 9; ebd., S.-F., 12. Vierteljahresbericht (August, September und Oktober 1979), o.O., o.D., S. 6.

241 Roth, The Paradoxes of Aid Work, S. 50.

242 Uma Kothari, From Colonialism to Development. Reflections of Former Colonial Officers, in: Commonwealth \& Comparative Politics 44/1 (2006), S. 118-136, hier: S. 118.

243 Interview \#123, GTZ-Experte. 
Bereicherung, andererseits als Vorwurf der Entfremdung. ${ }^{244}$ Obwohl auch zahlreiche afroamerikanische expatriates oder Fachkräfte aus anderen afrikanischen Ländern in Tansania tätig waren, war der Begriff in populären Diskursen oft mit den Eigenschaften weiß, westlich und kapitalistisch verknüpft.

Ein dezidiertes Gegenbild zu den expatriates der kapitalistischen Welt bildeten in Tansania nicht die Fachkräfte aus der DDR oder der Sowjetunion, sondern jene aus China - zumindest für etwa ein Jahrzehnt. DDR-ExpertInnen und FreundschaftsbrigadistInnen, die zwischen 1965 und 1972 in Sansibar im Einsatz waren, erlebten die chinesische Präsenz als direkte Herausforderung. „Die Chinesen“, die „durch ihre Bescheidenheit bestochen“ haben, wie ein DDR-Lehrer meinte, seien eine „Billigkonkurrenz“ gewesen; sie hätten „nix gebraucht“, während DDR-Entsandte „bürgerlich“ in ihren eigenen Häusern - oft die Häuser der ehemaligen Kolonialbeamten - lebten. ${ }^{245}$ Die Staatssicherheit vermerkte 1967 in einem Bericht, dass Chinas Leistungen als „echte Hilfe“ galten und ,in letzter Zeit Vergleiche zwischen Experten aus der DDR und aus China angestellt“ wurden, „bei denen die Chinesen wegen ihrer bescheidenen Lebensweise, ihrer geringeren finanziellen Kosten für Sansibar und ihrer meist guten Suaheli-Kenntnisse“ besser abschnitten als das DDR-Personal. ${ }^{246}$ Bisweilen wurden die Entsandten persönlich mit den Diskrepanzen zu den chinesischen „Brüdern“ konfrontiert, so ein Lehrer der an einer sansibarischen Sekundarschule unterrichtete: „[M]eine Schüler kamen zu mir und sagten, Sir, wenn wir statt Ihnen Chinesen genommen hätten, dann hätten wir von Ihrem Gehalt fünf chinesische Lehrer bezahlen können. Und die Chinesen brauchen für die Gruppe ein Haus. Und Sie, Sie brauchen für Ihre Frau, Ihr kleines Kind und für sich ein ganzes Haus. Und so frech sind die dann aufgetreten.“247

In derartigen Kritiken wurde das Privatleben der expatriates zu einer politischen und moralischen Angelegenheit, die Differenz in den Lebensstandards zum Ausdruck kolonialer Kontinuitäten und deren Angleichung zum Zeichen wahrer Partnerschaft. In dieser Hinsicht wurde der individuelle Umgang mit Ungleichheit

244 Diese exptriateness konnte z.B. zugeschrieben werden, indem man jemanden als TX bezeichnete - TX war das Kennzeichen von Fahrzeugen in ausländischem Besitz. Siehe Askew, Performing the Nation, S. 314-315; vgl. auch Kap. 8 zu TIRDEP.

245 Interview \#113, DDR-Lehrerexperte.

246 BStU, MfS, HVA 229, Einzel-Information über imperialistische und chinesische Einflüsse in Sansibar und über die Haltung Tansanias gegenüber einigen afrikanischen Befreiungsbewegungen, Berlin, 27.10.1967.

247 Interview \#112, DDR-Lehrerexperte. 
und Privilegien bedeutend. ${ }^{248}$ Die chinesische Lösung, die Einsatzstandards an lokale Standards anzupassen, stand jedoch nie im Raum. Eine Umgestaltung der materiellen Einsatzbedingungen nach dem Muster chinesischer „Dumping-Bedingungen“, so der DDR-Konsul 1970, stellte für die DDR zu keiner Zeit eine Option dar. ${ }^{249}$ Die chinesische Herausforderung provozierte auf DDR-Seite keine strukturelle Änderung der Einsatzbedingungen, sondern lediglich Imperative in Form individualisierender Handlungsdirektiven. In einer Versammlung der SEDGrundorganisation wurde an die Mitglieder appelliert, angesichts von Beschwerden sansibarischer Seite über den Lebensstandard von DDR-Auslandskadern im Vergleich zum chinesischen Personal „alles zu vermeiden, was den Eindruck von Unbescheidenheit erwecken könnte. Das fängt mit dem Sprechen an, geht über die Kindererziehung, die Wohnungseinrichtung bis zur Art und Weise des Autofahrens“, und setzte sich im Umgang mit dem Hauspersonal, wofür insbesondere die mitausgereisten Ehefrauen verantwortlich seien, fort. ${ }^{250}$

Gerade hochrangige expatriates auf Experten- und Beraterebene stellten oft eine materielle Belastung für Tansania dar. Staatliche Institutionen mussten nicht nur standesgemäße Unterkünfte und Arbeitsplätze bereitstellen, sondern je nach den bilateral vereinbarten „Counterpartleistungen“ auch Mietzahlungen, Unterhalts- und Reparaturleistungen sowie Ein-, Aus- und Urlaubsreisekosten samt Gepäckzuschlägen für die ganze Familie übernehmen. Die DDR versuchte in Verhandlungen immer wieder, vor allem die Devisenkosten (z. B. für Flüge) so weit wie irgend möglich auf die tansanische Seite abzuwälzen und auch bei Delegationsbesuchen eine Kostenteilung zu erreichen. ${ }^{251}$ Die BRD pochte unter Berufung auf entwicklungspolitische Prinzipien einer „Partnerschaft auf Augenhöhe“ ebenfalls auf geteilte Verantwortlichkeiten. 1977 bat das Ministerium für Manpower Development die BRD aus ausdrücklich finanziellen Gründen bevorzugt integrierte ExpertInnen zu entsenden: Hier musste Tansania keine vertraglichen Verpflichtungen für irgendwelche Partnerleistungen eingehen. ${ }^{252}$ In manchen

248 Zum Ansatz, die Lebensbedingungen nicht als statische Tatsache, sondern als aktiven Aushandlungsprozess zu untersuchen, siehe Uma Kothari, Spatial Practices and Imaginaries. Experiences of Colonial Officers and Development Professionals, in: Singapore Journal of Tropical Geography 27/3 (2006), S. 235-253.

249 BArch Berlin, DC 20/11525, Büttner (DDR-Konsulat Sansibar), Abschlussbericht Juli 1967-Juni 1970, Berlin, 30.6.1970, Bl. 72.

250 SAPMO BArch Berlin, DY 30/98149, [Redebeitrag von] Gen. O., o.O. [Sansibar], o.D. [9.3.1967], B1. 292.

251 URT, Annual Manpower Report to the President 1972, Dar es Salaam 1973, S. vii-x.

252 PAAA, ZW 119252, BRD-Botschaft an AA, Dar es Salaam, 1.6.1977, S. 4. 
GTZ-Projekten machten diese Partnerleistungen weiterhin mehrere Hunderttausend DM aus. ${ }^{253}$

Diese materiellen Fragen waren mit kulturellen und moralischen Argumenten überformt. In Tansania hatten expatriates den Ruf, einem luxuriösen Lebensstil zu frönen, der dem Lebensstandard der Mehrheit gegenüber unangemessen und dem Aufbau einer egalitären Gesellschaftsordnung abträglich war. Die materielle Ungleichheit machte den Einsatz von expatriates auch in kultureller Hinsicht bedrohlich: Verdienten expatriates nicht ein Vielfaches ihrer tansanischen KollegInnen und leisteten sich einen Standard, „der die Tansanier vor Neid erblassen“ ließ, wie zwei DED-Ingenieure meinten? ${ }^{254}$ Hatte man nicht „als Weißer einen Sonderstatus und Gründe, sich aus allem herauszuhalten“ und „durch die hohe Bewertung ihrer Person und Stellung“ von den eigenen Problemen in der BRD zu erholen? ${ }^{255}$ Wie sollten ausländische Fachkräfte mit einem höheren Lebensstandard Vorbilder für den Sozialismus tansanischer Art sein, der Bescheidenheit und Arbeitseifer predigte und individuelle Luxusträume als unmoralisch und unsozial verdammte? Wie sollten die Privilegien und Sonderbedingungen, was Importe und den Zugang zu Devisen anging, zum Aufbau einer gerechteren Gesellschaft im Einsatzland beitragen?

\section{Der Umgang mit materieller Ungleichheit}

Materielle Ungleichheit wurde in den Berichten von Entsandten in Bezug auf drei Gruppen thematisiert: im Verhältnis zu anderen EntwicklungsarbeiterInnen, im Verhältnis zu tansanischen KollegInnen und Counterparts sowie zur lokalen Mehrheitsbevölkerung. Tatsächlichen Handlungsbedarf lösten in der Regel nur jene Ungleichheiten aus, die Entsandte im Vergleich $\mathrm{zu}$ anderen Entsandten wahrnahmen. Die anderen Ungleichheiten wurden wahrgenommen und teils kritisiert aber - wie auch das obige Beispiel der DDR in Sansibar zeigt - nur bei Kritik von außen in vereinzelte Handlungsaufforderungen übersetzt. Jens Niederhuts These, dass bei den DDR-Reisekadern im Ausland „von sozialistischen Moral- und Lebensprinzipien [...] oft nicht mehr viel übrig“ blieb, lässt sich jedoch nicht pauschal bestätigen. ${ }^{256}$ Wie in der DDR selbst wurde mit den Prinzipien auf

253 Im Projekt NECO wurden diese Kosten etwa mit 314.000 DM kalkuliert, davon allein die vertraglich zugesicherten Urlaubsheimflüge für den kinderreichen Projektleiter mit 17.100 DM. BArch Koblenz, B 213/33089, Rinne/Hanusch (GTZ) an BMZ, Eschborn, 21.11.1980.

254 K./W., Praxiserfahrungen, S. 12.

255 Ebd., S. 15.

256 Niederhut, Die Reisekader, S. 81. 
verschiedene Art und Weise umgegangen; Regeln und Normen wurden zwar unterlaufen, aber blieben immer präsent. Dabei konnte nicht nur Konsum, sondern auch Sparsamkeit als Abkehr von diesen Prinzipien ausgelegt werden, wie auf einer SED-Sitzung in Dar es Salaam verdeutlicht wurde:

\begin{abstract}
Als Kommunisten sind wir [...] angehalten, Erscheinungen des Egoismus und eines übertriebenen persönlich materiellen Denkens und Handelns rechtzeitig entgegenzutreten. Jeder DDR-Bürger erhält eine ausreichende Auslandsvergütung, die in erster Linie dafür da ist, ein ordentliches und niveauvolles Leben unter den Landesbedingungen zu führen und nicht, um so viel wie möglich zu transferieren oder in andere Güter für die spätere Nutzung in der Heimat umzusetzen. ${ }^{257}$
\end{abstract}

Die disziplinierende Funktion wurde dabei nicht nur vom Botschaftspersonal ausgeübt, sondern war auch im Habitus mancher DDR-Fachkräfte eingeschrieben, die sich so wiederum als „prinzipientreue“ und „klassenbewusste“ Kader profilierten. Konfliktstiftend waren dabei nicht die Unterschiede zu externen Gruppen, sondern immer die Differenzen innerhalb von DDR-,Kollektiven“. In der DDR-Lehrergruppe in Moshi kam es zu einem Disput um die korrekte „Haltung zu materiellen Dingen“, der das illustriert. Anlass für Kritik war die folgende Äußerung des Lehrers M. beim Kauf einer Kühlbox: „Ja wenn du die zu Hause auspackst und noch eine Flasche Whisky herausholst, da tropft dem Kumpel der Zahn." Sein DDR-Kollege S. befand, M. sollte als sozialistischer Mensch ,auf die erreichte Arbeit stolz sein und nicht auf den Erwerb materieller Güter“. S. machte die Einstellungsfrage bei der nächsten Parteisitzung zum Thema und schaltete, da die Aussprache im Rahmen der Grundorganisation keine Klärung brachte, auch das DDR-Konsulat in Dar es Salaam ein. ${ }^{258}$

Allzu sparsames Verhalten konnte jedoch ebenfalls als Bruch der sozialen Reziprozitätsnormen ausgelegt werden, die jedes „Kollektiv“ für sich aushandelte. So zeigte sich ein Lehrer in Mbeya enttäuscht, als sein bereits in die DDR zurückgekehrter Kollege ,aus eingesparten Valutamitteln ein Auto kaufte, obwohl er in Mbeya stets beteuert hatte, keinen Schilling transferiert zu haben“. ${ }^{259} \mathrm{Ge}$ -

257 SAPMO BArch Berlin, DY 30/15207, Rechenschaftsbericht der Leitung an die Berichtswahlversammlung der GO der SED der Auslandsvertretung, Dar es Salaam, 24.10.1988.

258 BArch Berlin, DR 2/25494, Informationsbericht März/April 1970 [eigentlich: 1971], o.O., o.D., S. 3.

259 BArch Berlin, DR 2/25496, Lehrergruppe Ifunda an MfV, Zur Einschätzung der Ereignisse in Ifunda durch das MfV, o.0., 31.3.1972, S. 3; vgl. auch BArch Berlin, DR 2/25496, Lehrergruppe Ifunda an MfV, Zur Einschätzung der Ereignisse in Ifunda durch das MfV, o.O., 31.3.1972, S. 5. DDRExpertInnen bekamen ihr tatsächliches Gehalt nach einem speziellen Schlüssel berechnet und periodisch an die Lebenshaltungskosten (den „Warenkorb“) angeglichen von der DDR-Seite 
genseitige Anschuldigungen, in deren Zentrum die Aushandlung von Konsumnormen stand, waren wohl häufig nur Kristallisierungen bereits schwelender kollegialer Konflikte, deren Ursachen weitaus komplexerer Natur oder auch nur persönlichen Animositäten geschuldet sein mochten, aber jedenfalls schwerlich in anerkannte Sprachregelungen und Verhaltensvorschriften gekleidet werden konnten.

Folgen zog eine Überschreitung der geschriebenen und ungeschriebenen Verhaltensregeln bei Einsätzen vor allem dann nach sich, so Berthold Unfried anhand von Beispielen aus Lateinamerika und Afrika, wenn es im Umgang mit Geld, Alkohol oder bei intimen Kontakten (v. a. der Verkehr mit Prostituierten) und Konflikten innerhalb wie außerhalb des „Kollektivs“ zu einer Gefährdung der Außendarstellung der DDR kam. ${ }^{260}$ Multiple Verstöße gegen die Verhaltensregeln und das Ideal der sozialistischen Persönlichkeit - darunter auch Tabubrüche wie das häufige „Singen von Naziliedern“ auf Parties, wie es einem DDR-Lehrer von seinen KollegInnen vorgeworfen wurde ${ }^{261}$ - konnten bei Bedarf zu einem kumulativen Delikt gebündelt werden. Dies war der Fall bei einem Theaterwissenschaftler, der von 1968 an als erster DDR-Wissenschaftler mehrere Jahre an der Universität in Dar es Salaam tätig war. Ein nicht gemeldeter Kontakt zu Westdeutschen, die Mitnahme der Frau auf eine Dienstreise nach Kenia ohne Genehmigung, ihr „exaltiertes Verhalten“ und mangelnde „Verbindung zum Kollektiv“ machten das Generalkonsulat misstrauisch; außerdem zählte er „zu den bestbezahlten DDR-Bürgern in Tansania, hat aber bis heute noch kein Geld in die DDR transferiert, obwohl er und seine Frau fast keinerlei Aufwand treiben (Kleidung, Wohnung etc.)“. ${ }^{262} \mathrm{Da}$ das Verhalten des Paares als unkontrollierbar eingestuft wurde, durften beide nicht wieder einreisen. Die Einschätzung, dass bei dem Dozenten und seiner Frau multiple Verstöße gegen (meist ungeschriebene) Normen vorlagen, veranlasste die Vertretung dazu, ihren nächsten Heimaturlaub zur Endausreise zu machen.

ausgezahlt. Die tansanischen Partnerinstitutionen zahlten in den meisten Fällen den üblichen Lohn in tansanischen Schilling an Limex bzw. intercoop; dieser Lohn wurde dann von der DDR aufgestockt.

260 Unfried, Scènes de la vie quotidienne.

261 BArch Berlin, DR 2/25496, Lehrergruppe Ifunda an MfV, Zur Einschätzung der Ereignisse in Ifunda durch das MfV, o.O., 31.3.1972, S. 2.

262 PAAA, MfAA, B 279/74, Schreiben DDR-Generalkonsul Butzke an Helbing (Abt. IB im MHF), Dar es Salaam, 30.3.1970. Dass die Botschaft über diesen Umstand Kenntnis hatte, lag auch am Auszahlungsmodus. Die Gehälter wurden in der Handelspolitischen Abteilung der Botschaft „in namentlich gekennzeichneten Papiertüten aufbewahrt und ausgegeben“, nicht entnommene Beträge „verblieben routinemäßig in den Tüten“. E-Mail eines ehemaligen DDR-Kulturattachés an den Autor, 27.6.2016. 
Auch auf BRD-Seite kritisierten Entsandte jene Landsleute, die sich nicht den (eigenen) moralischen und entwicklungspolitischen Normen entsprechend verhielten. Gerade GTZ-ExpertInnen gerieten mit ihren zahlreichen Privilegien immer wieder in die Schusslinie von Kritik aus den unteren „Klassen“ der westdeutschen Entwicklungsarbeit. GTZ-ExpertInnen genossen Steuerfreiheit und das Recht, Autos und Haushaltsgeräte zollfrei einzuführen. Sie bekamen zusätzliche Gehaltsaufschläge, eine umfassende soziale Absicherung und Hilfe bei der Wiedereingliederung. ${ }^{263}$ Über die GTZ hatten sie breiten Zugang zu Netzwerken, Fachliteratur, Geldern und Hilfspersonal. Die sogenannten integrierten ExpertInnen hingegen, die ein direktes Dienstverhältnis mit einem Arbeitgeber im Gastland eingingen und auch von diesen bezahlt wurden, hatten wie WissenschaftlerInnen, die vom Deutschen Akademischen Austauschdienst (DAAD) entsandt wurden, viele dieser Privilegien nicht und beklagten sich wiederholt über fehlendes „materielles backing up“.264

Eine integrierte Expertin echauffierte sich in einem Denunziationsbrief an das BMZ über vergnügungssüchtige expatriates im Allgemeinen und einen GTZ-Experten im Besonderen, der zwar vorgebe, „sich für diesen Job aufzuopfern“, ihn privat aber als „Urlaub mit gutem Gehalt“ anpreise und umfassenden Devisenschwarzhandel betreibe. Die Botschaft, so schrieb die integrierte Expertin weiter, beobachte das „Treiben“ schon seit Langem, sei „aber machtlos dagegen“. ${ }^{265}$ Auch in anderen Fällen, z. B. bei der widerrechtlichen Verwendung von Dienst-

263 Details waren abhängig von den jeweiligen bilateralen Abkommen. Pollvogt, Zur Anatomie, S. $108-110$.

264 Siehe z. B. BArch Koblenz, B 213/33046, G.M. an GAWI, Dar es Salaam, 13.9.1972; ebd., B 212/ 23664, Dr. R. G., Department of Physics, UDSM, Tätigkeitsbericht 1972, Dar es Salaam, 14.12.1972; ebd., B 212/59064, Niesel (DAAD), Vermerk über eine Besprechung mit deutschen Wissenschaftlern, die zur Zeit durch den DAAD gefördert an der University of Nairobi lehren, Nairobi, 28.1.1976. Ab 1980 war das Centrum für internationale Migration und Entwicklung (CIM) zuständig für diese Aufgaben, wobei aber auch der DAAD integrierte Fachkräfte im akademischen Bereich unterstützte. Ende der 1980er Jahre wurde in der BRD das „entwicklungspolitische Instrument“ der TZDozentur eingerichtet, also eine Mischung aus Technischer Zusammenarbeit und DAAD-Dozentur, die aber in Tansania bis 1990 unbedeutend blieb. Ein Dozent bzw. eine Dozentin kostete etwa 300.000 DM für zwei Jahre und die Empfängerländer waren oft wenig geneigt, „Professoren gegen Traktoren“ zu tauschen. Siehe DAAD-Archiv, B 212/91255, Vermerk über Besprechung am 29.1.1987 beim DAAD, S. 4. Siehe auch DAAD-Archiv, B 212/91255, Vermerk über Besprechung am 29.1.1987 beim DAAD; ebd., B 212/91255/2, DAAD an GTZ, Arbeitsvorschlag für TZ-Dozenturen, Bonn, 17.4. 1989.

265 BArch Koblenz, B 213/33100, E. Wulf an BMZ, Dar es Salaam, o.D. [1981]. Der tatsächliche Absender dieses Briefs ist ungeklärt; die integrierte Expertin gleichen Namens stritt ab, ihn verfasst zu haben. Entscheidend ist hier jedoch, dass - und wie - die Kritik vorgebracht wurde. 
fahrzeugen für private Jagdausflüge, blieb es bei Ermahnungen. ${ }^{266} \mathrm{GTZ}$, BMZ und Botschaft bemühten sich um die Einhaltung von Dienstvorschriften und einer Aufrechterhaltung des „Ansehen[s] der deutschen Entwicklungshilfe“ zu gewährleisten, überließen Konsumpraktiken, die Anstellung von Hauspersonal und ähnliche Fragen jedoch völlig dem eigenen Ermessen der Entsandten. Die häufigen Klagen über verschlechterte Lebensbedingungen in Tansania ab Anfang der 1970er-Jahre gingen meist von ExpertInnen aus und belegen, dass viele von ihnen nicht gewillt waren, von ihren Konsumgewohnheiten abzurücken. Augenscheinlich übersteigerte Erwartungen an Tansania führten einen GAWI-Experten 1974 zur Warnung,

nicht wie ich einen guten Arbeitsplatz aufzugeben, Möbel und Auto zu verkaufen, nur um einen Arbeitsplatz in einer ,Buschwerkstatt“ (ohne Toiletten übrigens) einzuhandeln und das in einem Lande wo es außer chinesischer Zahnpasta, local [sic] hergestellter Seife keinerlei sonst selbstverständlich erscheinende Toilettenartikel gibt. ${ }^{267}$

Dieser GAWI-Experte wurde von der deutschen Botschaft als gänzlich untauglich für einen Einsatz in Tansania eingestuft. In der Expertenentsendung wurden jedoch auch „Härtezulagen“ und Containerlieferungen zum Ausgleich von lokalen Versorgungsproblemen eingeführt; außerdem achtete die GTZ-Zentrale bei Einsätzen in Tansania zunehmend darauf, dass eine Bereitschaft zu Einbußen im Lebensstandard vorhanden war. Im Vergleich zu alternativen Einsatzorten schnitt Tansania gerade in den 1980er-Jahren schlecht ab. Das kapitalistische Nachbarland Kenia, wo GTZ-ExpertInnen - von ihren Pendants in Tansania aus gesehen „wie die Maden im Speck“ lebten, während im Land der sozialistischen self-reliance „gedarbt“ werden musste, ließ schon die bloße Anwesenheit im Lichte einer persönlichen Aufopferung erscheinen. ${ }^{268}$ Neben Versorgungsproblemen standen Einbruchskriminalität, Stromsperren, Wasserknappheit, unzureichende sanitäre Dienste und materielle Arbeitsbedingungen auf der Mängelliste. ${ }^{269}$

266 Hier spielten vor allem die rechtlichen Eigentumsverhältnisse eine Rolle, im vorliegenden Fall gehörte das Fahrzeug einem staatlichen tansanischen Unternehmen. Der betreffende GTZExperte war als General Manager dieses Unternehmens eingesetzt. BArch Koblenz, B 213/33089, Wiegmann (BMZ) an GTZ, Bonn, 9.2.1981.

267 BArch Koblenz, B 213/7679, P. D. S. an GAWI, Clausthal, 21.5.1974.

268 Interview \#8, GTZ-Expertin; PAAA, ZW 114925, BRD-Botschaft an AA, Dar es Salaam, 24.6. 1974; BArch Koblenz, B 213/7679, Rudolog (Leiter des Wirtschaftsdienstes der BRD-Botschaft) an GAWI, Dar es Salaam, 18.6.1974.

269 Siehe z. B. BArch Koblenz, B 213/7680, Wolfgang Kreuser, Aufbau der Ingenieurfakultät Dar es Salaam, Stand 1.10.1974, S. 9. 
In Interviews hingegen erinnerten sich DDR- wie BRD-Entsandte in meist verklärenden und romantisierenden Tönen an ihren Einsatz und beschrieben die „Jagd“ nach bestimmten Nahrungs- und Konsumgütern eher als eine Art Spiel, ${ }^{270}$ was ein deutlicher Hinweis darauf ist, dass expatriates lautstark über Versorgungsprobleme und die zunehmende Erschwerung des Zugangs zu sozialen Dienstleistungen klagen mochten, diese Tatsachen aber nicht annähernd solche Auswirkungen auf sie hatten wie auf ihre tansanischen Counterparts. In medizinischer Hinsicht etwa konnten viele Entsandte auf die Behandlung durch GTZ-, DED- und FDGB-ÄrztInnen zählen. Ein während der 1980er-Jahre an der Ingenieurwissenschaftlichen Fakultät tätiger Dozent aus der BRD befand im Interview, dass die bäuerliche Bevölkerung ja eigentlich „toll“ vom Subsistenzanbau leben konnte und niemand in Tansania hätte hungern müssen. Er selbst habe aus Prinzip nur tansanische Güter gekauft, was ihn auf eine Stufe mit den „tansanischen Leuten“ gesetzt habe. Gleichzeitig räumte er aber ein, und hier wird der Statusunterschied deutlich, dass die Gehaltszuschläge für ihn unverzichtbar gewesen seien („nur Uni-Gehalt hätte ich nicht haben wollen“). ${ }^{271}$ Grundsätzlich, und das belegt neben dem Statusunterschied auch gänzlich separate Alltagswelten, staunten westliche ExpertInnen in den 1980er-Jahren darüber, wie die Bevölkerung in Tansania während der Wirtschaftskrise überleben konnte, warum es keine Aufstände gab, warum es nicht zur „Katastrophe“ kam. ${ }^{272}$

Die Standards verschoben sich durch Anpassungen und Inflation immer wieder. Ein DED-Pharmazeut verdiente 1977 etwas weniger als seine KollegInnen aus Dar es Salaam; 1984 verdienten DED-LehrerInnen für die Verrichtung derselben Arbeit hingegen mehr als fünf Mal so viel wie ihre tansanischen KollegInnen. ${ }^{273}$ Auf Expertenebene ließ es sich konstant weitaus komfortabler leben, aber auch unter GAWI- bzw. GTZ-Personal kam es bisweilen zu Selbstkritik, wenn die Relationen in den Blick kamen. Die Diskrepanz zwischen lokalen Bedingungen und eigenen Ansprüchen wurde etwa 1973 auf einer Konferenz bundesdeutscher Projektleiter in Ostafrika thematisiert, stark beeinflusst durch die Kritik, die im tansanischen Diskurs zirkulierte. Ein Konferenzteilnehmer meinte, deutsche

270 Interview \#101, GTZ-Experte und -Projektleiter.

271 Interview \#105, BRD-Dozent (Lokaler Vertrag mit GTZ-Gehaltsaufstockung).

272 Interview \#96, GTZ-Projektleiter. Forschungen kommen zu dem Schluss, dass persönliche Netzwerke und parallele Märkte längst die Versorgungsfunktion des Staates übernahmen: Deborah Bryceson, Food Insecurity and the Social Division of Labour in Tanzania 1919-85, London 1990, S. 216.

273 Interview \#68, DED-Entwicklungshelfer; Privatarchiv S. R., [Educational Papers, Articles], o.A. [DED-Entwicklungshelfer], Bericht über meine Erfahrungen in der Usagara Sekundarschule in Tansania, o.O., o.D. [1984], S. 8. 
Experten würden ,immer weniger in dieses sozialistische Land [gehen], da deren Lebensstandard zu hoch sei“; ein anderer Experte wies darauf hin, dass die Kosten der Expertenwohnungen oft höher seien als die Gesamtaufwendungen für den einheimischen Counterpart. Diskutiert wurde auch ohne eindeutiges Ergebnis ob expatriates ein hoher Lebensstandard überhaupt zustehe und inwiefern „Neidgefühle“ der „Afrikaner“ gegenüber den Experten berechtigt seien. Der anwesende BMZ-Vertreter brachte eine vergleichende Perspektive ein und meinte, dass alle diese Fragen keineswegs tansaniaspezifisch waren. ${ }^{274}$ Der Begriff „Neid“, der auch in anderen Berichten immer wieder auftaucht, ${ }^{275}$ verhüllte die strukturellen Ungleichheiten, die zur ungleichen Bezahlung trotz gleichwertiger Qualifikation und Tätigkeit führen und verlagerte das Problem auf die individuelle Ebene, nämlich in die vermeintliche emotionale Inkompetenz oder charakterliche Unreife des jeweiligen individuellen Counterparts.

Mehrere interviewte TansanierInnen räumten ein, dass sie keine genaue Kenntnis darüber hatten, wie viel die deutschen Entsandten verdient hätten, schätzten aber, dass es sich um das Zehn- bis Hundertfache ihres eigenen Verdienstes handelte. Nur jene, die selbst höhere Leitungsspositionen bekleidet und z.T. selbst mit Gebern verhandelt hatten, sahen die Ungleichheit überhaupt nicht als Problem, sondern griffen ebenfalls auf das individualisierende Neid- und Aufopferungsmotiv zurück. Ein langjähriger Counterpart für GTZ-ExpertInnen, ein tansanischer Entwicklungsplaner, der durch die Arbeit seines Vaters auf einer Sisalplantage schon seit seiner Kindheit mit europäischem Personal vertraut war und dann beruflich über Jahrzehnte hinweg mit expatriates Umgang hatte, lobte die Aufopferungsbereitschaft mancher GTZ-ExpertInnen, die unter einfachsten Bedingungen lebten, mit Kohlen kochten, Wasser aus dem Brunnen holten und in einem kleinen Haus lebten, das nur wenige Stunden am Tag mit Strom versorgt wurde: „Ich rechne ihnen das hoch an, weil das Leben, das sie hier geführt haben, in Deutschland für niemanden akzeptabel wäre.“276

Für Entwicklungspersonal mit Expertenrang waren diese Lebensbedingungen und Verzichtgesten keinesfalls üblich. Aus Berichten von und über DEDEntwicklungshelferInnen sind hingegen zahlreiche Beispiele überliefert, die einen bewussten Verzicht auf Autos oder gar Motorräder, auf (für lokale Verhältnisse) luxuriöse Unterkünfte oder Hotelbesuche als Praktiken beschreiben, eigene

274 BArch Koblenz, B 213/7675, Krumbein, Bericht über Projektleitertagung in Dar es Salaam, Bonn, 8.3.1973.

275 Siehe z.B. K./W., Praxiserfahrungen.

276 Interview \#84, Tansanischer Entwicklungsplaner. Im Original: „Mimi nawasifu sana kwa sababu maisha ambayo walikuwa wanaishi hapa huwezi kusema mtu anaweza kukubali kuishi hivi Ujerumani hapana.“ 
Privilegien zurückzuweisen, um sich besser in die Gastgesellschaft integrieren zu können. Dem folgten jedoch oft Schilderungen, wie diese Strategie bei Counterparts und in der Umgebung auf Unverständnis stieß und an eigenen Komfortbedürfnissen oder einer vorrangigen Beachtung der Arbeitseffektivität scheiterte. ${ }^{277}$ Die moralischen Ansprüche erschlafften, wurden als nicht praxistauglich verworfen oder als naiv zurückgewiesen. Die Status- und Komfortkurve zeigte daher im Verlauf des Aufenthaltes bei allen Entsandten im Allgemeinen nach oben, nicht nach unten. Auch manche Achtundsechziger machten sich die Ansicht zu eigen, dass eine allzu starke „Anpassung an die Kultur“ den Respekt, der einem als expatriate entgegengebracht werde, verringere. ${ }^{278}$ So erhielten die meisten einen vergleichsweise hohen Lebensstandard - selbst angesichts der Warenknappheit.

Drei Versorgungskanäle sorgten dafür, dass die EntwicklungsarbeiterInnen aus beiden deutschen Staaten keinen akuten Mangel leiden mussten: neben (1) Importen aus Deutschland bzw. über internationale Versandhäuser, (2) die staatliche Zuteilung von Lebensmitteln über Botschaft und Arbeitsplatz sowie (3) der Austausch in raum-, nations- und statusübergreifenden Reziprozitätsnetzwerken.

BRD-BürgerInnen regelten Importe meist privat und in Eigenregie. Die opulenten Importe von Entsandten der „Entwicklungshilfe“ und der „Humanitären Hilfe“ sind spätestens seit den 1980er-Jahren ein klassischer Gegenstand von Polemik und Satire westlicher Diskurse. Ganze Haushaltseinrichtungen vom Kühlschrank bis zur Klopapierrolle, von einer „Komfortzelle im Busch“ schrieb etwa die Schweizer Journalistin Isolde Schaad, ließen sich EntwicklungsarbeiterInnen zusenden. ${ }^{279}$ DDR-BürgerInnen bezogen essenzielle Konsumgüter wie Mehl, Reis, Zucker, Konserven, Waschpulver, Seife und andere grundlegende Güter über die Versorgungsinstitution Ausland (Versina), die etwa vierteljährlich mit der DDR-Handelslinie per Schiff in Dar es Salaam eintrafen. In Zeiten tansanischer Versorgungskrisen kamen sämtliche Nahrungsmittel mit Ausnahme von Fleisch, Obst und Gemüse aus der DDR und Drittländern. Die DDR-Vertretung versorgte ihr diplomatisches Personal und (in begrenzterem Maße und erst ab den 1980er-Jahren) Auslandskader über die dänische Peter Justesen Company, dem größten Versandhaus für zoll- und steuerfreie Waren für das weltweite diploma-

277 Jäger, Shida kweli; Schaad, Knowhow am Kilimandscharo.

278 Interview \#122, GTZ-Experte.

279 Schaad, Knowhow am Kilimandscharo, S. 25. Siehe auch den Bestseller dieses Genres: Graham Hancock, Lords of Poverty. The Power, Prestige, and Corruption of the International Aid Business, Boston 1989. 
tische Korps. ${ }^{280}$ Als für mehrere Jahre kein Vertreter von Intercoop in Tansania präsent war, beschwerten sich DDR-Entsandte zunehmend über die „Probleme in der Absicherung der materiellen Lebensbedingungen“. ${ }^{281}$ Als Referenzpunkt durften in solchen Situationen natürlich nicht die westlichen expatriates gelten; erfolgversprechender war es, im Windschatten einer bereits erfolgten Erhöhung bei den sowjetischen KollegInnen $\mathrm{zu}$ argumentieren. ${ }^{282}$

Staatliche Zuteilungen federten die zu Krisenzeiten auftretende Warenknappheit ebenfalls ab und bedeuteten eine Privilegierung gegenüber der Mehrheitsgesellschaft. Im Gegensatz zum diplomatischen Korps hatte das Entwicklungspersonal üblicherweise keine direkten Anrechte auf die Waren, die den Botschaften und Konsulaten von der tansanischen Regierung zugeteilt wurden. Um die Arbeitsfähigkeit (und Präsenz am Arbeitsplatz) von staatlichen Angestellten und expatriates zu sichern, richtete die Regierung jedoch Sonderkontingente ein, um diesen Gruppen das stundenlange Anstehen für Reis oder Zucker zu ersparen. Der Zugang zu diesen Zuteilungen hing in erster Linie vom institutionellen Kapital ab: Wer in einem etablierten Projekt arbeitete, kam vergleichsweise leicht an die Versorgungsgüter, die für expatriates abgezweigt wurden. Mit der entsprechenden Genehmigung (kibali) war auch der Direkteinkauf bei staatlichen Betrieben und in Fremdwährungsgeschäften möglich. ${ }^{283}$ EntwicklungsarbeiterInnen, die nicht in großen und etablierten Projekten tätig waren, mussten sich allerdings ebenfalls - so Anfang der 1980er-Jahre in der Tanga-Region - zu Schwarzmarktpreisen im privaten Handel eindecken. 1982 wurde dieses System reformiert und eine zentrale Verteilung durch die Kooperativen-Läden vorgenommen, es kam aber weiterhin zu Ungleichheiten zwischen den 180 expatriateFamilien in der Region, von denen einige ihre Beziehungen (z. B. zu den Managern der staatlichen Unternehmen) spielen ließen, um die Richtlinien zu umgehen und Extrazuteilungen zu erhalten. ${ }^{284}$ Gerade der Status kapitalintensiver Projekte half, von den bereits erwähnten Zuteilungen zu profitieren. Einige tansanische Counterparts, die zu dieser Zeit in Tanga tätig waren, betonten die Hierarchien zwi-

280 Bols, Ende der Schweigepflicht, S. 158.

281 BArch Berlin, DR 3/2. Schicht/1514, P.K., Abschlussbericht über den Einsatz in der VR Tansania (September 82 bis Dezember 85), Zwickau, 3.2.1986.

282 SAPMO BArch Berlin, DY 30/15205, Sekretär GO DSM an Abt. Int. Verbindungen, ZK der SED, DSM, 18.9.1984.

283 Interview \#68, DED-Entwicklungshelfer.

284 Tanga Library, VDP [General Correspondences], TIRDEP Executive Manager an Regional Trade Officer, Tanga, 16.5.1983. 
schen expatriates und TansanierInnen einerseits sowie unter TansanierInnen andererseits, die sich in diesen Verteilungspraktiken wiederspiegelten. ${ }^{285}$

Der Austausch in privaten Reziprozitätsnetzwerken war eine mit diesen ungleichen Zuteilungen oft verknüpfte, aber auch eigenständige Möglichkeit, an Waren zu gelangen. Selbst hochbezahlte und devisenstarke GTZ-ExpertInnen verfolgten während der Versorgungskrise haushaltsübergreifende Subsistenzstrategien, um einen hohen Konsumstandard zu erhalten. Ein GTZ-Experte an der Universität Dar es Salaam etwa teilte mit seinen Nachbarn - einem tansanischen Chemie-Professor und einem Norweger - eine Kuh für die Milchversorgung. ${ }^{286}$ Besonders präsent in den Interviews waren Beschaffungsnetzwerke für Alkoholika; so nehmen Anekdoten über Wein von der französischen Botschaft oder seltene Glückstage, an denen „einer mal eine Flasche Sekt organisieren konnte“, in den Erinnerungsgemeinschaften breiten Raum ein. ${ }^{287}$ Das regelmäßig mit DDRSchiffen in Tansania einlangende Rostocker Hafenbräu zirkulierte ebenfalls durch die Netzwerke und fand seinen Weg über tansanische MittlerInnen auch in die Hände westdeutscher Entsandter. ${ }^{288}$ Staatliche und private Quellen spielten in der Erhaltung des Lebensstandards also ebenso eine Rolle wie nationale und transnationale Netzwerke.

Die Warenbeschaffung erschöpfte sich nicht im Konsum an sich, sondern reichte oft wieder in die professionelle Tätigkeit hinein. Der Zugang zu bestimmten Luxusgütern und die Bereitschaft, diese wieder zu „investieren“, war eine hervorragende Voraussetzung für die weitere vertikale und horizontale Vernetzung im sozialen Feld. Das Sammeln von Prestigepunkten durch Partys war eine populäre Methode, um ein gutes Arbeitsklima mit Vorgesetzten, PolitikerInnen, KollegInnen und Counterparts zu schaffen. „Feiern war oft viel wichtiger für die Arbeit als verschwitzt im Büro zu sitzen“, meinte ein Polytechnikberater über die Empfänge, die er mit Samosas, gegrilltem Ziegen- oder Schweinefleisch (abhängig davon, ob Muslime anwesend waren) und Gin und Schnaps von der DDR-Botschaft ausrichtete. ${ }^{289}$ Für angemeldete ,auslandsinformatische Aktivitäten“, wozu auch privat ausgerichtete Feiern zählten, stellte das DDR-Außenhan-

285 So etwa in diesen Äußerungen: „We used to get this. Of course not equivalent to what the mzungu is getting. A little bit less. You were not entitled to what they were getting.“ (Interview \#52, Tansanischer Landwirtschaftsexperte); „Expatriates were getting each and everything because of them being expatriates. And we also, when it goes down, there are differences. But those essential food items, we were given. “ (Interview \#16, Tansanischer Entwicklungsplaner)

286 Interview \#101, GTZ-Experte und -Projektleiter.

287 Interview \#106, GTZ-Experte.

288 Interview \#68, DED-Entwicklungshelfer; Interview \#117, DDR-Bildungsberater.

289 Interview \#117, DDR-Polytechnikberater. 
delsunternehmen Alkoholika zur Bewirtung der Gäste bereit. Eine richtiggehende Konvertierungskette verschiedener Kapitalarten schildert der DDR-Tierarzt Müller in seinen Erinnerungen. Für die kostenlose Behandlung von Haustieren westlicher expatriates bekam er, da er eine Bezahlung ablehnte, Getränke, die für ihn als devisenarmen DDR-Auslandskader unerschwinglich gewesen wären. Er konnte seinen Mangel an ökonomischem Kapital so durch kulturelles und soziales Kapital ausgleichen, um dann mit hochwertigen Alkoholika in seinem Haus Empfänge zu geben und Kontakte zu den lokalen politischen Entscheidungsträgern aufzubauen. ${ }^{290}$

DDR- und BRD-EntwicklungsarbeiterInnen ließen sich von TansanierInnen aber (insbesondere ab Mitte der 1970er-Jahre) in deren Strategien zur Einkommensdiversifizierung ${ }^{291}$ einspannen und waren Quellen für Startkapital, Devisen und Transportmöglichkeiten. Ein DDR-Planungsberater etwa wurde von seinem Kollegen davon überzeugt, seine Vorstellungen von Arbeitsdisziplin zu lockern und die privaten Einkommensstrategien zu unterstützen:

\begin{abstract}
Da sagt er, „Jetzt brauche ich dein Auto, jetzt müssen wir mal zum Flughafen fahren“, da sind wir während der Arbeitszeit zum Flughafen gefahren. An sich hätte ich das gar nicht alles gedurft. Aber, na ja, ist ja keiner da, der kontrolliert. Da sind wir rausgefahren zum Flughafen, und dann sind wir in die Stückgutabfertigung rein. Und dann kam jemand raus mit einem Wagen voll mit Küken, 500 Küken oder so (lacht). Da habe ich die ganzen Küken ins Auto gemacht, und dann sind wir rausgefahren zu seiner shamba da. Und dort haben wir dann die Küken ausgeladen. Oh, der war happy, der verkaufte nämlich - die haben ja auch nicht viel verdient, im ministry, der war studiert, aber trotzdem. Und da hat der seine Küken innerhalb von einem halben Jahr schlachtreif großgezogen und hat die an die Hotelketten verkauft. Der hat praktisch mit seinen Küken mehr verdient als mit seinem Beruf dort. „Ja“, sagt er, „ohne die Küken könnte ich gar nicht leben.“292
\end{abstract}

Zwei aus Tansania in die BRD zurückgekehrte Ingenieure beklagten 1979 im Magazin des links ausgerichteten Freiburger Informationszentrums 3. Welt hingegen einen „Warenfetischismus“, der das „Konsumangebot in den Industrieländern als Vorbild für gesellschaftlichen Fortschritt und Reichtum“ betrachte und auch jeglicher Verständigung im Weg stehe:

Dass es gesellschaftliche und soziale Probleme in den Industrieländern gibt, ist für die Tansanier unvorstellbar. Deshalb ist die eigene politische Anschauung und sind auch die Gründe für das Eintreten des politischen Programms Tansanias kaum zu vermitteln. [...] Hinter der Kontaktfreudigkeit von Tansaniern zu Europäern steht oft der Wunsch, darüber

290 Müller, Als DDR-Tierarzt in Tansania.

291 Siehe detailliert hierzu Tripp, Changing the Rules.

292 Interview \#21, DDR-Regierungsberater. 
Konsumgüter „Made in Europe“ zu erwerben. Berufliches und politisches Interesse sind bei den Kontakten zweitrangig. So wird man um alle möglichen Dinge gebeten; Uhren und Bluejeans sind die Hauptrenner, aber auch Schuhe, Kassettenrecorder, Maurerkellen und Wasserwaage „Made in Germany“ sind gefragt. [...] Der Entwicklungshelfer wird so zu einem personifizierten Werbeträger der Industriestaaten und trägt unbewusst dazu bei, einen Begriff von Entwicklung zu vermitteln, der sich am Standard der industrialisierten Länder orientiert. An diesen Tatsachen ändert auch die Haltung und das politische Verständnis des Entwicklungshelfers nichts. ${ }^{293}$

Ihre Kritik an einem Gesellschaftsmodell, das auf Massenkonsum basierte, fiel auf keinen fruchtbaren Boden. Die Versuche tansanischer KollegInnen, Zugang zu knappen und hochqualitativen Gütern zu erlangen, deuteten die beiden Ingenieure als Orientierung am Standard der westlichen Länder und letztendlich auch als eine Art falsches Bewusstsein, da sich dieses Begehren an einem unpassenden oder sogar grundlegend problematischen Entwicklungsmodell ausrichte. In dieser Perspektive stehen die Ingenieure als Individuen dem Kontext machtlos gegenüber; der Effekt ihres Einsatzes wird als das genaue Gegenteil ihrer Intention dargestellt. Die Schweizer Journalistin Schaad diagnostizierte nach mehreren Gesprächen mit Schweizer Linken in Tansania ein ähnliches Syndrom der Handlungsunfähigkeit: „Der alte Achtundsechziger kann die Verhältnisse brillant analysieren, aber er ist nicht fähig, sie zu leben, weil sie ihn ungewollt in ein Herrund-Knecht-Verhältnis zwingen. [...] Problembewusstsein ermöglicht nicht die bessere Praxis, Problembewusstsein schafft Probleme im Feld. Es verhindert eine natürliche Beziehung zu Menschen anderer Herkunft und anderen Standes““. ${ }^{294}$

DDR-Auslandskader sahen sich ebenfalls mit Erwartungen materieller Transfers konfrontiert, gingen damit aber anders um: Manche Wünsche konnten sie aus Devisen- bzw. Warenmangel in der DDR selbst nicht erfüllen, andere durchaus. So erinnerte sich ein Jurist an eine „Wunschliste“, die er bei jedem DDRUrlaub mit sich führte: „Manche dachten, du kommst aus dem Schlaraffenland. [...] Und da dachten die alle, ich bin aus dem Westen. Kofferradios, Uhren, und lauter solches Zeug, Schuhe. Was ich greifen konnte. [...] Das habe ich gerne gemacht. Das war- Die Freude! [...] Und alles an Sachen habe ich weitergeschenkt.“295 Bisweilen wurden Geschenke an tansanische KollegInnen oder Hausangestellte in den Berichten von DDR-Auslandskadern sogar als individuelle Solidaritätsleistungen deklariert.

293 K./ W., Praxiserfahrungen, S. 15; ähnlich: Krebs, Neema, S. 53-54.

294 Schaad, Knowhow am Kilimandscharo, S. 38-39.

295 Interview \#20, DDR-Universitätsexperte. 
Tansanische InterviewpartnerInnen äußerten sich durchgehend anerkennend über die materiellen Transfers auf persönlicher Ebene. Ein bereits seit 1979 für eine deutsche politische Stiftung tätiger Fahrer etwa erinnerte sich an einen Auslandsbüroleiter dieser Stiftung, der ihm nach mehreren gemeinsam verbrachten Arbeitsjahren zum Abschied seinen privaten Wagen überlassen hatte. Angesichts der restriktiven Importbedingungen für Ersatzteile und zu erwartender hoher Unterhaltskosten veräußerte der Fahrer den Wagen direkt an einen deutschen Angestellten der Stiftung. Mit dem Verkaufserlös konnte der Fahrer nicht nur den Bau eines halben Hauses finanzieren, sondern auch eine Hühnerzucht etablieren, um die sich dann seine Frau kümmerte und deren Erlös in die Fertigstellung des Hauses investiert wurde. Weitere MitarbeiterInnen der Stiftung stellten ihm zusätzlich Kredite und ein Fahrrad zur Verfügung. ${ }^{296}$ Viele GTZ-ExpertInnen beteiligten sich privat an Ausbildungskosten für Kinder tansanischer FreundInnen und KollegInnen, zumindest ab den 1980er-Jahren, als Teile des Bildungswesens wieder privatisiert wurden. ${ }^{297}$ Die Patronagebeziehungen dauerten im Fall mancher westdeutscher EntwicklungsarbeiterInnen sogar noch zum Zeitpunkt der Feldforschungen (2014) an, etwa in Form der Kostenübernahme für die Ausbildung von Kindern in befreundeten Familien. $\mathrm{Zu}$ diesen zählten bisweilen auch die Familien der ehemaligen Hausangestellten. Für ostdeutsche Entsandte war die Aufrechterhaltung von Beziehungen nach Tansania aufgrund der Kontaktbeschränkungen deutlich schwieriger und unüblich.

Zusammenfassend lässt sich feststellen, dass sich der Lebensstil vieler DDRKader in Tansania und Sansibar nur in manchen Aspekten wesentlich von dem ihrer westlichen Experten-KollegInnen unterschied. Mit Ausnahme der integrierten ExpertInnen war allen Entsandten der BRD und der DDR gemeinsam, dass sie (trotz verschiedener Entlohnungsstufen und Befugnisse) materiell abgesichert waren und durch die Entsendeorganisation institutionelle Rückendeckung hatten. Finanzielle Aspekte - gerade die geringere Verfügbarkeit von Devisen - und ein enges Korsett von Verhaltensregeln setzten sowohl der sozialräumlichen Distinktion wie auch der Integration Grenzen. Das „Kollektiv“ wurde in erster Linie durch hierarchisierte Rituale und Austauschbeziehungen geschaffen, die auch die Bindung an die DDR konservieren und ideologische Uniformität garantieren sollte. Es handelte sich beim „Kollektiv“ auch um einen Raum der Geselligkeit und der materiellen Versorgung, der gleichzeitig zur gegenseitigen Überwachung und Produktion konformen Verhaltens diente, darunter auch der hohe Erwartungsdruck, an Gemeinschaftsaktivitäten zu partizipieren.

296 Interview \#38, Tansanischer Fahrer einer bundesdeutschen politischen Stiftung.

297 Interview \#94, GTZ-Verwaltungsfachkraft. 
Gleichermaßen eröffnete der Auslandseinsatz in Tansania jedoch auch gänzlich neue Erfahrungsmöglichkeiten und bot Handlungsspielräume, die von vielen genutzt wurden. Kleinere „Kollektive“ jenseits der Kontrolle durch die Botschaft schufen einen eigenen modus vivendi, in dem Parteitreffen oder DDR-Feiertage fast keine Rolle mehr spielten. Am Arbeitsplatz und am Wohnort pflegten viele DDR-Auslandskader internationale Kontakte und unterhielten bisweilen sogar Freundschaften mit „Klassenfeinden“ aus der BRD oder den USA. Der zwangsläufige Weg zurück in die DDR bedeutete allerdings, dass sie keine kosmopolitischen Eliten im Stile mancher westlicher EntwicklungsexpertInnen werden konnten. Das persönliche Verhältnis zu Tansania als einem temporären Gastland war daher unter allen DDR-Entsandten relativ homogen. Das war im Interesse der DDR-Führung, die einen proletarischen Internationalismus auf der Basis einer stabilen Identifikation mit dem Herkunftsstaat vertrat, der sich nicht mit Aspirationen zum Weltbürgertum vertrug.

Beim westdeutschen Personal hingegen lässt sich in ein breiteres Spektrum konstatieren, das von Tansaphilie und Versuchen des going native bis hin zum Berufsnomadismus mit transnationalem Habitus reicht, in dem Tansania nur ein „Entwicklungsland“ neben anderen war. ${ }^{298}$ Die „BRD-Kolonie“ war in erster Linie ein Ort zum Informationsaustausch und hatte fließende Übergänge zu Kontaktund Bewegungsräumen anderer westlicher expatriates. Sie war kein Disziplinierungsraum in dem Sinne, wie es das DDR-Kollektiv war und auch weniger von hierarchischen Unterstellungsverhältnissen durchzogen. In Disziplinierungsfragen spielten eher die konkreten Anstellungsverhältnisse eine Rolle, während das Privatleben weitgehend unreguliert blieb.

Wie in anderen Einsatzländern schotteten sich selbst integrationswillige und aufgeschlossene DED-EntwicklungshelferInnen häufig ab. ${ }^{299}$ Kontakte zu TansanierInnen waren stark von Statusunterschieden und materiellen Ungleichheiten geprägt. Den Umgang mit diesen Ungleichheiten und den eigenen Privilegien in persönlichen Beziehungen empfanden westdeutsche Entsandte oft als Dilemma, während Ostdeutsche solche Erfahrungen kaum erwähnten und sich in der Regel auch nicht als privilegiert wahrnahmen. Der DED-Lehrer Malte Koos schrieb 1971, kurz nach seiner Rückkehr, dass er wie viele seiner KollegInnen vom Gefühl geplagt wurde, in „zwei Jahre[n] der verpaßten Gelegenheiten“ zu viel in der „Entwicklungshelfer-Clique [...] herumgesessen“ zu haben und mehr Energie in De-

298 Diese Begriffe orientieren sich an den Ausführungen von Florian Kreutzer/Silke Roth, Einleitung, in: Florian Kreutzer/Silke Roth, Hg., Transnationale Karrieren: Biografien, Lebensführung und Mobilität, Wiesbaden 2006, S. 7-31, hier: S. 15-17.

299 Vgl. Karola Elwert-Kretschmer/Georg Elwert, Mit den Augen der Béniner. Eine Evaluation von 25 Jahren ded in Bénin, in: Africa Spectrum 26/3 (1990), S. 335-350. 
batten über den eigenen Komfort („Unterhaltsgeld, die Mopeds, die Wohnung“) als in die entwicklungspolitische Wirksamkeit oder ein tatsächliches Kennenlernen des Landes investiert zu haben. Am Ende blieb für ihn die Frage: „Etwa 40 Studenten habe ich das Wissen für die Techniker-Prüfung beigebracht. War das alles? Ist das Entwicklungshilfe?““. ${ }^{300}$ Der Auslandseinsatz führte in vielen Fällen nicht zu einer Klärung von Fragen, sondern warf neue Probleme auf. Auf den folgenden Seiten wird die Entwicklungsarbeit mit ihren widersprüchlichen Rollenerwartungen und strukturellen Ungleichheiten anhand dreier zentraler Praxisbereiche - Transferieren, Disziplinieren und Politisieren - untersucht. Im Zentrum stehen dabei die Versuche, Diskrepanzen zwischen Anspruch und Wirklichkeit, Direktiven und eigenen Interessen zu überwinden. Gerade in den Counterpartbeziehungen zeigen sich jedoch die Dilemmata der Entwicklungsarbeit besonders deutlich.

\subsection{Entwicklungshandeln}

Der Einsatz ausländischen Personals galt zugleich als Voraussetzung und Bedrohung tansanischer Entwicklungsstrategien. Expatriates wurden einerseits als notwendig erachtet, um Projekte zu realisieren und Personallöcher in Wirtschaft, Verwaltung, Bildungs- und Gesundheitswesen zu stopfen. Das barg Risiken, darunter die Perpetuierung und Verstärkung der Abhängigkeit von außen, verbaute Aufstiegsmöglichkeiten für Counterparts sowie Ineffizienz aufgrund von Sprachproblemen und abweichender Standards. In einem Begleitschreiben zum Manpower Report an den Präsidenten im Jahr 1988 führte der Minister für Manpower Development C. T. Kassanji fünf Gründe an, warum Tansania fast drei Jahrzehnte nach der Unabhängigkeit in personeller Hinsicht noch immer auf expatriates angewiesen war. Erstens, so Kassanji, gebe es nach wie vor kein Vertrauen in die Fähigkeiten tansanischer ExpertInnen. Die Präsenz ausländischer Fachkräfte fördere dieses Misstrauen. Zweitens seien den meisten expatriates keine Counterparts zugeordnet, und wenn doch, dann hätten diese sich mit der frustrierenden Realität abzufinden, dass sie materiell benachteiligt seien und kaum relevantes Wissen vermittelt bekämen. In anderen Fällen seien die Zuordnungen rein nomineller Natur ohne Auswirkungen in der Praxis. Drittens fehle es an Weiterbildungsprogrammen und viertens an einer Institution, die die weitere Nationalisierung überwachte. Fünftens schließlich knüpften viele Geber die

300 Malte Koos, Irgendwie haben wir es doch geschafft, in: Ulrike Ries, Hg., Entwicklungshelfer. Deutsche in der Dritten Welt, Hannover 1971, S. 145-157, hier: S. 156. 
Vergabe materieller Hilfe an die Entsendung von Personal, das in erster Linie die Verwendung der Ressourcen überprüfen sollte. ${ }^{301}$ Nicht immer also seien expatriates aus einem „Wissensmangel“ heraus notwendig, stattdessen erfüllten sie Kontrollfunktionen für Geber und Investoren - und erhielten damit asymmetrische Machtbeziehungen aufrecht.

Kassanjis Beobachtungen decken sich in vielen Punkten mit dependenztheoretischen und postkolonialistischen Kritiken am Einsatz von Entwicklungspersonal. Wie bei Kassanji angedeutet, geht es in dieser Perspektive um ein Bündel negativer Auswirkungen, darunter sozialpsychologische (den „Afrikanern“ wird nach wie vor Inkompetenz unterstellt, während expatriates, insbesondere „Weiße“, als qualifiziert gelten), wirtschaftliche (Investitionen und Entwicklungsgelder werden an die Entsendung von Personal gebunden, das die Implementierung überwachen soll; expatriates empfehlen die Technologien ihrer Herkunftsländer) und politisch-diplomatische (Widerspruch kann schwerwiegende Folgen wie z.B. Entzug von Fördergeldern haben, Entscheidungen und Vorschläge werden daher möglichst den expatriates überlassen). Die Intentionen der einzelnen Beteiligten gelten hierbei - aufgrund der zugrunde liegenden Machtstrukturen - als irrelevant. ${ }^{302}$

Ob Entsandte zur Vertiefung von Abhängigkeiten oder zur Erlangung von selfreliance beitrugen, lässt sich jedoch nicht pauschal beurteilen: Es machte durchaus einen Unterschied, welche Position die oder der Einzelne im entwicklungspolitischen Feld einnahm und wie die Counterpartbeziehungen gestaltet wurden. Die Counterpartbeziehungen verdienen nicht zuletzt deshalb mehr Aufmerksamkeit, weil die Interessen und Positionen der tansanischen Counterparts keinesfalls homogen waren. Der Begriff des Counterparts - in seiner breiten Definition - bezieht sich auf jene Beteiligten einer entwicklungspolitischen Intervention, die eine repräsentative Funktion für das Empfängerland bzw. dessen Institutionen einnehmen. ${ }^{303}$ Politische Delegierte können also ebenso als Counterparts fungieren wie Verwaltungskräfte und sekundiertes oder angestelltes Personal. Der Begriff fasst im breiteren Sinn Counterparts nicht nur als fachliche KollegInnen in der Einsatzinstitution, sondern auch als AnsprechpartnerInnen in

301 URT, Annual Manpower Report to the President 1985, Dar es Salaam 1988, S. 48-49. 302 Philip G. Altbach, Damned if You Do - Damned if You Don't: Counterparts, Neocolonialism, Dependency and the International Balance of Power, in: Irving J. Spitzberg, Hg., Exchange of Expertise: The Counterpart System in the New International Order, Boulder 1978, S. 65-80.

303 Hubertus Büschel/Daniel Speich, Einleitung - Konjunkturen, Probleme und Perspektiven der Globalgeschichte von Entwicklungszusammenarbeit, in: Hubertus Büschel/Daniel Speich, Hg., Entwicklungswelten: Globalgeschichte der Entwicklungszusammenarbeit, Frankfurt/Main 2009, S. 7-29, hier: S. 8. 
politischen Aushandlungen und Verwaltungsvorgängen. ${ }^{304}$ Im engeren Sinn sind Counterparts Fachkräfte, die den expatriates direkt (als anzulernende Kräfte) oder als funktionale Äquivalente zugeordnet sind. Im Idealbild der geplanten Intervention sollen sie zukünftig jene Aufgaben wahrnehmen, die von den expatriates ausgeführt werden. Bis zum Rückzug der ausländischen Fachkraft obliegt dem Counterpart in dieser Konstellation die Rolle als Lehrling oder Zweitbesetzung. ${ }^{305}$ In manchen Fällen sind die zugeordneten Counterparts aber auch zu beratende Vorgesetzte, was gerade bei Regierungsberatern der Fall ist (siehe Kapitel 6). Selbst im engeren Sinn sind die Beziehungen also vielgestaltig.

In der offiziellen Partnerschaftsrhetorik der Entwicklungspolitik blieb ausgeblendet, dass Counterpartbeziehungen konfliktiv sein konnten und die Partner sich bisweilen gegenseitig als Störfaktoren, Konkurrenz oder Bedrohung wahrnahmen. Das hat strukturelle Ursachen. Kassanji verwies auf materielle Ungleichheiten und ungleich geschätztes Wissen. Der Anthropologe Thomas Bierschenk hat darauf hingewiesen, dass internationales und nationales Entwicklungspersonal sich in gänzlich anderen Handlungsrahmen bewegen. Die expatriates bewegen sich Bierschenk zufolge in einem technokratischen Handlungsrahmen, der auf die Regeln und Vorgaben der Entsendeinstitution hin orientiert ist, während die VertreterInnen der nationalen Bürokratie sich in einem klientelistischen Handlungsrahmen bewegen, dessen Fixpunkt die nationale politische Elite darstellt. ${ }^{306}$ Eine detaillierte Betrachtung der Handlungsrahmen zeigt aber, dass das entsandte Entwicklungspersonal auch selbst mit widersprüchlichen Erwartungen und Ansprüchen umzugehen hatte, die über den technokratischen Rahmen hinausgingen. Bierschenks Schilderung trifft zudem nur auf westdeutsche ExpertInnen im Projektkontext zu (der in Kapitel 8 besprochen wird). Für DDR-ExpertInnen, aber auch integrierte ExpertInnen und DED-EntwicklungshelferInnen in Tansania galt hingegen, dass sie oft in „Linienfunktion“ eingesetzt wurden, also eine reguläre Stelle in einer tansanischen Institution besetzten und sich - „[w]ie jeder andere Tansanier auch“- mit „ganz

304 In einem Überblick über die Einzelprojekte des regionalen Entwicklungsprogramms TIRDEP etwa ist für zwei Projekte nur je ein Counterpart angegeben, während in anderen sechs, 16 oder gar 59 verzeichnet sind - bei nie mehr als vier GTZ-Entsandten. Zusätzlich wurden tansanische MitarbeiterInnen extra gelistet, also nicht als Counterparts gezählt. BMZ, B 213/48200, TIRDEP SIPU Heft 7, TIRDEP [Overview], o.O., August 1988.

305 Im Entwicklungsjargon wird für die Aufgabe dieses Typs von Counterpart (der die Aufgabe vom expatriate übernehmen soll) auch der Begriff „to understudy“ gebraucht. Aus der Sprache des Theaters entlehnt beschreibt er die Aktivität der ErsatzdarstellerInnen, sich auf einen eventuellen Einsatz vorbereiten, wenn die Erstbesetzung ausfällt.

306 Thomas Bierschenk, Development Projects as Arenas of Negotiation for Strategic Groups: A case study from Bénin, in: Sociologia Ruralis 28/2-3 (1988), S. 146-160, hier: S. 153-154. 
normale[n] Aufgaben“ und den (meist tansanischen) Vorgesetzten, KollegInnen, Angestellten, SchülerInnen oder Studierenden zu arrangieren hatten. ${ }^{307}$ Sie hatten im Vergleich zu ExpertInnen im Projektrahmen keinen gesicherten Zugang zu institutionellem Kapital und Ressourcen, die im Rahmen von Projekten verfügbar wurden. Selbst ExpertInnen in Projekten waren aber in vielerlei Hinsicht von ihren Counterparts abhängig und hatten mit widersprüchlichen Rollenerwartungen umzugehen.

Ein Blick auf drei Aspekte der Counterpartbeziehungen erlaubt, die widersprüchlichen Rollenerwartungen und ihre Relevanz in der Praxis greifbar zu machen. Zuerst geht es um die Frage von Transfers. Während das Ideal vom expatriate als Berater den Wissenstransfer in den Vordergrund stellt, spielten in der Praxis materielle und finanzielle Transfers oft eine ebenso bedeutende oder sogar wichtigere Rolle als die Expertise - zumal „Expertise“ selbst keine stabile Größe darstellte. Ebenfalls eng an die institutionelle Einordnung gebunden war der Spielraum, wenn es um Disziplinierungs- und Politisierungsversuche ging. In allen diesen drei Aspekten - Transferieren, Disziplinieren, Politisieren - hatten tansanische Counterparts (im breiten wie im engen Sinn) großen Einfluss und stimmten keinesfalls immer mit dem Entwicklungspersonal aus der BRD und der DDR überein.

\section{Transferieren}

Das üblichste Praxismodell für den Verhaltenswandel durch entwicklungspolitische Interventionen ist der „Wissenstransfer“, der von einem Nord-Süd-Gefälle beim Wissen ausgeht, das - ganz entsprechend den Annahmen der Modernisierungstheorie - vom „fortschrittlichen“ Norden zum „rückständigen“ Süden fließen sollte. Wissenstransfers spielen die zentrale Rolle beim Verständnis von Entwicklungspersonal als Katalysatoren sozialen Wandels oder agents of change. Zwischen dem abstrakten Ideal von Wissenstransfers und den konkreten Beziehungen klaffte aber eine große Lücke, für deren Überwindung es keine allgemeingültigen Handlungsanleitungen gab. Aus der Perspektive tansanischer Counterparts in Projekten, aber auch in der Bürokratie waren Entsandte oft weniger für Wissenstransfers, sondern für die Anbahnung und Durchführung materieller Transfers von Bedeutung.

Ein zentrales Problem von den 1960ern bis in die 1980er-Jahre blieb der Counterpartmangel, insbesondere in Positionen, die eine hohe Qualifikation vor-

307 Interview \#28, Berater mit GAWI-Vertrag im Planungsministerium. 
aussetzten. Es fehlte an Fachkräften und aus Sicht der jeweiligen Vorgesetzten, die eher an Effizienz und schnellen Ergebnissen denn an langfristiger Nationalisierung interessiert waren, musste es widersinnig erscheinen, gleich mehrere der rar gesäten Fachkräfte auf ein und derselben Stelle einzusetzen. ${ }^{308}$ Expatriates fanden sich damit häufig ohne Counterpart und bisweilen in einer unerwartet verantwortungsvollen Position. Ein (wahrgenommener) Missbrauch des Einflusses barg allerdings die Gefahr, sich den Vorwurf einzuhandeln, der Nationalisierung tansanischer Institutionen entgegenzuwirken.

Eine grundlegende Frage war, inwieweit expatriates ausführende oder nur beratende Funktionen einnehmen sollten: Die Handlungsempfehlung von offizieller Seite schlug dabei oft eher in Richtung beraten, seltener in Richtung exekutieren aus. Schon 1966 aber stellte der westdeutsche Soziologe Bernward Joerges fest, dass die „goldene Regel“ der Technischen Hilfe, der zufolge ein Experte immer nur beratend wirken und nie in den Entscheidungsprozess eingreifen sollte, in der Praxis kaum aufrecht zu erhalten war, da sich „[d]ie tatsächliche Funktion des Experten [...] stark mit seinem Verhältnis zu den einheimischen Counterparts und im zeitlichen Ablauf“ ändere. ${ }^{309}$ Auf BRD- wie DDR-Seite kam es häufig vor, dass Entsandte zwischen beratenden und ausführenden Funktionen changierten. DDR-Entsandte nahmen jedoch das „Prinzip der Nicht-Einmischung“ in den meisten Fällen ernst und interpretierten es als Enthaltsamkeit in Bezug auf angebotene Führungspositionen und das Treffen wichtiger Entscheidungen. Aus DDR-Sicht war das Nichteinmischungsprinzip nicht nur Antwort auf afrikanische Emanzipationsbestrebungen und Ausdruck politischer Überzeugungen, sondern auch ein Sicherheitsnetz in Prestigefragen: Die Verantwortung für Misserfolge lag somit auf der tansanischen Seite. Auslandskader zögerten, repräsentative Entscheidungsfunktionen einzunehmen, selbst wenn derartige Anfragen von tansanischer Seite vorgebracht wurden. ${ }^{310}$ Ausnahmen konnten nur mit der Abwesenheit von Counterparts begründet werden. ${ }^{311}$

Bei der BRD gab die Frage der „funktionalen Einordnung“ - in Beratungsfunktionen einerseits oder exekutiven Leitungsfunktionen andererseits - wie-

308 Vgl. auch Hein, Die Westdeutschen, S. 171.

309 Bernward Joerges, Experten, in: Hans Besters/Ernst E. Boesch, Hg., Entwicklungspolitik. Handbuch und Lexikon, Stuttgart 1966, S. 1127-1135, hier: S. 1127-1128.

310 BArch Berlin, DR 2/25494, B., Informationsbericht Mai 1971, Dar es Salaam, 23.5.1971, S. 2. Vgl. auch Bettina Husemann/Annette Neumann, DDR - VR Angola: Fakten und Zusammenhänge zur bildungspolitischen Zusammenarbeit von 1975 bis 1989, in: Heyden, Ulrich van der u.a., Hg., Engagiert für Afrika: Die DDR und Afrika II, Münster 1994, S. 158-178, hier: S. 171-173.

311 Müller, Als DDR-Tierarzt in Tansania, S. 101. 
derholt Anlass für Kräftemessen auf diplomatischer Ebene. ${ }^{312}$ Das BMZ als Hüter der entwicklungspolitischen Relevanz versuchte - insbesondere ab Mitte der 1970er-Jahre - wiederholt, die als nachhaltiger erachtete Beratungstätigkeit durchzusetzen und so die Konsolidierung personeller Abhängigkeiten zu verhindern. ${ }^{313}$ Die Praxis war jedoch weniger von den ausgehandelten Stellenbeschreibungen als von den Verhältnissen, Erwartungen und Konstellationen vor Ort geprägt. Versuche der BRD, das Problem formalistisch zu lösen und Tansania in Abkommen über die Technische Hilfe zur Stellung von Counterparts zu verpflichten, schafften keine Abhilfe. Gerade bei Entwicklungsprojekten der GTZ zeigte sich auch, dass die tansanischen Behörden und staatlichen Unternehmen ab Mitte der 1970er-Jahre oft weniger Interesse an „Beratung“, sondern mehr an einer direkten Übernahme der Tätigkeit hatten - in der Erwartung, dass mit der personellen Unterstützung umfassende materielle Transfers einhergehen würden. $^{314}$

Die ExpertInnen mussten daher oft einen Balanceakt zwischen der Stellenbeschreibung einerseits und den Erwartungen von Counterparts wie tansanischen Vorgesetzten andererseits vollbringen. In solchen Fällen - weiter angetrieben durch Projektpläne und Ergebnisdruck - wurde oft ein hemdsärmeliger Macherhabitus wirksam, durch den sich die Entsandten immer mehr Kompetenzen aneigneten. ${ }^{315}$ Da ein Experteneinsatz aber immer auf Zeit angelegt war, „musst du von vornherein überlegen, wie du da wieder rauskommst“, so ein ehemaliger GTZProjektleiter. ${ }^{316}$ Das „Zurückschrumpfen“ in eine Beraterrolle, das dieser Projektleiter als Ideal ansah, gelang hingegen nur wenigen. Gerade jene ExpertInnen, die gegen ihren Willen abgezogen wurden, argumentierten mit Vorliebe, dass sie unverzichtbar geworden seien und ihr Abschied eine von tansanischen Counter-

312 Siehe z.B. BArch Koblenz, B 213/33081, Förstner (GTZ), Vermerk über die Dienstreise vom 8.8-12.8.1978, Eschborn, 18.8.1978.

313 BArch Koblenz, B 213/33081, Förstner (GTZ), Vermerk über die Dienstreise vom 8.8. bis 12.8. 1978, Eschborn, 18.8.1978, S. 3. Siehe auch Kapitel 6.1.

314 In einem Landwirtschaftsprojekt in den 1980er Jahren in der Tanga-Region etwa sah das BMZ für die GTZ-Experten eine Beratungstätigkeit vor, während die zu dieser Zeit extrem unterfinanzierte Counterpartbehörde für die Umsetzung zuständig sein sollte. Die tansanischen Verwaltungsspitzen hingegen erwarteten sich materielle Hilfe in Verbindung mit Management und Umsetzung durch die expatriates. BMZ, B 213/48195, RADO Heft 13, Project Manager Small Scale Irrigation Project an RDD, Fifth Half Yearly Progress Report, Tanga, 19.12.1986, S. 2.

315 Belege dafür liefert etwa eine psychologische Studie: Privatarchiv S. R., [PESP Kilimo Handouts + Dev. Articles], Andreas Bittner, Gespräche mit der Praxis, Auswertung von 35 Interviews mit unter Vertrag stehenden deutschen Fachkräften in der EZA, Wiesbaden, Mai 1984. Siehe auch Interview \#102, GTZ-Experte.

316 Interview \#102, GTZ-Experte. 
parts „nicht zu füllende Lücke“ hinterlasse. ${ }^{317}$ Die BRD-Botschaft berichtete 1987also nach fast drei Dekaden bundesdeutscher Personalentsendung - besorgt über die Tendenz, dass „sich unsere Fachkräfte zu ,Superstars“ entwickeln, die es dem einheimischen Counterpart erschweren, sich aufzubauen“. ${ }^{318}$ Das war vor allem der Fall in Projekten mit fünf, zehn oder noch mehr deutschen Fachkräften, wo die GAWI- bzw. GTZ-ExpertInnen die Umwelt des Öfteren als feindlich wahrnahmen, das Projekt gegen den Einfluss anderer Akteure abzuschirmen versuchten und Formen „autoritär angelegte[r] Willensbildung“ praktizierten. ${ }^{319}$ Die bereits zwei Jahrzehnte zuvor geforderte Abkehr vom autoritären „Schmalspurfachmann“ und seinem „bornierten Überlegenheitsgefühl“ in „der Tradition kolonialer Denkgewohnheiten“ war immer noch nicht vollzogen, die partnerschaftliche Teamarbeit eher die Ausnahme als die Regel. ${ }^{320}$

$\mathrm{Ob}$ es überhaupt ein Interesse gab, Wissen an Counterparts zu transferieren, hing auch vom Rollenverständnis ab: War Entwicklungsarbeit nur das Füllen temporär bestehender Fachkraft-Lücken oder mehr als das? Die zweite Achse in den Transfers nach dem Unterschied von Exekutieren oder Beraten wird durch den Unterschied von Integrieren oder Positionieren gebildet. Viele DED-EntwicklungshelferInnen verschrieben sich der Absicht, nur „solange es an tansanischen Fachkräften mangelt [...] zur Überbrückung [...] eingesetzt“ zu werden. ${ }^{321}$ Dementsprechend, so eine Entwicklungshelferin, nehme man „keinem Afrikaner die Verdienstmöglichkeit“, sondern fülle die Lücke lediglich so lange aus, wie die tansanische Seite dies benötigte und stehe damit den Emanzipations- und selfreliance-Bestrebungen nicht im Weg. ${ }^{322}$ DED-EntwicklungshelferInnen bezeichneten sich und die anderen in Tansania präsenten expatriates bisweilen demonstrativ als „Gastarbeiter“.323

Für die DDR-Außenpolitik galt die Besetzung von Lücken als Gelegenheit, Stellen „zu besetzen“ und so einen politischen und diplomatischen Einfluss zu

317 BArch Koblenz, B 213/33110, H. M. S.-F., Projektfortschrittsbericht Nr. 5/1980, Köln, 28.11. 1980.

318 BMZ, B 213/63790, BRD-Botschaft, Entwicklungspolitischer Zweijahresbericht Tansania, Dar es Salaam, August 1987, S. 12.

319 BArch Koblenz, B 213/7678, BRD-Botschafter Müllenheim an AA, Dar es Salaam, 19.7.1973.

320 Köhler, Zwischen den Welten, S. 48-49.

321 K./W., Praxiserfahrungen, S. 11.

322 Krebs, Neema, S. 10.

323 Der Begriff wurde auch für die Tätigkeit in anderen „Entwicklungsländern“ herangezogen. Siehe das Kapitel „Gastarbeiter in der ,Dritten Welt““ in Erhard Meueler, Hg., Unterentwicklung. Wem nützt die Armut der Dritten Welt? Reinbek 1974; Krebs, Ein tansanisches Tagebuch, S. 107; K./ W., Praxiserfahrungen, S. 11; Pater, Vorwort, S. 5. 
sichern. ${ }^{324}$ Ebenso hatten manche GAWI- bzw. GTZ-ExpertInnen, v.a. in der Wirtschaftsberatung das Ziel, ihre Position möglichst langfristig zu besetzen, um Geschäftskontakte aufrechtzuerhalten und durch ihre Präsenz das Vertrauen von Investoren $\mathrm{zu}$ stabilisieren, was auch dem Interesse tansanischer Manager entsprechen konnte (siehe Kapitel 6). Diese Logik stand im Gegensatz zum Grundprinzip der Technischen Hilfe, demzufolge sich die expatriates durch Wissenstransfer möglichst schnell überflüssig machen sollten.

Das hängt mit der dritten Achse zusammen: War entsandtes Personal für den Transfer von kulturellem oder ökonomischem Kapital zuständig? Ein westdeutscher Landwirtschaftsexperte betonte im Interview, dass seine Counterparts stets einen Vorsprung beim „lokalen Wissen“ hatten. Ausländische ExpertInnen mussten daher, was „moderne“ Technologien anging „immer die Nase ein bisschen vorn haben“, andernfalls wäre man als „überflüssig“ erachtet und nicht mehr respektiert worden. ${ }^{325}$ Den Wissensabstand zu wahren, um die eigene Position zu legitimieren - diese Strategie ist von akademischer Seite als „institutionalisierte Besserwisserei“ kritisiert worden, da sie die Rollenverteilung zwischen „entwickelte[m] Wissenden“ und „unterentwickelte[m] Lernenden“ festschreibe. ${ }^{326}$ Entwicklungspolitische Innovationen und Moden wie partizipative Ansätze und neue Planungsinstrumente, so etwa Uma Kothari, würden dazu beitragen, das Machtgefälle zwischen expatriates und Counterparts zu verstetigen statt zu überwinden. ${ }^{327}$

Mit einem Blick auf die Praxis ist die Annahme vom Wissensvorsprung weiter zu relativieren. Mehrere Entsandte mit Expertenstatus aus beiden deutschen Staaten erwähnten in Interviews und Berichten, dass sie in Tansania in Bereichen arbeiteten, in denen sie weder Fachwissen noch Erfahrung aufweisen konnten und sich die gefragten Kompetenzen erst aneignen mussten. Für tansanische Counterparts und KollegInnen - wenn sie vorhanden waren - gab es zudem häufig Lob und fachliche Anerkennung. Das Rollenspiel, in dem sich die expatriates stets als TrägerInnen fortschrittlichen und überlegenen Wissens präsentierten, wurde zu einer Farce, wenn der Counterpart gleichwertiges Wissen oder sogar mehr Erfahrungen besaß. So kritisierte ein tansanischer Landwirtschaftsexperte, der erst in der DDR und dann in Westberlin studiert hatte, dass uner-

324 Siehe z. B. BArch Berlin, DR 3/B 1383a/1b, DDR-Botschaft an MHF, Dar es Salaam, 4.9.1974. 325 Interview \#102, GTZ-Experte.

326 Philipp H. Lepenies, Lernen vom Besserwisser: Wissenstransfer in der „Entwicklungshilfe“ aus historischer Perspektive, in: Hubertus Büschel/Daniel Speich, Hg., Entwicklungswelten: Globalgeschichte der Entwicklungszusammenarbeit, Frankfurt/Main 2009, S. 33-59, hier: S. 33. 327 Uma Kothari, Authority and Expertise. The Professionalisation of International Development and the Ordering of Dissent, in: Antipode 37/3 (2005), S. 425-446, hier: S. 428. 
fahrene GTZ-ExpertInnen, die am Beginn ihrer Laufbahn standen, weiterhin den Vorzug vor ihm erhielten.

And some of them [expatriate experts from West Germany], we were doing the same course, in Berlin. Seminar für Landwirtschaftliche Entwicklung. But then there they come, they are like passing the information to you. [...] They did the same course, some of them later than myself, but then they would be considered experts. [...] [L]ike you still need to be trained and trained and trained. [...] You cannot be continued to be understudying somebody. Some of them come very junior. [...] And that is something which is still happening. ${ }^{328}$

Hier kommen Frustration, Entmutigung und Desillusionierung als psychologische und emotionale Konsequenzen der fortwirkenden Ungleichheit in den Fokus. Das Zitat weist auch darauf hin, dass es die (ökonomischen wie politischen) Machtmittel braucht, um die neuen Moden und den (teils nur vermeintlichen) Wissensvorsprung tatsächlich durchsetzen zu können. In den allermeisten Fällen waren die expatriates - wie oben bereits festgehalten - „mehr ein Ersatz für fehlende einheimische Fachkräfte als ,Ausbilder““, wie eine Evaluierung 1977 feststellte. ${ }^{329}$ In der Regel blieb auch unklar, welche Art von Wissen transferiert werden sollte. Mit Ausnahme genuiner Ausbildungsprojekte verlief die „Lehrlingsbeziehung“, was angesichts der sonstigen Planungs- und Ergebnisfixiertheit in der Entwicklungspolitik durchaus bemerkenswert ist, ungeplant. ${ }^{330}$

In der Praxis zeigte sich, dass Counterparts Wissenstransfers oft weniger Bedeutung beimaßen als materiellen Transfers. Expatriates und Counterparts waren in der Regel nicht gleicher Meinung, wenn es darum ging festzustellen, warum sich Entwicklungsprozesse nicht wie erhofft entfalteten. Counterparts nannten den Mangel an ökonomischem Kapital und Ausrüstung als größte Hürden, forderten also meist mehr materielle Ressourcen und modernste, kapitalintensive Technologien. Ausländische ExpertInnen hingegen betonten Expertisemangel und Verwaltungsprobleme - und rationalisierten damit auch die eigene Präsenz. ${ }^{331}$ Dementsprechend wurde auch die Rollenverteilung in den Counter-

328 Interview \#63, Tansanischer Landwirtschaftsexperte und späterer GTZ-Projektleiter.

329 BArch Koblenz, B 213/33062, Heinrich von Massow/Karsten Roger, Evaluierung von Entwicklungshilfeprojekten - TIB, Zürich und Buxtehude, März 1977, S. 48.

330 Altbach, Damned if You Do.

331 Privatarchiv S. R., [PESP Kilimo Handouts + Dev. Articles], Andreas Bittner, Gespräche mit der Praxis, Auswertung von 35 Interviews mit unter Vertrag stehenden deutschen Fachkräften in der EZA, Wiesbaden, Mai 1984, S. 8. Ähnlich die Ergebnisse einer quantitativen Studie, die in sechs westafrikanischen Ländern (1962-1975) durchgeführt wurde: Von den befragten Counterparts sahen $76 \%$ den Mangel an Ausrüstung oder Kapitalknappheit als Hauptprobleme für Entwicklungsinterventionen, während 79\% der expatriates administrative Mängel und Humanressourcen als zentrale bottlenecks identifizierten. Arye Globerson, Interaction between Foreign 
partbeziehungen unterschiedlich gesehen. Mehrere tansanische Counterparts erwähnten im Interview, dass die expatriates in fachlicher Hinsicht keinesfalls überlegen gewesen seien. ${ }^{332}$ Ihre Aufgabe sei eher gewesen, Ressourcen zu „bewachen“ (kuchunga), Verantwortung für die richtige Verwendung der westdeutschen Steuergelder zu übernehmen (kusimamia hela) und sicherzustellen, dass die finanziellen und materiellen Flüsse nicht versiegten. ${ }^{333}$ Die BRD hatte - wie die meisten westlichen Geber - ihre eigenen Spielregeln für den Erhalt von „Hilfe“ aufgestellt und die expatriates sorgten dafür, dass diese befolgt wurden. ${ }^{334}$ ProjektleiterInnen verwalteten Budgets, entschieden über Ressourcenallokation und stellten sicher, dass die Geberorganisation die Berichte im richtigen Format erhielt (siehe auch Kapitel 8).

Insbesondere durch die Ressourcenallokation waren expatriates keineswegs „neutrale“, externe Akteure, sondern in klientelistische und hierarchische Verteilungsnetzwerke eingebunden. Einer ehemaligen GTZ-Projektleiterin und späteren Gutachterin zufolge war es in den 1980er Jahren (und später) durchaus üblich, dass expatriates mit „Geschenken“ (zawadi, etwa Fahrzeugen für die Counterpartbehörde oder Stipendien für Studienaufenthalte) das Wohlwollen von Counterparts erwirkten, um die Projektziele zu erreichen oder persönliche Vorteile zu erlangen. ${ }^{335}$ Da nur ein geringer Teil der entsandten ExpertInnen Langzeitverträge besaß und die Posten oft projektspezifisch waren, beeinflussten persönliche Karriereinteressen zwangsläufig auch Diskussionen über Projektverlängerungen. ${ }^{336}$

Wiederholt beschwerten sich DDR-Auslandskader, dass westliche expatriates mit „Geschenken“ mühelos Sympathien gewannen, während sie auf bisweilen geradezu lächerlich wirkende symbolische Gesten wie die Überreichung von Wimpeln angewiesen waren, die Counterparts schwerlich von der Übelegenheit des Sozialismus der DDR und der Schlagkraft der Völkerfreundschaft überzeugen

Assistance Personnel and Local Counterparts, in: Irving J. Spitzberg, Hg., Exchange of Expertise: The Counterpart System in the New International Order, Boulder 1978, S. 159-179, hier: S. 174. 332 Interview \#56, Tansanischer Landwirtschaftsexperte, Counterpart und späterer Projektmanager.

333 Zum Beispiel Interview \#64, Tansanischer Veterinär; Interview \#51, Tansanischer Techniker und Abteilungsleiter; Interview \#80, Tansanischer Landwirtschaftsexperte.

334 Interview \#90, Tansanischer Ingenieur.

335 Interview \#6, GTZ-Projektleiterin.

336 Nur 7\% aller Entsandten der GTZ (ohne Jahresangabe, ca. Anfang der 1990er Jahre) hatten einen unbefristeten Vertrag. Köhler, Mittler zwischen den Welten, S. 63. 
konnten. ${ }^{337}$ Ein Ingenieur erinnerte sich an diese demütigende Erfahrung in seiner Tätigkeit für das Ministerium für Wasser- und Energiewirtschaft:

Sie als DDR-Bürger kommen dahin, sie sollen möglichst viel Geld verdienen, was sie selber nicht kriegen. Aber hinbringen dürfen Sie nichts. Und dann kommt die BRD, [...] gehen da ein und aus, und kommen mit Geschenken, und du machst deine Arbeit und stehst manchmal wie ein dummer Junge da. ${ }^{338}$

\section{Disziplinieren}

Ein weiterer essenzieller Teil der Praxis der Entwicklungsarbeit und Counterpartbeziehungen bestand in der „Pädagogisierung“ und „Disziplinierung derer [...], denen die Entwicklungsinterventionen gelten“. ${ }^{339}$ Während Wissenstransfers aus epistemologischen Gründen äußerst schwer nachzuweisen sind, ${ }^{340}$ lassen sich Disziplinierungspraktiken - die ebenfalls Lernprozesse und Verhaltensänderungen induzieren sollten - durchaus spezifizieren. Techniken der Planung, Überwachung und Belohnung dienten dazu, Verhaltensregeln ohne Zwangsmittel durchzusetzen - also „Disziplin ohne Unterdrückung“ zu installieren. ${ }^{341}$ Die allgemeinen Ansprüche an die Gestaltung der Counterpartbeziehungen ähnelten sich in beiden deutschen Staaten. Der (in der Regel männlich konzipierte) Experte sollte Berater statt Vorgesetzter oder Schulmeister sein und mit Überzeugungskraft statt Zwang eine Änderung von Verhaltensweisen erreichen. ${ }^{342}$ Was als zumutbare Disziplinierung oder Unterdrückung von wem durch wen wahrgenommen wurde, hing von der jeweiligen Position im sozialen Raum und eigenen Erfahrungen ab. Ein tansanischer Landwirtschaftsfachmann, der sowohl in der DDR als auch in der BRD studiert hatte und viele Jahre für die GTZ als Experte und

337 Interview \#121, DDR-Universitätsexperte; BArch Berlin, DR 2/51007, Leiter der Lehrergruppe S., Fortschreibung des Jahresberichtes zum Studienjahr 1981/82, Dar es Salaam, 2.6.1982.

338 Interview \#111, DDR-Experte im Ministry of Water and Energy.

339 Hacker, Queer entwickeln, S. 81-82.

340 Die Feststellung von Wissenstransfers ist äußerst komplex, denn sie setzt detaillierten Einblick in den Wissensstand vor und nach der Intervention voraus. Wenn in Interviews bestimmte Transformationen durch die Entwicklungsarbeit erwähnt werden, kommen meist auch frühere biografische Erfahrungen zur Sprache, die ebenfalls auf die erklärten Wissensformen oder Verhaltensweisen hindeuten - vgl. Kapitel 4 und Kapitel 8.

341 Eric Worby, „Discipline without Oppression“: Sequence, Timing \& Marginality in Southern Rhodesia's Post-War Development Regime, in: The Journal of African History 41/1 (2000), S. 101125.

342 Büschel, Hilfe zur Selbsthilfe, Teil II (Die Praktiker); Joerges, Experten, S. 1127-1128; Köhler, Zwischen den Welten, S. 48-49. 
Projektleiter tätig war, berichtete über die Gangart seiner westdeutschen KollegInnen im Projekt:

Some [GTZ] people would use very harsh- You know, the straight, forward way of Germans doing things. But it was not strange for me, because I had spent some seven years there. But some Tanzanians felt that the Germans were behaving like colonial masters. But by and large it was a very good working relationship with the Germans. ${ }^{343}$

In diesem Zitat sind drei soziale Positionen - die disziplinierenden (West-)Deutschen, tansanische KollegInnen, sowie ein eigener, kulturell hybrider Standpunkt - genannt, die in ein und demselben Raum koexistierten und ausgehandelt wurden. Hochrangige Counterparts - von denen die älteren noch koloniale Bildungsinstitutionen durchlaufen und im Ausland studiert hatten - teilten mit deutschen Entsandten generell die Ansicht, dass Ordnung und Arbeitsdisziplin Grundlage und Zeichen sozioökonomischen Fortschritts waren. ${ }^{344}$ Ein anderer Counterpart, ebenfalls Landwirtschaftsexperte mit einem Universitätsabschluss aus Leipzig, brachte diese Position im Interview auf den Punkt: „There is no soft in development. “345 Ein tansanischer Techniker befürwortete Planungs- und Überwachungstechniken als Voraussetzung von Effektivität: „Wenn es keine strikten Regeln gibt, die einen zwingen, kommt man nicht voran. “346 Für expatriates wie Counterparts gilt dabei die grobe Faustregel: Je höher die eigene Position und damit die Machtmittel, desto eher wurden Disziplinierungsmittel gutgeheißen und angewendet. Folgerichtig waren es vor allem jene, die diszipliniert wurden (bzw. werden sollten), die dieses Verhalten als koloniale Mentalität kritisierten. Ihre Erfahrungen legen nahe, dass es sich in der Entwicklungsarbeit um die fortgesetzte Universalisierung einer sehr partikularen Logik von Disziplin handelte.

Das moderne westliche (auch im Realsozialismus in vielerlei Hinsicht wirksame) Disziplinregime kann mit Karl Polanyi als ein Arrangement verstanden werden, das in erster Linie auf Produktivität, Effizienz und Profitabilität ausgerichtet ist. Die Herausbildung dieses Regimes setzte die Herauslösung marktförmiger Beziehungen aus den kulturellen und sozialen Netzwerken voraus, in die

343 Interview \#63, Tansanischer Student in der DDR und Doktoratsstudent in der BRD, späterer GTZ-Experte und -Projektleiter.

344 Eckert, Herrschen und Verwalten, S. 160-165, S. 256-258.

345 Interview \#78, Tansanischer Veterinär mit DDR-Studienabschluss.

346 Interview \#51, Tansanischer Techniker und Abteilungsleiter. Im Original: „Kama hakuna utaratibu ambao mkali wa kukubana hauwezi kwenda vizuri.“ 
sie zuvor eingebettet waren und die als Beschränkung gewirkt hatten. ${ }^{347}$ Alternative Disziplinregimes, die etwa Anstand, Gerechtigkeit oder ein nicht-ausbeuterisches Verhältnis zwischen Menschen oder zur Natur als Ziel hatten, wurden als Antithese zur westlichen Moderne aufgefasst. Expatriates sind als Outsider und Neuankömmlinge prädestiniert dafür, kulturelle und soziale Beschränkungen nicht zu erkennen oder in kolonialer Tradition als irrelevant, irrational oder rückständig zurückzuweisen. Der britische Sozialhistoriker E. P. Thompson, der sich ausführlich mit der Genese und Disziplinierung der englischen Arbeiterklasse auseinandergesetzt hatte, charakterisierte „Entwicklungshilfe“ als Versuch, die Disziplinierungsstrategien der europäischen Industrialisierung nun auch außerhalb Europas durchzusetzen. ${ }^{348}$ Tatsächlich vertraten viele Entsandte ein Selbstbild, das auf die Verbreitung von Selbstführungstechniken und Disziplinnormen des homo oeconomicus der kapitalistischen (und sozialistischen) Industriegesellschaft wie Pünktlichkeit, Ordnung, Sauberkeit und Verlässlichkeit ausgerichtet war. Mit der Achtundsechziger-Bewegung wurde dieses Regime jedoch einer grundlegenden Kritik unterworfen, sodass nicht davon ausgegangen werden kann, dass dieser Auftrag weiterhin universal geteilt wurde. ${ }^{349}$

Aus Berichten und Interviews lassen sich grundlegend drei Modelle herausarbeiten, die in der Entwicklungsarbeit zur Interpretation und Manipulation der Arbeitsdisziplin herangezogen wurden: ein kulturalistisches, ein materialistisches und ein idealistisches Modell. In der Praxis wurden diese Modelle je nach eigener Position und Anlass flexibel herangezogen, vermischt oder zurückgewiesen. Sie werden hier analytisch getrennt, um die Disziplinierungsräume abzustecken. Diese waren nämlich durch die Spielregeln des entwicklungspolitischen Feldes ebenso begrenzt wie durch die tansanische Ujamaa-Politik.

Im kulturalistischen Interpretationsmodell wird die Arbeitshaltung als Ergebnis kultureller Prägungen gedeutet. Hier wird zwischen Selbst- und Fremdbild eine scharfe Grenze gezogen und in der Regel auf rassistische Verallgemeinerungen und ein koloniales Deutungsrepertoire zurückgegriffen. Das kulturalistische Modell wies in der Praxis drei grundlegende Probleme auf. Erstens war es mit den Partnerschaftserwartungen inkompatibel, zweitens wurden „eigene“ und „andere“ Verhaltensweisen so strikt getrennt, dass Unterschiede innerhalb der postulierten Gruppen („Afrikaner“, „Europäer“) nicht erklärbar waren und drittens folgten daraus keine gangbaren Disziplinierungsmodelle - sieht man von einem kontraproduktiven Kulturrelativismus ab, der nahelegte, die „eigene“ Er-

347 Karl Polanyi, The Great Transformation. Politische und ökonomische Ursprünge von Gesellschaften und Wirtschaftssystemen, Berlin 2015 [1944].

348 Mass, Eine Art sublimierter Tarzan, S. 77 (Fußote 3).

349 Ebd., S. 88-89. 
wartungshaltung herunterzuschrauben (was einer Selbstdisziplinierung entsprach, die der Outputfixiertheit der Entwicklungsarbeit entgegenstand).

Konservative westdeutsche Entsandte zogen für die Deutung von „anderem“, also in der Regel unerwünschtem Verhalten unter anderem die hegelsche Figur des afrikanischen Kontinents als vorgeschichtlichen Ort heran und leiteten aus ihr ab, dass die „Partner“ weder Zeitgefühl noch historisches Bewusstsein besaßen, ihnen daher auch jegliches Verständnis für niedrigere Lebensstandards in der europäischen Vergangenheit fehle. ${ }^{350}$ Kulturalistische, hierarchisierende Diskurse wurden nicht nur in westlichen Schulbüchern (,Der Trieb zur Arbeit, wie wir ihn kennen, ist beim Afrikaner ursprünglich nicht groß“351) und Medien aktualisiert, sondern auch im Zuge jahrelanger Einsätze scheinbar „bestätigt“. In Interviews mit einigen ehemaligen GTZ-ExpertInnen kamen rassistische Behauptungen zur Sprache, dass „Afrikaner“ planungsunfähig seien, Geld immer nur konsumierten statt sinnvoll investierten, aus kulturellen Gründen zur Korruption neigten und ständig überwacht werden müssten (die fälschlich verallgemeinernde und damit kontrafaktische Natur dieser Aussagen wurde im Übrigen durch konkrete Beispiele in denselben Interviews widerlegt). ${ }^{352}$ In der DDR waren derartige rassistische Äußerungen tabuisiert und aus dem öffentlichen Deutungsrepertoire verbannt, aber freilich trotzdem durch ältere Literatur und Diskurse jenseits des offiziellen Skripts weit verbreitet. ${ }^{353}$

Linke EntwicklungshelferInnen stellten in Selbstreflexionen fest, wie tradierte Rassismen ihre Wahrnehmung selbst gegen den eigenen Willen strukturierten. Ein DED-Arzt bemerkte 1981, dass viele EntwicklungshelferInnen angesichts von Unpünktlichkeit, Materialmangel und Unzuverlässigkeit in eine Spirale von „Enttäuschung über das Land, Frustration, Abwehr“ gerieten, was sich „zum offenen Rassismus entwickeln“ könne. Obgleich er den Rassismus seiner DEDKollegInnen kritisierte, stellte er auch an sich selbst fest, nun leichter zu diskriminierenden Verallgemeinerungen zu neigen: „[Ich] spüre [...] in mir das, was ich an so vielen Entwicklungshelfern ablehne und wovor ich mich fürchte. “354 Das Gegengift bestand in zwei diskursiven Immunisierungsstrategien. Einerseits betonte er individuelle Unterschiede zwischen TansanierInnen und lobte, wie auch

350 Otto Schnellbach, Probleme der Menschenführung in Afrika (II), in: Überseepraktiker, I-II. Beilage zum Auslandskurier 10/3, 1969.

351 Theo Neufeld, Aktuelles Lehrmaterial über Technische Zusammenarbeit, in: Auslandskurier, 18/3 (1977), S. 10.

352 Interview \#101, GTZ-Projektleiter; Interview \#8, GTZ-Projektleiterin.

353 Siehe Landolf Scherzer, Die Fremden. Unerwünschte Begegnungen und verbotene Protokolle, Berlin 2002.

354 Jäger, Shida Kweli, S. 49. 
ein westdeutscher Arzt, seine KollegInnen als ,äußerst kompetent[e], [...] unermüdlich[e] Arbeiter“, andererseits hob er die Unzulänglichkeiten und Disziplinlosigkeiten von expatriates hervor (die bereits im Unterkapitel 5.2 angesprochen wurden). ${ }^{355}$ Damit versuchte er kulturalistische Deutungen aufzubrechen und die so scheinbar eindeutigen Trennlinien zwischen „eigenen“ und „fremden“ Arbeitshaltungen zu unterlaufen. Ebenso wie politisch links orientierte EntwicklungsarbeiterInnen aus der BRD grenzten sich auch DDR-Akteure (jedenfalls in öffentlichen Äußerungen) von Rassismen und Kulturalismen ab. Sie wählten jedoch bevorzugt das materialistische Register als Erklärungsmodus.

Das materialistische Interpretationsmodell deutet Produktivität und Arbeitsdisziplin als Funktionen materieller Bedingungen. Eine Handlungsempfehlung, die sich aus dem materialistischen Denken ableitete, war insbesondere die Einführung von Anreizen, etwa ein als adäquat erachteter Reallohn, die Erhöhung von Lohnnebenleistungen oder in den Sekundarschulen, eine Mitbestimmung über die Verwendung der Ernte von dem Feld, dass die SchülerInnen bestellten. Im weiteren Sinne wurden auch die materiellen Gegebenheiten außerhalb der Arbeitsstätte mit einbezogen: Mangelernährung, fehlende Transportmöglichkeiten oder die Notwendigkeit, einem Nebenerwerb nachzugehen, um die Familie zu ernähren. Eine DED-Lehrerin wies darauf hin, dass sie im Gegensatz zu ihren tansanischen KollegInnen „nicht lange anstehen [musste], um mal ein Kilo Zucker oder etwas Seife zu bekommen“ (weil sie „reichliche Sonderzuteilungen für Expatriates“ erhielt), nicht den langen Weg zur Schule gehen musste (weil sie ein Motorrad hatte), nicht auf den Eigenanbau von Mais und Gemüse angewiesen war (weil sie genug Geld für einen Restaurantbesuch hatte) und statt einem kleinen Zimmer, das auch die Familie mitbenutzte, ein ganzes Haus samt Arbeitsraum zur Verfügung hatte. ${ }^{356}$ In einem produktionsorientierten GTZ-Projekt wurde der „Hang zu Sitzpausen und ausgiebigem Palaver“ unter tansanischen Arbeitern vom Projektleiter nicht als Faulheit oder kulturelle Eigenheit, sondern als Ergebnis der schlechten Auftragslage gedeutet, zumal fehlendes Werkzeug und kaputte Maschinen jeden Arbeitseifer lähmten. ${ }^{357}$

Gerade FunktionärInnen bemühten mit Vorliebe das materialistische Interpretationsmodell, da es die diplomatischste, konsensfähigste und am wenigsten

355 BArch Koblenz, B 213/7679, Dr. V. J. S., Tätigkeitsbericht 1.12.1972-31.12.1973, Tanga, 30.1. 1974.

356 Landmann, Aufgeben oder durchhalten, S. 194.

357 BArch Koblenz, B 213/33089, P. E., Projektbericht (Zeitraum 15.9.1978 - 31.7.1980), o.O., 29. 8. 1980, S. 18. 
kontroverse Sichtweise war. ${ }^{358}$ Das Modell passte sich in das offizielle Skript des Partnerschaftsdiskurses ein, da die Ursachen in externen Faktoren und langlebigen Strukturen verortet wurden. Die materialistische Darstellung hatte durchaus Schnittmengen mit der kulturalistischen, nur dass Kultur hier als Funktion der Produktionsverhältnisse gesehen wurde. Der historische Materialismus, in dem DDR-Auslandskader und westdeutsche MarxistInnen geschult waren, legte nahe, dass eine disziplinierte Arbeitshaltung, gekennzeichnet durch Planung, Pünktlichkeit und Pflichtbewusstsein, das Ergebnis der Industrialisierung war. Diese longue durée überstieg freilich den knappen Zeithorizont von Personaleinsätzen. Gegenmaßnahmen mussten also zwangsläufig an einer Verbesserung der Bedingungen im direkten Umfeld der Intervention ansetzen.

Ideen für die Umgestaltung kamen in erster Linie aus dem eigenen Erfahrungshorizont. In der DDR war im Zuge der Wirtschaftsreformen der 1960er-Jahre ein „System der materiellen Hebel“ eingeführt worden, in dem die Leistung des Einzelnen auch individuell belohnt wurde. ${ }^{359}$ Im Versuch, materielle Eigeninteressen und eine sozialistische Gesellschaftsordnung in Einklang zu bringen, wurde „materiellen Stimuli“ in der praxisnahen Rubrik Propagandisten fragen - Wir antworten im SED-Journal Einheit 1966 eine „moralbildende[.] Bedeutung“ zugeschrieben. ${ }^{360}$ Ein egalitäres Gehaltsschema, in dem Qualifikation und Erfahrung keine Rolle spielten, wurde hingegen - auch über die wirtschaftliche Experimentierphase der 1960er Jahre hinweg - als „Gleichmacherei“ abgelehnt. Auslandskader versuchten, die ihnen bekannten Anreiztechniken zu exportieren. ${ }^{361}$ Die Brigade der Freundschaft auf Sansibar riet den Counterparts zur Steigerung der Produktivität zu „Normen für die wichtigsten Gewerke, Nachweissystem, Anreiz“, empfahl also eine Mischung aus Planungs-, Überwachungs- und Belohnungstechniken. ${ }^{362}$

Zur Umsetzung dieser Ideen waren die Auslandskader auf die Zustimmung relevanter Akteure vor Ort angewiesen. Die Funktionäre im sansibarischen „Rat der Jugendcamps“ stellten sich jedoch gegen eigenmächtige Versuche der DDRLehrausbilderInnen, „materielle Leistungsanreize“ einzuführen und „fleißige“

358 Mosler, Als DDR-Auslandskader in Mosambik, S. 65, S. 143; Interview mit Heinzjürgen Hagenmüller, Strausberg, 29.12.2015.

359 Stefan Wolle, Der Traum von der Revolte. Die DDR 1968, Berlin 2008, S. 18, 35-38, 47.

360 Toni Hahn/Gerhard Muth, Materielle und moralische Stimuli der Sozialistischen Arbeit richtig verbinden, in Einheit 21/7 (1966), S. 1081-1086, hier: S. 1083.

361 Die Durchführung eines „sozialistischer Wettbewerbs“ als Versuch, Methoden des Zwangs zu umgehen, findet sich auch bei Scherzer, Das Camp von Matundo, S. 66-67, S. 82.

362 SAPMO BArch Berlin, DY 24/19211, BdF Sansibar, „Einschätzung der gegenwärtigen Stellung und Rolle der Afro-Shirazi-Jugendliga in Zanzibar“, November 1970, S. 19. 
sansibarische Lehrlinge mit Leistungsprämien in Form von Geld oder Kleidung zu belohnen. ${ }^{363}$ Wenn EntwicklungsarbeiterInnen materielle Anreize wie Bonuszahlungen zur Verbesserung der Arbeitsdisziplin einführen wollten, stießen sie nicht nur in Sansibar, sondern auch am Festland unter Ujamaa auf den Widerstand egalitärer Gehaltsschemata und mussten folglich oft andere Methoden wie symbolische Anerkennungsgeschenke, die Inaussichtstellung von Stipendien oder Lohnnebenleistungen ausweichen. Für diejenigen wiederum, die diszipliniert werden sollten, bot sich dieses Modell an, um Forderungen nach materieller Unterstützung zu stellen (siehe Kapitel 7 und 8).

Das idealistische Interpretationsmodell als dritte Variante der Wahrnehmung und Veränderung von Disziplin hob auf die Frage der richtigen Einstellung ab und war in mancher Hinsicht eng mit dem kulturalistischen Modell verknüpft; so etwa die unter tansanischen Offiziellen in den 1970er Jahren weitverbreitete Ansicht, die staatliche Entwicklungspolitik „scheitere“ an Unwissenheit und Aberglaube der bäuerlichen Bevölkerung. ${ }^{364}$ Zusätzlich kam hier aber ein politisierender Aspekt hinzu. Wie in Kapitel 2 dargestellt, wurden Faulheit, Gammlertum und „unproduktive Tätigkeiten“ von Tansanias Elite genauso verdammt. Im Jargon von DDR-Berichten ausgedrückt handelte es sich dabei um „ideologische Probleme“, eine „reaktionäre Haltung“ oder den „falschen Klassenstandpunkt“. Unter Ujamaa galt, wie auch in der DDR, politische Erziehung als vielversprechendste Maßnahme, um die gewünschte Arbeitsdisziplin zu gewährleisten. Nicht nur TansanierInnen, auch Ujamaa-affine expatriates sahen politische Erziehung als probates Mittel zur Erhöhung der Produktivität. ${ }^{365}$ ArbeiterInnen, Angestellte und BeamtInnen mussten verstehen, dass der Sozialismus nur durch harte Arbeit bei gleichzeitiger Genügsamkeit zu erreichen war, durch maximale Produktion bei bescheidener, gemeinschaftsverträglicher Konsumption. ${ }^{366}$ Symbolische Auszeichnungen für herausragende Arbeitsleistungen und „sozialistische Wettbewerbe“, wie sie in der DDR üblich waren, wurden von der Partei in Tansania jedoch abgelehnt. Von den mittleren Ebenen des Parteiapparats wurden gelegentlich Bitten an die Parteiführung gerichtet, besonders fleißige Personen

363 Die Vorschläge durften nur in minimierter Form umgesetzt werden. Bericht der BdF Sansibar an den ZR der FDJ vom 1.4.1969, zit. nach Büschel, Hilfe zur Selbsthilfe, S. 472.

364 Schneider, Government of Development, S. 75.

365 CCMA, 1003 - Chuo cha Chama cha Kivukoni, Griffiths Cunningham/David Bleakley, Comments on a Report on Workers' Education written by Mr. Max Lemprecht [sic], o.O., 20.8.1968, Bl. 59; BArch Koblenz, B 213/33089, P. E., Projektbericht (Zeitraum 15.9.1978-31.7.1980), o.O., 29.8.1980, S. 10 .

366 Siehe z.B. A. N. Kweka, Political Education as a Tool for Socialist Transformation of a Society, in: Mbioni 8/8 (1977), S. 1-32. 
auszuzeichnen oder über das Radio zu ehren. Die Führung lehnte derartige Initiativen zur Ausrufung von „Helden der Arbeit“ jedoch als kontraproduktive Kampagnen ab. ${ }^{367}$

Damit zeigt sich, dass alle drei Modelle - das kulturalistische, das materialistische und das idealistische - auf Grenzen in der Umsetzbarkeit stießen. Viele deutsche EntwicklungsarbeiterInnen äußerten in Interviews, Berichten und autobiografischen Texten Unbehagen und Selbstzweifel und klagten über stark eingeschränkte Handlungsspielräume, wenn es um Fragen der Disziplinierung ging. Ähnlich verhielt es sich in Bezug auf die Politisierung - in diesem Bereich werden die oft widersprüchlichen Rollenerwartungen an das Entwicklungspersonal sowie die historisierenden Rechtfertigungsstrategien für die Praxis besonders deutlich.

\section{Politisieren}

Toni Weis hat am Beispiel der DDR-Beziehungen zur namibischen Befreiungsorganisation SWAPO vorgeschlagen, die DDR-Solidarität als eine politics machine zu verstehen. ${ }^{368}$ Damit stellt er das Argument des Anthropologen James Ferguson auf den Kopf, der („westliche“) Entwicklung als entpolitisierende anti-politics machine beschrieben hatte. ${ }^{369}$ Entwicklungsvorhaben, so Fergusons These, würden in technokratischer, apolitisch scheinender Rationalität daherkommen und globale Ungleichheiten ebenso ausblenden wie gesellschaftliche Machtbeziehungen. Wenngleich die vorgegebenen Interventionsziele oft unerreicht bleiben würden, führe die Intervention selbst aber doch $\mathrm{zu}$ einer Ausweitung der staatlichen Macht. Weis zufolge stellte die Politisierung internationaler Beziehungen und des Weltwirtschaftssystems hingegen einen zentralen Teil der Kooperation zwischen DDR-Stellen und der SWAPO dar - die zu diesem Zeitpunkt allerdings eine Befreiungsbewegung und noch nicht Regierungspartei eines unabhängigen Staates war. Wie aber gingen DDR-Auslandskader mit politischen Fragen und dem Zusammenhang von Entwicklungsmaßnahmen und Machtbeziehungen in einem unabhängigen Staat um? Die These der anti-politics machine lässt sich nicht nur für die Seite der DDR, sondern auch für den westlichen Kontext differenzieren. Einige westdeutsche Entsandte - gerade jene, die einen Freiwilligendienst ab-

367 CCMA, THQ/A.25/7/Vol. 2, Z. C. Maswi (TANU-Sekretär im Außenministerium) an TANU General Executive Secretary, o.0., 6.7.1970.

368 Toni Weis, The Politics Machine: On the Concept of 'Solidarity' in East German Support for SWAPO, in: Journal of Southern African Studies 37/2 (2011), S. 351-367.

369 Ferguson, The Anti-Politics Machine. 
solvierten - vertraten ein politisiertes Verständnis von Entwicklung und Personaleinsätzen, das im Gegensatz zu den DDR-Auslandskadern auch mit expliziter Kritik am eigenen Entsendestaat sowie dem Modell einer industrialisierten Konsumgesellschaft verbunden war. ${ }^{370}$ Marktwirtschaftliche wie antikapitalistische Politikentwürfe beruhten dabei immer auch auf bestimmten Geschichtsbildern.

DED-EntwicklungshelferInnen wiesen offensiv auf die Widersprüche der politischen und wirtschaftlichen Praxis der BRD hin: Wie sollten sie Partei für die „Dritte Welt“" ergreifen und Solidarität mit den Armen üben können, wenn die BRD gleichzeitig Diktatoren stützte und Handelsbeziehungen mit Staaten unterhielt, die von Kolonial- und weißen Minderheitsregimen regiert wurden? In der Wächtersbacher Resolution, die DED-Personal und EntwicklungshelferInnen 1970 verabschiedeten, galt die Entwicklungshilfe - und damit auch die Entsendung durch den DED selbst - als Praxis, die Abhängigkeiten konsolidierte. ${ }^{371}$ Mit der Wächtersbacher Resolution war ein selbstkritisches Tätigkeitsbild etabliert, das sich aber bereits vom Determinismus der radikalen Kritik abgrenzte. Die radikale Kritik mit ihrer These, dass Entwicklungshilfe per se imperialistisch sei, blieb eine Minderheitenmeinung: Die Mehrheit der EntwicklungshelferInnen vertrat gemäßigtere Positionen oder war überhaupt unwillig, sich an derartigen theoretischen Diskussionen zu beteiligen. ${ }^{372}$

Der politischen Betätigung in den Zielländern war durch den Imperativ der Nichteinmischung in interne Angelegenheiten ein Riegel vorgeschoben. Aktivistische DED-Freiwillige in Tansania nahmen trotzdem in Eigenregie Kontakt zu Befreiungsbewegungen auf und veröffentlichten ein Interview mit dem FRELIMOGründungsmitglied Marcelino dos Santos, in dem dieser die BRD für ihre Waffenlieferungen an Portugal und damit auch die Verlängerung des Kolonialkrieges verurteilte. Das Interview wurde in der tansanischen Presse veröffentlicht, an 60 deutsche Zeitungen geschickt und sorgte für Missstimmung in Bonn. ${ }^{373}$ Bei einer DED-Versammlung in Sambia setzte Minister Eppler zur Standpauke gegenüber den eigensinnigen Freiwilligen an und mahnte, dass „überall in der Welt [...] eine Einmischung in Angelegenheiten des Gastlandes die Ausweisung zur Folge“ habe und er nur für den DED eintreten könne, wenn dieser „nicht Untergrund-Arbeit leiste“. Anderenfalls, so drohte er, werde er die Auflösung des DED veranlassen. ${ }^{374}$ Gesellschaftliche Veränderungen, so Eppler in einem Interview mit dem Nach-

370 Jennings, Surrogates of the State, S. 202; Hein, die Westdeutschen.

371 Hein, Die Westdeutschen, S. 211.

372 Ebd., S. 146, 185, 222; Büschel, Hilfe zur Selbsthilfe, S. 348.

373 Der Spiegel 38/1971, Häßliche Deutsche, 13.9.1971.

374 PAAA, B58-IIIB2/1069, Vermerk über ergänzende Einzelheiten des Besuchs von Bundesminister Dr. Eppler in Sambia und Tansania, Bonn, 29. Juli 1971, S. 5-6. 
richtenmagazin Der Spiegel 1971, könnten nur „in Form konkreter Projektarbeit, nicht durch politische Agitation“ erreicht werden - was an die bereits erwähnte DDR-Vorgabe erinnert, dass die Entsandten die „politische Wirksamkeit“ in erster Linie durch ihre fachliche Tätigkeit realisieren sollten. ${ }^{375}$

Auch aktivistische Entsandte des DED waren in dieser Hinsicht angehalten, ihre politisierenden Aktivitäten einzuschränken. Ein Überblick des Auswärtigen Amtes über Botschaftsberichte aus dem Jahr 1972 konstatierte, dass „Schwierigkeiten“ durch „sozialrevolutionäre Ideen“ eine Seltenheit seien. ${ }^{376}$ Oft war hier weniger die Disziplinierung von oben, sondern die Konfrontation mit den Komplexitäten der Praxis ausschlaggebend. In einer Einleitung zu gesammelten Erinnerungen von DED-EntwicklungshelferInnen hieß es 1971, dass sich die „ehrgeizigen humanitären und politischen Ziele [...] vielfach auf alltägliche, konzeptionslose Handwerkelei“ reduzierten. Der „friedliche Revolutionär“ des DED, der soziale Transformationen und Bewußtwerdungsprozesse anstoßen sollte, war „in Wirklichkeit häufig ein von der Bevölkerung isolierter, selbst hilfloser und enttäuschter Einzelkämpfer“, schon damit ausgelastet, eine Nische und Tätigkeitsfeld zu erschließen, um „sich irgendwo nützlich machen zu können. ${ }^{377}$ Am Ende stand gerade bei idealistisch motivierten EntwicklungsarbeiterInnen eine gewisse Ernüchterung. Die hohen entwicklungspolitischen Erwartungen, die an die eigene Tätigkeit gestellt wurden - das bereits erwähnte Wirksamkeitsmotiv - blieben unerfüllt. ${ }^{378}$ Bisweilen wurde die eigene Wirksamkeit gar als dezidiert negativ bewertet. Auf einer DED-Konferenz 1979 in Tansania stellten die westdeutschen LehrerInnen fest, dass sie mit ihrer Tätigkeit an den Sekundarschulen zur Ausbildung einer kleinen Bildungselite beitrugen und deren Ansprüche auf einen sozialen Aufstieg untermauerten, statt den Aufbau einer egalitären Gesellschaft voranzutreiben. Die Rolle, die sie ihrer Meinung nach im historischen Entwicklungsprozess einnahmen, stand weder mit den Zielen von Ujamaa noch mit ihren eigenen Ansprüchen in Einklang. ${ }^{379}$

375 Erhard Eppler zit. nach Der Spiegel 38, Häßliche Deutsche, 13.9.1971.

376 PAAA, AV Neues Amt 10910, AA an BRD-Auslandsvertretungen, „Auswertung der zum letzten Berichtstermin eingegangenen Berichte der Auslandsvertretungen in den Entwicklungsländern“, Bonn, 8.5.1972, Anhang, S. 7 .

377 Ulrike Ries, Vorwort, in: dies., Hg., Entwicklungshelfer. Deutsche in der Dritten Welt, Hannover 1971, S. 7-18, hier: S. 9.

378 Koos, Irgendwie haben wir, S. 156.

379 BArch Berlin, DR 2/50567, Lehrergruppe in der VR Tansania, Jahresbericht 1980, Dar es Salaam, 12.11.1980, S. 27. 


\section{Die DDR-,Auslandsinformation“: Grenzen der Propaganda}

War die politische Betätigung für westdeutsche Entsandte in der Regel eine Privatangelegenheit und Frage des persönlichen Engagements, waren DDR-Auslandskader über ihre fachliche Tätigkeit hinaus verpflichtet, Aufgaben der „Auslandsinformation“, also der Propagierung des Gesellschaftssystems der DDR und dessen politischer Grundlagen, zu übernehmen. Da diplomatische Kanäle und Foren wie die UN für die DDR bis 1972 unzugänglich waren, nahm die protodiplomatische Funktion gerade bis in die frühen 1970er-Jahre einen hohen Stellenwert ein, blieb aber auch in den späten 1980er-Jahren integraler Teil der Einsatzdirektiven. Bisher ist nicht untersucht worden, wie die Entsandten, deren persönliche Einsatzmotive selten vordergründig politisch waren, mit den Direktiven zur „Auslandsinformation“ umgingen und ob die DDR-Propaganda auf offene oder taube Ohren stieß. Im Falle Tansanias war der Erfolg der „Kontaktarbeit“ stark von persönlichen Allianzen, mehr noch aber übergeordneten historischen Konstellationen und politischen Interessenslagen abhängig.

Berichte zeigen deutlich, dass die politische Konfrontation nicht nur mit dem Kapitalismus, sondern auch in Bezug auf andere Sozialismus-Modelle identifiziert und gesucht wurde. Ein Lehrer berichtete 1970 auf China verweisend: „[W]ir hatten vielen Einflüssen $\mathrm{zu}$ begegnen, die uns die Arbeit nicht leicht gemacht haben, aus dem fernen Osten genau wie aus dem Westen“. ${ }^{380}$ Neben dem globalen ideologischen Wettbewerb formten auch Machtkämpfe der politischen Elite in Tansania sowie DDR-spezifische Faktoren die Spielräume der Entsandten, sodass der Erfolg der „Auslandsinformation“ weniger von Disseminationsstrategien oder persönlichem Geschick, sondern in erster Linie von den Interessen und politischen Einstellungen der Counterparts abhing. So war die Propaganda der DDR im postrevolutionären Sansibar nur bis 1966 - die DDR konnte „bei Maßnahmen der Selbstdarstellung völlig ungehindert“ agieren ${ }^{381}$ - gern gesehen. Ab 1967 duldeten die sansibarischen Behörden weder Nachmittagsveranstaltungen noch Wandzeitungen über DDR-Errungenschaften an den Schulen, da solcherlei Aktivitäten nunmehr als Einmischung in innere Angelegenheiten aufgefasst wurden; die Freundschaftsbrigade durfte ihren sansibarischen Lehrlingen keine DDR-Filme mehr zeigen. ${ }^{382}$ Der Leiter der Freundschaftsbrigade stellte angesichts derartiger Verbote 1970 die Rationalität des Brigadeeinsatzes grundsätzlich infrage. Reduziert auf eine rein fachliche Tätigkeit und ohne Möglichkeit, die sansibarischen Jugendlichen mit der DDR vertraut zu machen, verfehle die Brigade ihr Einsatz-

380 Privatarchiv E. W., E. W. an die SED-Kreisleitung, Sansibar, 9.10.1970.

381 Weiser, DDR-Lehrer nach Sansibar, S. 232.

382 BArch Berlin, DR 2/23068, Einschätzung der Tätigkeit der Lehrergruppe in Sansibar/Pem[b]a im Schuljahr 1968, Sansibar, 18.12.1968. 
ziel. ${ }^{383}$ Der zuständige FDJ-Funktionär in Ostberlin pflichtete dieser Einschätzung bei, wies alle Erklärungsversuche für eine ineffektive „Auslandsinformation“ als unzulänglich zurück und forderte, die „uns von der Partei gestellten Aufgaben auf auslandsinformatorischem Gebiet unbedingt durchzusetzen““.384

Eine Gruppe von VeterinärmedizinerInnen auf dem Festland in der Region Tabora stellte ebenfalls fest, dass Kontakte zu lokalen Verwaltungskräften und Politikern ab Mitte 1968 deutlich schwieriger herzustellen waren. Ein Grund war, dass die tansanische Führung die Niederschlagung des „Prager Frühlings“ verurteilt hatte (und damit der offiziellen DDR-Position diametral gegenüberstand); ein anderer, dass TANU-Mitbegründer und Parlamentarier Joseph Kasella-Bantu, der in der DDR Swahili unterrichtet hatte und weiterhin enge Kontakte zur DDR unterhielt, aufgrund innenpolitischer Machtkämpfe im September 1968 inhaftiert und einen Monat später aus der Partei ausgeschlossen wurde. ${ }^{385}$ Kasella-Bantu hatte nach der Verkündung der Deklaration von Arusha die Umwandlung der TANU in eine ideologisch einheitliche Avantgardepartei gefordert. ${ }^{386}$ Die DDRVeterinärInnen in Tabora gingen jedoch auch äußerst eigen-sinnig mit der Direktive zur Auslandsinformation um: Im stadteigenen Klubleben unterhielten die DDR-Auslandskader Kontakte mit expatriates aus Kanada und England, luden diese zum Tag der Republik ein und versuchten dabei, wie es im Bericht hieß, sie „in unsere politische Richtung einzubeziehen““. ${ }^{387}$ Sie deuteten den Imperativ der Auslandsinformation also in eine Legitimation für den persönlichen Kontakt mit Personen um, die sonst als „Klassenfeinde“ galten. Nach der diplomatischen Anerkennung der DDR durch Tansania 1972 nahm der Druck auf die Auslandskader, propagandistisch tätig zu sein, ab. Auch von tansanischer Seite gab es nur

383 SAPMO BArch Berlin, DY 24/19211, Böhme (Leiter der Abt. BdF im ZR der FDJ) an Pabst (Leiter BdF Sansibar), Berlin, 12.6.1970.

384 Ebd., Böhme (Leiter der Abt. BdF im ZR der FDJ) an Pabst (Leiter BdF Sansibar), Berlin, 22.7. 1970.

385 BArch Berlin, DR 3/2. Schicht/B 1449/1b, o.A., Quartalsbericht, Tabora, 7.12.1968, S. 1. Zu Kasella-Bantu, dessen Lebensweg ihn erst über Indien und England in die DDR und nach seiner Freilassung in die BRD führte, siehe auch die Informationen in Paul Bjerk, Julius Nyerere, Athens, Ohio 2017; Molony, Nyerere, S. 81; Bienen, Tanzania, S. 438; Mwakikagile, Nyerere and Africa, S. 91; Pratt, The Critical Phase, S. 246; Tordoff/Mazrui, Left and Super-Left in Tanzania, S. 438-439; UAL, DIB 550, Brauner, Aktennotiz über ein Gespräch mit Joseph Kasella Bantu (Tanzania) am 18.2.1987 in den Räumen der Sektion ANW, Leipzig, 19.2.1987, Bl. 45-46. Kasella-Bantus eigene Position zu einer (früheren) Festnahme wegen vermuteter Involvierung in einen Mord findet sich in einem Schreiben an die TANU-Führung: CCMA, THQ/A.25/3, Kasella-Bantu (MP) an TANU Executive Secretary Pius Msekwa, Nzega, 9.9.1967.

386 Roberts, Politics, S. 53; Tordoff/Mazrui, Left and Super-Left in Tanzania, S. 438-439.

387 BArch Berlin, DR 3/2. Schicht/B 1449/1b, o.A., Quartalsbericht, Tabora, 7.12.1968, S. 2. 
noch in Einzelfällen Widerstand gegen die ,auslandsinformatische Arbeit“. Hier spielten persönliche Dispositionen eine Rolle; 1982 etwa drängte ein Schulleiter alle tansanischen LehrerInnen, sich die DDR-Erfahrungen aufmerksam anzuhören und sogar mitzuschreiben, während der Leiter einer anderen Schule dem Lehrkörper die Teilnahme an DDR-Veranstaltungen verbot. ${ }^{388}$

Zur Umsetzung der Direktiven konnten die Entsandten auf ein Repertoire an Aktivitäten zurückgreifen, das ein Spektrum von lockerer, sich unpolitisch gebender Unterhaltung bis hin zur unverblümten Vermittlung von DDR-Errungenschaften umfasste. Üblich war, wie oben bereits angedeutet, die Projektion von Dokumentar- und Spielfilmen aus der DDR, darunter Berlin 1945-heute, Spreegeschichten, Bezirk Schwerin, Unser Zeichen ist die Sonne, Gedanken zum November, Begegnungen mit der DDR, Kleine Reise durch die DDR, Magazin NVA, Kirchen in der DDR, Nackt unter Wölfen, Sport macht Spaß, Studenten der Bergakademie Freiberg oder - sogar in einer Swahili-Fassung - Lenin im Oktober. Weitere verbreitete Aktivitäten waren Vorträge und das Anbringen von Wandzeitungen zu Anlässen wie DDR-Jahrestagen oder den runden Geburts- und Jahrestagen von Lenin, Marx und Engels sowie die Verteilung der DDR-Zeitschrift Urafiki („Freundschaft“), die in Swahili herausgegeben wurde.

Die Debatten im Rahmen von Ausstellungen, Film- und Diskussionsabenden sollten dazu dienen, Fragen über das DDR-Gesellschaftsmodell zu diskutieren, etwa wie der DDR die „Brechung des Bildungsprivilegs“ durch die Förderung von „Arbeiter- und Bauernkindern“ in der Praxis gelungen war, wie Disziplin und Bestrafung im Schulalltag geregelt wurden oder welche Stellung LehrerInnen in sozialer und materieller Hinsicht einnahmen. ${ }^{389}$ Die öffentlichen Diskussionen waren von DDR-Seite als Werbemaßnahme gedacht, konnten aber zum Bumerang werden, da sie ein Forum für Kritik eröffneten. Kritisiert in Bezug auf das Bildungssystem wurde vom tansanischen Publikum in einem Fall der fehlende Religionsunterricht; in anderen Diskussionen mutmaßten TansanierInnen, dass diejenigen, die aus der DDR flüchteten, vor allem religiöse Motive hatten - hier zeigt sich der anhaltende Einfluss stark christlich geprägter Diskurse über die kommunistische Welt, wie sie schon in den frühen 1960er-Jahren in lokalen Zeitungen anzutreffen waren (siehe Kap. 3.1). ${ }^{390}$ Häufig handelte es sich bei Einwänden und Kritikpunkten um Argumentationslinien, die auch von westlichen und chinesischen Quellen in den Medien verbreitet wurden und in Tansania be-

388 BArch Berlin, DR 2/50567, Lehrergruppe der VR Tansania, Jahresbericht 1982/83, Dar es Salaam, 10.6.1983, S. 24.

389 BArch Berlin, DR 2/25494, Baier an MfVobi, Dar es Salaam, 13. 8.1971, S. 6-10.

390 BArch Berlin, DR 2/13851, Staatlicher Leiter der Lehrergruppe Mazimbu, Bericht 9/89, Mazimbu, 12.10.1989, S. 12. 
sondere Resonanz fanden. Ein ausführlicher DDR-Bericht über die „ideologische Lage“ an tansanischen Schulen aus dem Jahr 1971 zeigt das deutlich: Während das DDR-Engagement für die Befreiungsbewegungen allgemein gelobt werde, seien auch „verzerrte Ansichten“ gang und gäbe: Die DDR sabotiere die Wiedervereinigung, gewähre als kommunistisches Land keine Glaubensfreiheit und vernachlässige ihre materiellen Pflichten in der Entwicklungshilfe. Vorbildliche Unterstützung hingegen leiste das uneigennützige China, auch die materiellen Leistungen westlicher Länder würden als selbstlos gelten, wenngleich z.B. die Beziehungen der BRD zu Portugal und Südafrika eine wahre Freundschaft verunmöglichten. Die Sowjetunion werde wie die USA als „Supermacht“ identifiziert und die „chinesische Theorie“ des globalen Arm-Reich-Gegensatzes allgemein anerkannt. 391

Nur in Einzelfällen bekannten sich tansanische KollegInnen und Vorgesetzte zu einer pro-sowjetischen Position in außenpolitischen Fragen oder dem Prinzip, alle Kinder und Jugendlichen wie in der DDR sozialistisch zu erziehen. Der Staatliche Leiter, der die Aussagen aller DDR-LehrerInnen über ihre auslandsinformatorischen Bemühungen zu einem peniblen Bericht kompiliert hatte, wies jedoch auf das allgemeine Desinteresse für politische Fragen in den Kollegien hin, gerade bei Themen, die (aus tansanischer Perspektive) nur Europa betrafen. ${ }^{392}$ Eine Gruppe von drei Lehrerfamilien in Mbeya antwortete auf die Kritik vom Ministerium für Volksbildung, dass die Kontaktarbeit zu nachlässig betrieben werde, dass „daß das massive [A] uftreten von DDR-Bürgern an einer relativ kleinen Schule dazu führt, daß sich die afrikanischen Kollegen gehemmt fühlten und zurückhaltend reagierten.“ ${ }^{393}$ Einerseits versuchte die Gruppe damit wohl, die Erwartungen im Ministerium zu senken; gleichzeitig wurden derartige Reaktionen auch in anderen Berichten beschrieben: Tansanische KollegInnen wichen politischen Diskussionen gerade in öffentlichen Situationen aus. Rangniedrige Angestellte und BeamtInnen mit Aufstiegshoffnungen taten gut daran, sich auf dem politisch umkämpften Terrain Tansanias, wo die Ujamaa-Ideologie keineswegs von allen befürwortet wurde, nicht mit einer abweichenden Positionierung zu exponieren. Die eigene Haltung offenbarten sie bestenfalls in persönlichen Gesprächen. Außerdem war es angesichts des weitverbreiteten Misstrauens gegenüber ausländischer Einflussnahme inopportun, expatriates allzu laut beizupflichten, gerade wenn diese wie die DDR-Kader „fremde“ Ideologien vertraten.

391 BArch Berlin, DR 2/25494, Baier an MfVobi, Dar es Salaam, 13. 8.1971.

392 Ebd.

393 BArch Berlin, DR 2/25494, H. R., Bericht über die Tätigkeit der Lehrergruppe in Mbeya, Schuljahr 1971, Mbeya, 14.11.1971, S. 3. 
Nyerere selbst hatte wiederholt Stellung gegen sowjetische und marxistische Positionen bezogen. ${ }^{394}$

So schimmert in manchen Berichten auch eine Relativierungserfahrung durch: Von Tansania aus betrachtet waren die DDR und selbst die Sowjetunion Nebenschauplätze. Bisweilen ging der Ideologietransfer sogar in eine von den Entsendestellen der DDR nicht intendierte Richtung. Reisen und der Aufenthalt in Tansania boten Auslandskadern die Gelegenheit, heterodoxe Sozialismen ebenso wie „bürgerliche“ Positionen kennenzulernen. Die Techniken der „Auslandsinformation“ wie öffentliche Debatten im Rahmen von Filmabenden konnten diesen Austausch weiter intensivieren. Je nach Einsatzfeld, eigenen Ansprüchen und Zeitraum mussten DDR-Auslandskader eine Gratwanderung zwischen verschiedenen ideologischen Entwürfen vollführen. Ein Foto, das im Rahmen eines Lehrerseminars aufgenommen wurde, zeigt mit bedeutungsschwangerer Symbolik das Ideal aus tansanischer Sicht: Nyerere als Präsident und „Vater der Nation“ gibt die Richtung für den Afrikanischen Sozialismus im Land vor, die DDR-LehrerInnen folgen - orientieren sich mit ihren Blicken allerdings in eine andere Richtung (Abbildung 5.1). Dieses Bild funktionierte im engen Kontext eines Tansania-Einsatzes als Darstellung der Konformität und Eingliederung ins nationale Entwicklungsprojekt, aber es unterlief den sowjetischen Anspruch als sozialistische Führungsmacht mit ideologischer Deutungshoheit wahrgenommen zu werden. Daher ist kaum denkbar, dass dieses (aus einem Privatarchiv stammende) Foto je für öffentliche Zwecke genutzt wurde: Wie konnten marxistisch-leninistische Kader dem Afrikanischen Sozialismus Nyereres folgen, der in vielerlei Hinsicht als rückständig und defizitär galt? Angesichts ihrer Biografieerwartungen (Rückkehr in die DDR) und den Konsequenzen, die „Fehltritte“ haben konnten, sicherten sich viele DDR-Kräfte in der Praxis mittels Formalismus ab. Sie achteten strikt darauf, ihre (fachlichen) Pflichten in der tansanischen Institution genauso zu erfüllen wie die DDR-Direktiven, die das politische und soziale Leben betrafen.

Die „Auslandsinformation“ nahm im Laufe des Jahrzehnts einen immer defensiveren Charakter an. Ende der 1980er-Jahre brachten tansanische GesprächspartnerInnen die DDR-Auslandskader angesichts von glasnost und perestroika immer wieder in Erklärungsnot. Die „Verleumdungen“ über Wandel, Krise und Desintegration im sowjetischen Einflussbereich waren kaum noch zu-

394 Siehe Kapitel 2, siehe auch Roberts, Politics, Kap. 1. 


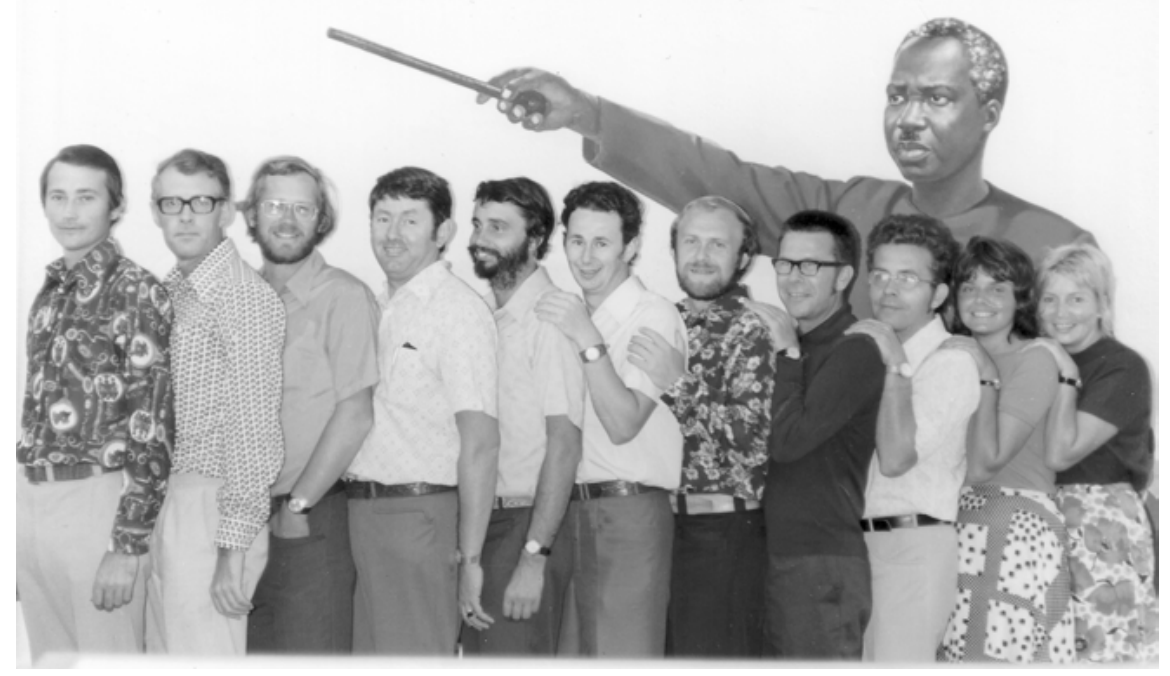

Abbildung 5.1: In Diensten zweier Sozialismen: DDR-LehrerInnen vor einem Wandgemälde des tansanischen Präsidenten Julius Nyerere. Das Bild wurde anlässlich eines Lehrerseminars mit tansanischen KollegInnen im August 1975 in Dar es Salaam aufgenommen (Quelle: Privatbesitz).

rückzuweisen. Die Botschaft, die die jeweils geltende Doxa aus Ostberlin weiterleitete, kam mit der Unterweisung der Auslandskader nicht mehr nach. ${ }^{395}$

Die DDR-Geschichte als Modell: „Prophet Mohamed scheint mit den Prinzipien des Klassenkampfes noch nicht richtig vertraut zu sein“

Auch die (offizielle Version der) DDR-Geschichte wurde von Entsandten in den 1980er-Jahren immer seltener als nachahmenswertes Modell dargestellt. Noch bis in die 1970er-Jahre hatten viele DDR-Auslandskader bei der Schilderung ihrer Eindrücke in Tansania explizit auf die Geschichte der DDR zurückgegriffen. Ein Universitätsdozent, der während der Intensivierung der Umsiedlungskampagnen in Tansania weilte, zeigte sich erstaunt angesichts der frappierenden Ähnlichkeiten zwischen den Kollektivierungsbemühungen in Tansania und der DDR, wie sie etwa im Stufenmodell in der Vergenossenschaftlichung der Landwirtschaft

395 BArch Berlin, DR 2/13851, Staatlicher Leiter der Lehrergruppe Mazimbu, Bericht 9/89, Mazimbu, 12.10.1989. 
sichtbar wurden. ${ }^{396}$ Tansania wurde in solchen Fällen auf einer früheren Stufe des „sozialistischen Aufbaus“ verortet, den die DDR bereits „gemeistert“ hatte. Eine explizite Absage an die Relevanz der DDR-Erfahrungen erteilten nur wenige. Eine DDR-Veterinärgruppe beschwerte sich während ihres Einsatzes in Tabora 1971, dass man in Ost-Berlin anscheinend kein „klares Bild über Entwicklungsstand der Region“ habe; DDR-Gewohnheiten im Veterinärwesen seien schon aufgrund des unterschiedlichen Klimas nicht übertragbar und auch die Erfahrungen aus der DDR-Genossenschaftsbewegung „nur von bedingtem Wert“. 397 Üblicher war die affirmative Bezugnahme auf die Gemeinsamkeiten unter Ausblendung aller Differenzen. In einer Ausgabe der Daily News aus dem Oktober 1972 wird der Rektor der Karl-Marx-Universität Winkler in einer Art und Weise zitiert, die nicht nur die Kollektivierungen in der DDR idealisierte, sondern auch die Umsiedlungskampagne in Tansania, die zu dieser Zeit zunehmend mit Zwang durchgeführt wurde, legitimierte:

By deciding to encourage the people to live together, Tanzania was doing exactly what was done in the GDR in 1952. From that year, he [Winkler] said, lives of workers and peasants in his country had greately [sic] changed and the relations between the people and their Government were better. ${ }^{398}$

Die „Meisterung der Übergangsperiode 1945-1963“ in der DDR, die manch ein Universitätsdozent in Dar es Salaam zum Gegenstand seiner Vorlesungen machte, ${ }^{399}$ sollte Vorbildcharakter für Tansania haben. Im Bildungsbereich eingesetzte

396 Interview \#31, DDR-Universitätsexperte: „Mensch, die haben wohl die Genossenschaftsstatuten aus der DDR zugrunde gelegt - Wie kommen die denn zu ähnlichen Dingen? Hier in der DDR gab‘s ja drei Stufen der Genossenschaften, ja, LPG Typ 1, 2, 3. [...] [D]as ist ja auch die Erfahrung in der DDR gewesen mit den Genossenschaftsbildungen, die Armen sind immer die bereitwilligsten, weil die keine Alternative haben.“

397 BArch Berlin, DR 3/2. Schicht/B 1449/1b, Bauer (Parteisekretär GO Tabora) und Gudat (Staatl. Leiter der Spezialistengruppe Tabora) an Limex, MHF und Rat für Land- und Nahrungsgüterwirtschaft, Tabora, 26.7.1971.

398 Daily News, “Tanzania impresses Professor”, 12.10.1972.

399 BArch Berlin, DR 3/2. Schicht/1514, Uni-Gruppe der DDR in der VR Tansania, Arbeitsplan Studienjahr 1984/85, Dar es Salaam, Anhang: L. H., „Verpflichtungen zum 35. Jahrestag der DDR“. Diese Übergangsperiode wurde von einem Regierungsberater untergliedert in die Phasen des „antifaschistisch-demokratischen Neuaufbaus“ (1946-1949), die Gründung des „Regimes der sozialistischen Umgestaltung unter Führung der SED“ (1949-1952), der „Festigung der Grundlagen des Sozialismus“ (1952-1958) sowie „des Kampfes um den Sieg der sozialistischen Produktionsverhältnisse“ (1958-1961). BArch Berlin, DE 1/58117, Helmut Jung, Thesen zur Promotion B: Zu einigen Erfordernissen und Problemen der Erfahrungsvermittlung und der Tätigkeit von 
ExpertInnen - also LehrerInnen und HochschuldozentInnen - sollten die Erfahrungen aus dem Aufbau des DDR-Bildungswesens, vor allem ,aus der Periode der antiimperialistisch-demokratischen Entwicklung und den ersten Jahren des sozialistischen Aufbaus“, „schöpferisch“ in ihrer Tätigkeit anwenden, wie es in einer Rahmendirektive des Ministeriums für Hoch- und Fachschulwesen für alle Auslandskader aus dem Jahr 1984 hieß. ${ }^{400}$

Auffällig ist, dass von DDR-Akteuren fast ausschließlich auf die eigene nationale und nur selten auf die sowjetische Geschichte (oder gar jene anderer kommunistischer Staaten) Bezug genommen wurde. Obwohl die Produktionsund Klassenverhältnisse im vorrevolutionären Russland ${ }^{401}$ den tansanischen Bedingungen weitaus mehr ähnelten als jene der DDR nach 1945, sollten in erster Linie DDR-Erfahrungen vermittelt werden. Einige Auslandskader scheinen nicht zuletzt aufgrund ihrer eigenen Biografie die Neuerungen und Umwälzungen in der DDR nicht nur für vorbildhaft erachtet zu haben, sondern auch im besonderem Maße davon überzeugt gewesen zu sein, dass ein „Nachmachen“ und umgehende Erfolge auch im Sansibar der 1960er (weniger im Tansania der 1970er Jahre und nur noch in seltenen Ausnahmefällen in den 1980er Jahren) möglich seien. Ein Beispiel für den Umgang mit dem DDR-Modell ist ein Lehrer, der zur Gruppe der „Neulehrer“ gehörte. Diese Gruppe war innerhalb weniger Jahre in der DDR ausgebildet worden; ihre Mitglieder konnten oft einen beträchtlichen sozialen Aufstieg realisieren - so auch dieser Lehrer, der nach einigen Jahren im Schulbetrieb nach Sansibar entsandt wurde. ${ }^{402}$ Probleme, auf die er und andere DDR-ExpertInnen in Sansibar stießen, wurden von ihm im Rückgriff auf DDRErfahrungen gedeutet:

Ich erlebe nun die Umgestaltung des Schulwesens in einem Entwicklungslande mit, das sich nicht klar für unseren Sozialismus entschieden hat, also immer wieder nach einem eigenen, sogenannten dritten Weg sucht und aus diesem Grunde vieles ungelöst bleibt. Gemessen an der Entwicklung dieses Landes wird immer wieder demonstriert, dass in der Entwicklung des DDR Schulwesens jeder Schritt wohlüberlegt geplant und durchgeführt worden ist. ${ }^{403}$

Regierungsberatern der DDR in den um ihre nationale und soziale Befreiung kämpfenden Ländern mit sozialistischem Entwicklungsweg“, Maputo, März 1985, S. 3.

400 BArch Berlin, DR 3/2. Schicht/1512, Minister für Hoch- und Fachschulwesen Böhme, Rahmendirektive, Berlin, 26.6.1984, S. 2.

401 So argumentiert auch Walter Rodney, Tanzanian Ujamaa and Scientific Socialism, in: The African Review: A Journal of African Politics, Development and International Affairs 1/4 (1971), S. $61-76$.

$402 \mathrm{Zu}$ „Neulehrern“ siehe Fulbrook, The People’s State, S. 198-199.

403 Privatarchiv E. W., E. W. an A. [SED-Kreisleitung], Sansibar, 7.7.1970; Formatierung im Original. 
Die Umformulierung des sansibarischen Problems in ein Lob für die DDR hatte wohl auch damit zu tun, dass es sich beim Adressaten des Briefes um einen SEDFunktionär im Heimatkreis handelte, der über die berufliche Zukunft mitentschied. Im Laufe seines Aufenthalts war der Lehrer zur Einsicht gekommen, dass es unmöglich war, die DDR-Erfahrungen direkt zu übertragen. Alle DDR-LehrerInnen seien „,von einem den Studenten fremdem Standpunkt ausgegangen“, wie er in einer Analyse schrieb:

Versuche unseres Lehrerkollektivs, Erfahrungen und Ergebnisse aus den DDR-Schulen, Auffassungen über moderne Unterrichtsgestaltung, Fragen der Erkenntnisgewinnung und der Persönlichkeitsentwicklung den Studenten zu übermitteln, brachten nicht die erwarteten Ergebnisse. [...] Die Studenten bezogen natürlicherweise all unsere Darlegungen auf die Schulen Sansibars, während wir vom Entwicklungsstand der DDR-Schulen ausgegangen sind. Dadurch kam es, daß wir über die Köpfe der Studenten hinweg unterrichtet haben und daß unsere Darlegungen nicht immer akzeptiert wurden. ${ }^{404}$

Es sei, so meinte er nun, eine Anpassung der Konzepte auf den „Entwicklungsstand Sansibars“ notwendig, um dann „Elemente unserer modernen Auffassung über Schule und Unterrichtsgestaltung einfließen zu lassen“. ${ }^{405}$ Der Glaube an die „Richtigkeit“ des DDR-Bildungssystems und die Ansicht, dass sich auch das sansibarische System schließlich in dieselbe Richtung entwickeln würde, blieben also unangetastet. Die DDR hielt die Position, dass es im Bildungsbereich in erster Linie um „Erfahrungsvermittlung“ gehe, im Falle Tansanias noch bis Ende der 1980er-Jahre. ${ }^{406}$ Aus der oben zitierten Quelle geht nicht klar hervor, welche Darlegungen der DDR-LehrerInnen von den SchülerInnen „nicht immer akzeptiert wurden“. Anhand der Schreiben anderer DDR-Auslandskader in Sansibar lässt sich vermuten, dass mit dieser Formulierung in erster Linie das Aufeinanderprallen materialistischer und religiöser Denkfiguren gemeint war. So hieß es in einem Bericht der DDR-Lehrergruppe 1968:

Die islamische Weltanschauung bereitet uns oft Schwierigkeiten, den Studenten das Wirken naturwissenschaftlicher Gesetzmäßigkeiten in Natur und Gesellschaft begreiflich zu machen und sie zur positiven Diskussion solcher Probleme zu erziehen. Viele Studenten lehnen eine

404 Ebd., E. W., Versuch einer Analyse der Arbeit an den Primary Schools von Sansibar und daraus sich ergebende Schlussfolgerungen für die am T.T.C. unterrichtenden DDR-Lehrer, Oktober 1969, S. 1.

405 Ebd.

406 BArch Berlin, DR 2/50566, Stv. des Ministers für AA Winter an Stv. des Ministers für Volksbildung Gen. Werner Engst, Berlin, 6.5.1987. 
materialistische Betrachtungsweise ab und hängen noch zu sehr an den Überlieferungen des Korans. $^{407}$

Religion und Religiosität galten als Zeichen der Rückständigkeit, markierten aber auch die Grenzen des Handlungsspielraums: Die „materialistische“ Perspektive wurde auf der vorgesehenen Empfängerseite offensichtlich eindeutig zurückgewiesen. Die DDR-Entsandten erhielten ihre materialistische Eschatologie jedoch aufrecht. Das „noch“ verwies auf die nach wie vor bestehende Erwartung, dass die zentrale Stellung des Islam - und überhaupt jeglicher Religion - bald der Vergangenheit angehören werde. Der erwähnte Neulehrer teilte diese Ansicht. Er berichtete 1970 dem zuständigen SED-Kreisschulrat von der wiederholten Verschiebung von Prüfungsterminen. Die Verzögerung des Heimaturlaubs bedauernd fügte er hinzu:

\begin{abstract}
Eigentlich hatten wir ja angenommen, von der Ernte [in der DDR] schon einiges mitzubekommen, aber der große Prophet Mohamed scheint mit den Prinzipien des Klassenkampfes noch nicht richtig vertraut zu sein und vor allem respektiert er in keiner Weise unseren Anspruch auf Urlaub in der DDR. Wir sind aber sehr optimistis[ch] und sind davon überzeugt, dass auch er sich eines Tages den Prinzipien der kommunistischen Weltbewegung unterordnen muss. ${ }^{408}$
\end{abstract}

Wenngleich mit einem doppelten Boden aus Humor ausgestattet, zeigt dieser Brief doch deutlich, wie die Interpretationsfiguren der Weltrevolution und des Klassenkampfes die Erwartungshaltung von DDR-Auslandskadern strukturierten insbesondere, wenn Ereignisse für Kontakte in der Heimat eingeordnet werden sollten. Dass die Revolution auf Sansibar nicht unter klinischen Laborbedingungen stattfand, dass es Massaker gegeben hatte und gerade als „fremd“ erachtete Bevölkerungsgruppen über Jahre massiven Repressionen ausgesetzt blieben, wurde in dieses Schema eingepasst. Ein ehemaliger Dolmetscher der FDJBrigade erinnerte sich an die „harschen“ Verhältnisse in Sansibar und meinte, er und andere DDR-Entsandte hätten „das alles noch unter dem Verständnis eines revolutionären Umbruchs betrachtet“. 409

Die Ergebnisse solcher Betrachtungen fielen divers aus. Von Sansibar aus versuchten DDR-Auslandskader etwa zu einer Einschätzung zu gelangen, was die Deklaration von Arusha 1967 für den Sozialismus in Tansania bedeutete - denn wie sollten Erfahrungen aus der DDR für selbigen vermittelt werden, wenn

407 BArch Berlin, DR 2/23068, Einschätzung der Tätigkeit der Lehrergruppe in Sansibar/Pem[b]a im Schuljahr 1968, Sansibar, 18.12.1968, S. 8.

408 Privatarchiv E. W., E. W. an A. [SED-Kreisleitung Querfurt], Sansibar, 7.7.1970.

409 Interview \#29, Dolmetscher einer FDJ-Brigade in Sansibar. 
überhaupt nicht klar war, wie die Politik in Tansania und der „Entwicklungsstand“ des Landes überhaupt einzuschätzen waren? Bewegte sich der Afrikanische Sozialismus in die richtige Richtung? Bei einer Sitzung der Grundorganisation der SED in Sansibar traten mit solchen Fragen auch Zweifel zum Vorschein, ob das sozialistische Programm in Tansania nicht „verfrüht“ war. Der Bericht vermerkte Fragen aus dem Kollektiv, ob die Deklaration „von den bisherigen Erfahrungen, dem Entwicklungsstand und der Mentalität der Afrikaner“ ausgehe, ob „die Afrikaner mit ihrer Ideologie überhaupt den Sozialismus aufbauen“ könnten und „warum [...] wir durch die Erklärung überrascht“ wurden. ${ }^{410}$ Während einige Auslandskader auf dieser Sitzung ihre Skepsis über die Realisierbarkeit des Sozialismus äußerten und dabei ideologische, materialistische und kulturalistische Vorbehalte einbrachten, äußerste sich ein leitendes Parteimitglied sehr positiv über die TANU: diese entwickele sich in die richtige Richtung, also hin zur Kaderpartei. ${ }^{411}$

Biografische Erfahrungen gingen dabei mitunter in der Projizierung (einer offiziösen Version) der DDR-Geschichte in Tansania auf. Ein ehemaliger DDRBerater für polytechnische Bildung erzählte, dass er die DDR-Zwangskollektivierung in der Landwirtschaft in seiner eigenen Familie erlebt hatte und „dafür eingestanden“ war; die Etablierung der Ujamaa-Dörfer galt ihm als ein „deutlicher Sprung nach vorn“, weil der Staat dort soziale Dienstleistungen für die Bevölkerung bereitstellen konnte. Von Gewaltanwendung bei den Umsiedlungsaktionen in Tansania hatte er nach eigener Aussage jedoch nichts mitbekommen. ${ }^{412}$ Ein anderer, zur selben Zeit eingesetzter DDR-Experte, der durch seine Tätigkeit als Wassertechniker weite Teile des Landes persönlich bereiste, erinnerte sich, die Umsiedlung sei offensichtlich „nicht ganz freiwillig“ vonstattengegangen: „Mit LKWs rangefahren, die eingesackt, dann ging das los. “413 Bei einem Arbeitseinsatz habe er erlebt, wie die Bevölkerung gegen eine Zwangsumsiedlung im Rahmen eines Staudammprojekts protestierte und einen Brand im Camp legte, in dem er mit dem Probebohrungen durchführenden Erkundungsteam wohnte. Auch er bewertete die Umsiedlungsmaßnahmen aus einer technokratisch-wohlfahrtsstaatlichen Sicht aber als positiv, denn die Ujamaa-Dörfer seien „für unsere Tätigkeit“ (das Brunnenbohren) eine gute Sache gewesen, das Leben dort sei „ge-

410 SAPMO BArch Berlin, DY 30/98149, o.A., „Welche Anstrengungen unternehmen die Genossen des Konsulats zur Verbesserung der politischen Führungsarbeit ...“ (Manuskript für einen Vortrag auf der GO-Versammlung), Sansibar, 9.3.1967, Bl. 283.

411 SAPMO BArch Berlin, DY 30/98149, [Redebeitrag von] Gen. O., o.O. [Sansibar], o.D. [9.3.1967], Bl. 286

412 Interview \#117, DDR-Polytechnikberater.

413 Interview \#111, DDR-Experte beim Ministry of Water and Energy. 
ordnet“ zugegangen, die ansässige Bevölkerung habe in der Folge „[a]lles, was man für das tägliche Leben im Busch braucht,“ gehabt. ${ }^{414}$ „Ordnung“ und wohlfahrtsstaatlicher Interventionismus galten somit als wünschenswerter Fortschritt, der notfalls gegen Widerstände durchgesetzt werden musste. Auch in Sansibar half die DDR der Führung beim „Hau-ruck, um die Bevölkerung in die Moderne zu bringen“, wie es ein ehemaliger Dolmetscher einer FDJ-Brigade formulierte. 415

Während DDR-Auslandskader viele Inventionen im Rahmen der Vorstellung einer wohlfahrtsstaatlichen, sozialistischen Moderne guthießen, nahmen sie längst nicht alle Transformationsversuche und -visionen unkritisch hin. Der DDR-Vizekonsul etwa kam nach einer Stadtrundfahrt mit einem Funktionär der Jugendorganisation TYL zum Schluss, dass dieser zwar eine ,zutiefst anti-kapitalistische Grundeinstellung“ aufwies, da sich sein „Hass gegen Ausbeuter“ aber einzig auf Inder projizierte, auch „stark rassistische Tendenzen“ zeigte. ${ }^{416}$ In solchen Situationen gingen die Entsandten einer offenen Konfrontation jedoch oft aus dem Weg (siehe auch Kapitel 6.1). In Bezug auf „Auslandsinformation“ und die Propagierung eigener Weltdeutungen lässt sich somit festhalten: DDR-Auslandskader waren keine Propagandaautomaten, sie warfen die „Politikmaschine“417 gezielt nur dort an, wo ihr Betrieb keine diplomatischen Konflikte oder andere Nachteile einbrachte. In Hinblick auf nationale Machtverhältnisse mündete die diplomatische Haltung und „Nichteinmischung“ bisweilen in einer Entpolitisierung - ein Vorwurf, der der westlichen Entwicklungshilfe oft gemacht worden ist.

\section{Marktwirtschaft und Massenkonsum als Königs- oder Irrweg}

Auch viele BRD-Entsandte wussten, dass die Umsiedlungsaktionen durch Staat, Partei und Jugendorganisation mit Zwang durchgesetzt wurden. ${ }^{418}$ Manche sahen mit eigenen Augen, wie Exekutivkräfte Häuser und Pflanzungen niederbrannten, um die ländliche Bevölkerung von einer Rückkehr abzuhalten und wussten, dass humanitäre Hilfslieferungen bei Hungersnöten bisweilen an Bedingungen (wie eben die Zustimmung zur Umsiedlung) geknüpft waren. Ein GAWI-Experte,

\section{Ebd.}

415 Interview \#23, Dolmetscher einer FDJ-Brigade in Sansibar.

416 SAPMO BArch Berlin, DY 30 IV A 2/20961, Aktenvermerk über Gespräch des DDR-Vizekonsuls Köhn mit Funktionären der TANU-Jugendliga, Dar es Salaam, 1.11.1966, Bl. 37; siehe auch Interview \#113, DDR-Lehrerexperte.

417 Weis, The Politics Machine.

418 Interview \#101, GTZ-Experte und Projektleiter. 
ebenfalls ein Augenzeuge von Umsiedlungsmaßnahmen, war explizit der Meinung, dass Tansania ,auf dem Weg zur sozialistischen Umgestaltung [...] durch eine Phase der Gewalt“ müsse. ${ }^{419}$ Diese Ansicht war in den 1970ern keine Seltenheit. Die Sowjetunion und China galten gerade in manchen marxistisch inspirierten Kreisen - wenngleich auch hier stark debattiert - als erfolgreiche Alternativmodelle für Modernisierung und beschleunigten sozioökonomischen Wandel. Verstaatlichungen und vor allem der „Zugriff“ auf die bäuerliche Bevölkerung wurden als notwendige und alternativlose Schritte in die Moderne gesehen. Letzteres galt freilich auch für „westliche“ Modernisierungsvorhaben und die Ideologie der Weltbank als Teil eines blockübergreifenden Entwicklungsetatismus. ${ }^{420}$ Wer sozioökonomischen Wandel wollte - diese Meinung war im globalen Entwicklungsdiskurs hegemonial - musste vom Mobilisierungspotenzial und Gewaltmonopol des Staates Gebrauch machen. Entwicklungsdiktaturen waren en vogue, afrikanische Länder galten als unreif für die liberale Demokratie nach westlichem Vorbild. ${ }^{421}$ Ein westdeutscher integrierter Experte, der 1971 mit antikommunistischen Untertönen aus Tansania berichtete, stellte eine der kritischsten Stimmen im Quellenkorpus dar:

\begin{abstract}
Uniformen nehmen zu wie die Holzgewehre aus China vom Kindergarten an aufwärts. Statt Bildung und Lernen von nützlichen Dingen werden Parteiphrasen und sozialistische Parolen verfüttert, zusammen mit der Hetze gegen die Weissen und Asiaten, ausser den Chinesen, Nordvietnamesen und Nordkoreanern selbstverständlich. Ich halte es trotzdem für nötig, den afrikanischen Menschen zu helfen, die nichts für die Fehler ihrer Regierenden können, da ich Kollektivschuld auch hier für nicht gerechtfertigt halte. Aber man sollte nicht das System mit grossen Geldmitteln unterstützen, um den Menschen hier die letzte Freiheit zu nehmen. ${ }^{422}$
\end{abstract}

Viele BRD-Entsandte kamen erst im Rückblick zu dem Schluss, dass die Zwangsmaßnahmen in Tansania nicht legitim waren. Retrospektiv wunderten sie sich bisweilen ostentativ selbstkritisch über die damaligen Scheuklappen und dass „niemand [...] mal das Maul aufgerissen“ hat. ${ }^{423}$ Gerade die Begeisterung für den Präsidenten hatte jede Kritik abgefedert: „Nyerere war jemand, mit dem konnte man das kritisch diskutieren [...]. Man konnte mit ihm wirklich auch kritisch reden da drüber und das verurteilen“. ${ }^{424}$ Solange ein vernünftiger und

419 BArch Koblenz, B 213/7679, BRD-Botschaft an AA, Dar es Salaam, 19.9.1974, S. 3.

420 Hydén, Beyond Ujamaa.

421 Franz Ansprenger, Politische Geschichte Afrikas im 20. Jahrhundert, München 1992, S. 83.

422 BArch Koblenz, B 213/7679, R. S., Bericht über meine Tätigkeit im Entwicklungsland Tanzania 1971 und die Entwicklung im Lande in dieser Zeit, Machame, 20.12.1971.

423 Interview \#28, GAWI-Experte.

424 Interview \#101, GTZ-Experte und Projektleiter. 
selbstkritischer Mann wie Nyerere an der Spitze des Staates stand, so dachten viele, musste Tansania auf dem richtigen Weg sein. Die BRD galt vielen Entsandten jedenfalls nicht als Vorbild für Tansania. Tansaphile Westdeutsche wiesen zudem nicht nur auf die deutsche „Kolonialschuld“ hin (während konservative Entsandte eher den „Fortschritt“ durch den Kolonialismus betonten), ${ }^{425}$ sondern betonten auch Fehlentwicklungen der industrialisierten Gesellschaften. Die Entwicklungshelferin Ursula Krebs nahm die Konsumhoffnungen und materiellen Wünsche in ihrer Umgebung mit Verstörung auf, weil sie die eigene postmaterialistische Haltung und die Kritik an der Marktwirtschaft zu einem nicht kommunizierbaren Kuriosum machten:

Viele Afrikaner träumen von einem ,Benzi‘ (Mercedes Benz), von Jeans und anderen Konsumgütern. Sie kennen nicht den Preis, den wir dafür bezahlen, vom ,Mensch` zum ,Wirtschaftsfaktor‘ degradiert zu werden. Ich kann es hier den Kollegen so schwer erklären. ${ }^{426}$

Die BRD und das System Marktwirtschaft galten Entsandten wie Krebs als Irrlicht, das zu einer maschinisierten, standardisierten, entmenschlichenden und von der Natur entfremdeten gesellschaftlichen Realität führe. ${ }^{427}$ Tansanias proklamierte Entwicklungsstrategie mit einem Fokus auf Tradition, Gemeinschaft und landwirtschaftliche Produktion erschien wie ein möglicher Ausweg aus der Sackgasse, in die die industrielle Moderne geraten war.

Politisch konservativere Entsandte aus der BRD waren eher der Meinung, Tansanias Weg müsse in eine Marktwirtschaft münden. Solche Entsandten - die in der Regel auch die Beraterposten in staatlichen Unternehmen und Ministerien mit Wirtschafts- oder Finanzressort einnahmen - erachteten das Konzept des Entwicklungsstaates als nur bedingt nützlich. Der bereits erwähnte Landwirtschaftsexperte Geuting etwa, der Nyerere 1963-1964 persönlich beriet, sah dem damaligen Zeitgeist entsprechend zwar eine gewisse Planung als notwendig an, fürchtete aber ganz im bipolaren Denken der Systemkonkurrenz, dass eine Überbetonung der Planung „radikale Elemente“ in Tanganjika stärken könnte. Er machte es zu seinem Hauptanliegen, „dem Marktmechanismus mehr und mehr zur Wirksamkeit verhelfen, damit die zunächst notgedrungenermaßen in Kauf zu nehmende planwirtschaftliche Weichenstellung nicht durch Gewöhnung zementiert wird“. ${ }^{428}$ Seine Tätigkeit deutete er über die engere entwicklungspoliti-

425 Peter B. Szuca, Tanzania - Land des Ujamaa, in: Ulrike Ries, Hg., Entwicklungshelfer. Deutsche in der Dritten Welt, Hannover 1971, S. 195-213, hier: S. 196, 198.

426 Krebs, Neema, S. 53-54.

427 Szuca, Tanzania, S. $210-213$.

428 BArch Koblenz, B 213/33011, Geuting, Bericht Nr. 2, Dar es Salaam, 25.6.1963, S. 3. 
sche Konzeption mit dem Ziel „freiheitliche[r] Wirtschaftspolitik und zielstrebige[r] wirtschaftliche Entwicklung des Landes“ hinaus als Stärkung der politischen Position des Westens allgemein und der Förderung westdeutscher politischer und wirtschaftlicher Interessen im Besonderen. Er beriet nicht nur tansanische Politiker, sondern auch Firmenvertreter aus der BRD, die ihn um Investitions- und Handelsempfehlungen baten. ${ }^{429}$ Eine offene Propagierung kapitalistischer Prinzipien, wie sie Geuting in der ersten Hälfte der 1960er-Jahre noch hatte vornehmen können, war nach der Deklaration von Arusha nicht mehr opportun. In der Praxis förderten jedoch viele BRD-Entsandte - zum Teil nach Desillusionierungen mit Genossenschaftsprojekten, die in ihrer Erfahrung in „Sümpfe“ von Korruption und „Bauernausbeute“ gemündet waren - Kommerzialisierung und individualistisches Unternehmertum. Das Interesse von tansanischen ElitevertreterInnen an Ressourcenzuflüssen aus der BRD und Wirtschaftskontakte zu Privatfirmen trieben derartige Allianzen zusätzlich an. ${ }^{430}$

Auch kapitalismuskritische Entsandte griffen auf ihre Modelle und Erfahrungen aus der BRD zurück und wollten diese auf Situationen in Tansania anwenden. „Den Kollegen Arbeitern“, so schrieben die bereits erwähnten konsumkritischen Ingenieure über ihren Freiwilligeneinsatz in einer Stadtverwaltung, „wurden wir als neuer Chef vorgestellt, und diese warteten nun auf neue Anweisungen. “ ${ }^{431}$ Im Kontrast zur Erwartung auf tansanischer Seite teilten die Ingenieure das Selbstbild als Chef nicht, sondern nutzten ihr Einsatzfeld als Laboratorium für Selbstverwaltungsexperimente, wie sie zu dieser Zeit in der BRD unternommen oder zumindest propagiert wurden. ${ }^{432}$ Dem Bericht der Ingenieure zufolge scheiterte die Initiative an der Ablehnung des Inspektors und der Vorarbeiter, über deren Ansicht sich die einfachen Arbeiter nicht hinwegsetzen wollten: „Letztendlich war allen klar, daß unsere Zeit als Vorgesetzte begrenzt ist und es auf die Dauer von größerer Bedeutung war, sich mit den tansanischen Vorgesetzten gutzustellen. “433 Dass es im Gefolge der Parteirichtlinien von 1971 eine Reihe von Streiks und Selbstverwaltungsversuchen gegeben hatte, die vom Staat mit Entlassungen, Drohungen und Polizeieinsätzen unterdrückt worden waren, bleibt in ihren Erinnerungen ausgeblendet, stellte wohl aber auch einen ent-

429 Ebd., Geuting an GAWI, Dar es Salaam, 18.5.1964, S. 4. Geutings weiterer Werdegang und seine Vermittlerrolle während der Hallstein-Krise, die er durch seine exzellenten persönlichen Kontakte zu Nyerere und anderen führenden Politikern ausübte, wurden bereits in Kapitel 3 thematisiert.

430 Interview \#8, GTZ-Projektleiterin; siehe auch Kapitel 6.2.

431 K./W., Praxiserfahrungen, S. 11.

432 Ebd.

433 Ebd., 12-13. 
scheidenden Hinderungsgrund für den Transfer ihren Ideen dar. ${ }^{434}$ Im Gegensatz zu diesen beiden arrangierten sich andere „Achtundsechziger“ mit der Rolle als disziplinierende Chefs und Chefinnen (siehe Kapitel 8) und praktizierten Politik bevorzugt in Form einer entpolitisierenden Technokratie.

\section{Fazit}

Dieses Kapitel hat querschnittsartig Motive, Selektionsmechanismen, Vorbereitungsprogramme, Lebensbedingungen und Handlungsformen der Entwicklungsarbeit analysiert - und dabei die Perspektiven der Entsandten in den Vordergrund gestellt. Es handelt sich beim Entwicklungspersonal um eine heterogene Akteursgruppe, differenzierbar nach Herkunftsland und Einsatzort, Beruf, Status innerhalb der Hierarchie der Entsandten, Geschlecht, politischer Positionierung und generationeller Zugehörigkeit sowie spezifischen biografischen Erfahrungen, um nur einige Faktoren zu nennen. Diese Faktoren schlugen sich gemeinsam mit zeitspezifischen Opportunitätsstrukturen in den Einsatzmotiven deutlich nieder, während die eigens eingeführten Vorbereitungsprogramme - mit Ausnahme der Einimpfung von Bedrohungsszenarien auf DDRSeite - generell wenig Einfluss hatten.

Für DDR-BürgerInnen war der Auslandseinsatz ein besonderes Privileg, insbesondere in Hinblick auf die politischen Selektionsmechanismen, die große Teile der Bevölkerung von vornherein von einem Einsatz exkludierten. Verglichen mit dem westdeutschen Entwicklungspersonal mussten DDR-Auslandskader mit engmaschigeren Disziplinierungsmechanismen und Erwartungen an das Verhalten im „Kollektiv“ umgehen. Verglichen mit dem DDR-Alltag eröffneten sich jedoch gänzlich neue Erfahrungs- und Aneignungsmöglichkeiten. Teil dieser Erfahrungen in Tansania war - für DDR-Auslandskader ebenso wie für viele westdeutsche Entsandte - der Einblick in die Begrenztheit eigener Handlungsspielräume, wenn es darum ging, Handlungs- und Denkweisen zu transferieren und für bestimmte gesellschaftliche Modelle zu werben. Dabei war es weniger wichtig, ob es sich bei dem bevorzugten Modell um eine romantisierte Version des „sozialistischen Aufbaus“ der DDR in der Nachkriegszeit eine aus Nyereres Reden zurechtgeschnitzte Idealversion von Ujamaa oder eine utopische Gesellschaft jenseits materieller Konsumwünsche handelte: Entscheidend für die Umsetzbarkeit und tatsächliche Operationalisierung waren die konkreten Einsatzbedin-

434 Die Erinnerungen stammen aus dem Jahr 1979, es liegt also nahe, dass sie in Tansania ankamen, als diese Welle der frühen 1970er Jahre bereits wieder abgeebbt war. 
gungen und Aushandlungen mit Counterparts vor Ort. Die institutionelle Einordnung und der Zugang zu den verschiedenen Kapitalarten steckten den Handlungsspielraum von Entsandten weiter ab.

Nicht identifizieren lässt sich ein wie auch immer gearteter Automatismus, der die fraglos existenten Widersprüche und Machtungleichheiten der Entwicklungsarbeit automatisch in Dominanz, Zwang und Gewalt münden ließ. ${ }^{435}$ Wohl aber zeigt sich, dass viele Entsandte sowohl der DDR als auch aus der BRD materielle Ungleichheiten eher innerhalb ihrer Gruppen als im Vergleich zur tansanischen Gesellschaft thematisierten und staatlicher Gewaltanwendung (wie während der Umsiedlungskampagne) aus der Sympathie für Ujamaa und einem fortschrittsgläubigen Geschichtsverständnis heraus affirmativ gegenüberstanden. Der universalistische Fortschrittsoptimismus der Modernisierungstheorien wurde aber keinesfalls von allen geteilt. Gleichzeitig herrschte bei einer bestimmten Strömung von westdeutschen Entsandten eine „antimoderne Grundstimmung“, die „sich einer eindeutigen Kategorisierung als liberal oder konservativ im heute gängigen Sinne“ entzog und durch den Versuch gekennzeichnet war, gesellschaftliche Partikularitäten zu beachten. ${ }^{436}$

In jedem Fall hatten die Entsandten zwischen verschiedenen, bisweilen widersprüchlichen Imperativen von Ergebnisorientierung und Partnerschaftlichkeit, der Orientierung an Counterparts und zu vollbringender Transformation zu navigieren. Über die Partikularität von Einzelerfahrungen hinweg lässt sich dabei durchaus eine Verschiebung der Handlungsspielräume feststellen. Politische Ziele formten die Handlungsmöglichkeiten besonders in den späten 1960er und frühen 1970er-Jahren; die Wirtschaftskrise der späten 1970er und 1980er-Jahre verlieh den Counterpartbeziehungen dann jedoch neue Dynamiken und zwang zu neuen Umgangsstrategien - wie die folgenden, detaillierten Einblicke in verschiedene „Arenen“ verdeutlichen.

435 Eine derartige, fast automatische Dynamik von konzeptuellen Widersprüchen hin zu Exklusion und Gewalt wird nahegelegt in Büschel, Hilfe zur Selbsthilfe.

436 So mit Bezug auf westdeutsche Experten in Indien in den 1960er Jahren: Unger, Entwicklungspfade in Indien, S. 138; siehe auch ebd., S. 137. 
